\title{
Modelling non-equilibrium secondary organic aerosol formation and evaporation with the aerosol dynamics, gas- and particle-phase chemistry kinetic multilayer model ADCHAM
}

\author{
P. Roldin $^{1,3}$, A. C. Eriksson ${ }^{1}$, E. Z. Nordin ${ }^{2}$, E. Hermansson ${ }^{1}$, D. Mogensen ${ }^{3}$, A. Rusanen ${ }^{3}$, M. Boy ${ }^{3}$, E. Swietlicki ${ }^{1}$, \\ B. Svenningsson ${ }^{1}$, A. Zelenyuk ${ }^{4}$, and J. Pagels ${ }^{2}$ \\ ${ }^{1}$ Division of Nuclear Physics, Lund University, P.O. Box 118, 22100 Lund, Sweden \\ ${ }^{2}$ Ergonomics and Aerosol Technology, Lund University, P.O. Box 118, 22100 Lund, Sweden \\ ${ }^{3}$ Department of Physics, P.O. Box 48, University of Helsinki, 00014 Helsinki, Finland \\ ${ }^{4}$ Pacific Northwest National Laboratory, P.O. Box 999, MSIN K8-88, Richland, WA 99354, USA
}

Correspondence to: P. Roldin (pontus.roldin@nuclear.lu.se)

Received: 13 December 2013 - Published in Atmos. Chem. Phys. Discuss.: 10 January 2014

Revised: 27 May 2014 - Accepted: 11 June 2014 - Published: 11 August 2014

\begin{abstract}
We have developed the novel Aerosol Dynamics, gas- and particle-phase chemistry model for laboratory CHAMber studies (ADCHAM). The model combines the detailed gas-phase Master Chemical Mechanism version 3.2 (MCMv3.2), an aerosol dynamics and particle-phase chemistry module (which considers acid-catalysed oligomerization, heterogeneous oxidation reactions in the particle phase and non-ideal interactions between organic compounds, water and inorganic ions) and a kinetic multilayer module for diffusion-limited transport of compounds between the gas phase, particle surface and particle bulk phase. In this article we describe and use ADCHAM to study (1) the evaporation of liquid dioctyl phthalate (DOP) particles, (2) the slow and almost particle-size-independent evaporation of $\alpha$ pinene ozonolysis secondary organic aerosol (SOA) particles, (3) the mass-transfer-limited uptake of ammonia $\left(\mathrm{NH}_{3}\right)$ and formation of organic salts between ammonium $\left(\mathrm{NH}_{4}^{+}\right)$ and carboxylic acids ( $\mathrm{RCOOH}$ ), and (4) the influence of chamber wall effects on the observed SOA formation in smog chambers.

ADCHAM is able to capture the observed $\alpha$-pinene SOA mass increase in the presence of $\mathrm{NH}_{3}(\mathrm{~g})$. Organic salts of ammonium and carboxylic acids predominantly form during the early stage of SOA formation. In the smog chamber experiments, these salts contribute substantially to the initial growth of the homogeneously nucleated particles.

The model simulations of evaporating $\alpha$-pinene SOA particles support the recent experimental findings that these par-
\end{abstract}

ticles have a semi-solid tar-like amorphous-phase state. ADCHAM is able to reproduce the main features of the observed slow evaporation rates if the concentration of lowvolatility and viscous oligomerized SOA material at the particle surface increases upon evaporation. The evaporation rate is mainly governed by the reversible decomposition of oligomers back to monomers.

Finally, we demonstrate that the mass-transfer-limited uptake of condensable organic compounds onto wall-deposited particles or directly onto the Teflon chamber walls of smog chambers can have a profound influence on the observed SOA formation. During the early stage of the SOA formation the wall-deposited particles and walls themselves serve as an SOA sink from the air to the walls. However, at the end of smog chamber experiments the semi-volatile SOA material may start to evaporate from the chamber walls.

With these four model applications, we demonstrate that several poorly quantified processes (i.e. mass transport limitations within the particle phase, oligomerization, heterogeneous oxidation, organic salt formation, and chamber wall effects) can have a substantial influence on the SOA formation, lifetime, chemical and physical particle properties, and their evolution. In order to constrain the uncertainties related to these processes, future experiments are needed in which as many of the influential variables as possible are varied. ADCHAM can be a valuable model tool in the design and analysis of such experiments. 


\section{Introduction}

Aerosol particles in the atmosphere have substantial impact on the global climate, air quality, and public health. Measurements around the world have demonstrated that a large fraction of the submicron aerosol particles are composed of organic compounds (Jimenez et al., 2009). To date, many important biogenic and anthropogenic secondary organic aerosol (SOA) precursors have been identified. However, the scientific knowledge about the SOA formation mechanisms, the SOA composition and properties is still very uncertain (Kroll and Seinfeld, 2008; Hallquist et al., 2009).

Traditionally, the important SOA formation mechanisms are modelled as pure gas-phase oxidation processes followed by equilibrium partitioning between the gas and a liquid organic particle phase (e.g. Pankow, 1994; Donahue et al., 2011). However, during the last $\sim 10$ years, other processes occurring in the particle phase have also been identified as important mechanisms for the formation and properties of SOA. These include acid-catalysed oligomerization (e.g. Gao et al., 2004; Iinuma et al., 2004; Kalberer et al., 2004; Tolocka et al., 2004), heterogeneous oxidation reactions (e.g. Knopf et al., 2005; Nash et al., 2006; Rudich et al., 2007; Maksymiuk et al., 2009), organic salt formation (e.g. Na et al., 2007; Smith et al., 2010; Kuwata and Martin, 2012; Yli-Juuti et al., 2013), organosulfate formation (e.g. Liggio and Li, 2006; Surratt et al., 2007) and saltingout effects (e.g. Smith et al., 2011; Bertram et al., 2011). The term salting-out refers to the process in which interactions with dissolved ions (generally inorganic) drive nonpolar organic compounds out of the mixed phase, either into a different organic-rich (liquid) phase or out to the gas phase (Zuend et al., 2011).

Several independent laboratory experiments have also shown that secondary organic aerosol particles can form a solid or semi-solid amorphous phase (e.g. Virtanen et al., 2010; Vaden et al., 2010; Vaden et al., 2011; Kuwata and Martin, 2012; Zelenyuk et al., 2012; Abramson et al., 2013; Zhou et al., 2013), at least for relative humidities (RH) below $65 \%$ (Saukko et al., 2012). Recently, Abramson et al. (2013) measured the evaporation rates of pyrene that was imbedded inside SOA particles formed from $\alpha$-pinene ozonolysis in the presence of pyrene vapour, based on which the authors estimated a diffusion coefficient of $2.5 \times 10^{-17} \mathrm{~cm}^{2} \mathrm{~s}^{-1}$ for pyrene in the fresh SOA under dry conditions. For particles aged for $\sim 24 \mathrm{~h}$ the diffusivity was an additional $\sim 3$ times slower. Using the Stokes-Einstein relation for the binary diffusion coefficients gives an SOA viscosity of $\sim 10^{8} \mathrm{~Pa}$ s for fresh SOA and $\sim 3 \times 10^{8} \mathrm{~Pa}$ s for the aged particles. These high viscosity values are typical for tar- or pitch-like substances (Koop et al., 2011). For a particle with a diameter of $100 \mathrm{~nm}$, this gives a characteristic time of mass transport (e-folding time of equilibration) of $\sim 28 \mathrm{~h}$ for fresh SOA and $\sim 84 \mathrm{~h}$ for the aged SOA particles (Seinfeld and Pandis, 2006). A similar study was performed by Zhou et al. (2013), who observed mass-transport-limited degradation of benzo[a]pyrene $(\mathrm{BaP})$ with ozone when coated with $\alpha$ pinene SOA. Based on kinetic double-layer model simulations the authors estimate that the BaP diffusion coefficients (in $\mathrm{cm}^{2} \mathrm{~s}^{-1}$ ) are $2 \times 10^{-14}, 8 \times 10^{-14}$ and $>10^{-12}$ for dry $(\mathrm{RH}<5 \%), 50 \% \mathrm{RH}$ and $70 \% \mathrm{RH}$, respectively. The estimated diffusion coefficient of $\mathrm{BaP}$ in $\alpha$-pinene SOA (under dry conditions) from Zhou et al. (2013) is $\sim 3$ orders of magnitude larger than the diffusion coefficient of pyrene estimated by Abramson et al. (2013). One reason for this could be that the $\alpha$-pinene SOA in Zhou et al. (2013) is very fresh ( $\sim 1 \mathrm{~min}$ ), while in Abramson et al. (2013) the SOA particles are aged for at least $1 \mathrm{~h}$, thus having time to form a substantial fraction of viscous oligomers.

If a viscous phase is formed, the mixing within the particle bulk will be kinetically limited and the gas-particle partitioning cannot be well represented by an equilibrium process (Pöschl, 2011; Shiraiwa and Seinfeld, 2012), which the traditional partitioning theory assumes (Pankow, 1994). This may not be evident from pure SOA mass formation experiments where the condensable organic compounds are continuously formed by gas-phase oxidation of different precursor compounds (see e.g. Odum et al., 1996; Hoffmann et al., 1997; Griffin et al., 1999; Ng et al., 2007; Pathak et al., 2007). However, in the atmosphere the aerosol particles are present with a broad size range and are exposed to more variable concentration, temperature and humidity conditions. Hence, atmospheric aerosol particles will never be entirely in equilibrium with the gas phase. Dzepina et al. (2009) showed that their equilibrium partitioning model substantially overestimate the evaporation of SOA in the Mexico City metropolitan area.

In well-controlled laboratory experiments, Grieshop et al. (2007) and Vaden et al. (2011) illustrated that the evaporation of SOA particles formed from $\alpha$-pinene ozonolysis is a slow process (hours to days). Vaden et al. (2011) showed that this is orders of magnitude slower than expected from the seven-product volatility basis set (VBS) parameterization from Pathak et al., 2007. This parameterization is based on a large number of smog chamber experiments of $\alpha$-pinene ozonolysis, which resemble the experiments by Vaden et al. (2011). This VBS parameterization lacks substantial fraction of low-volatility material. The slow evaporation of SOA can be due to the presence of low-volatility oligomers in combination with mass transfer limitations and mixing effects (Grieshop et al., 2007; Vaden et al., 2011). Saleh et al. (2013) did not observe a strong evaporation inhibition because of diffusion limitations in the particle phase of $\alpha$-pinene SOA particles. However, in Saleh et al. (2013) only $\sim 20 \%$ of the SOA particle mass (corresponding to a few monolayers) was evaporated in their thermodenuder. This early-stage evaporation of freshly formed SOA particles may indeed not be strongly diffusion-limited because low-volatility bulk-phase oligomers may not have formed a complete monolayer thick surface coverage, which inhibits further evaporation of monomers. 
Vaden et al. (2011) illustrated that the evaporation of ambient SOA particles is even slower than for the pure $\alpha$-pinene SOA and better resembles the evaporation of aged $\alpha$-pinene SOA particles in the presence of different hydrophobic organic compounds. If the ambient SOA particles studied by Vaden et al. (2011) are representative of typical atmospheric SOA particles, then the evaporation due to dilution in the atmosphere (e.g. in urban plumes downwind from the source) will be almost negligible. This can increase the lifetime and concentrations of SOA (and, for example, $\mathrm{NH}_{4} \mathrm{NO}_{3}$ ) in the atmosphere (Vaden et al., 2011).

For the past decade, large discrepancies between fieldmeasured and model-predicted SOA loadings have stimulated intense research that was mostly focused on the search for additional SOA precursors. However, these models have all treated SOA assuming it to be a semi-volatile equilibrated solution. A recent study (Shrivastava et al., 2013) has shown that it is possible to improve agreement between measured and modelled SOA loadings by treating SOA, in accord with experimental data as a non-volatile semi-solid. Similarly, considering the highly viscous, non-volatile nature of SOA offers a simple explanation for the observed long-range transport of persistent organic pollutants by atmospheric particles (Zelenyuk et al., 2012).

A number of model studies have been performed to explore detailed gas-phase reaction mechanisms which can be responsible for the SOA formation of known biogenic and anthropogenic SOA precursors (e.g. Bloss et al., 2005a, b; Johnson et al., 2005, 2006; Li et al., 2007; Hu et al., 2007; Metzger et al., 2008; Rickard et al., 2010; Camredon et al., 2010; Valorso et al., 2011). However, relatively few attempts have been made to perform detailed process-based modelling on the influence of phase state (Shiraiwa et al., 2010, 2011, 2012; Pfrang et al., 2011), oligomerization (Vesterinen et al. 2007; Pun and Seigneur, 2007; Li et al., 2007; Hu et al., 2007; Ervens and Volkamer, 2010), heterogeneous oxidation mechanisms (Shiraiwa et al., 2010; 2011, 2012; Pfrang et al., 2011), organic-inorganic interactions (e.g. salting-out effects, acidity effects) (Zuend et al., 2010; Zuend and Seinfeld, 2012), organic salt formation (Barsanti et al., 2009), and non-equilibrium gas-particle partitioning and aerosol dynamics (e.g. Korhonen, et al., 2004; Vesterinen et al., 2007; Boy et al., 2006; Roldin et al., 2011a, b) on the SOA formation and properties, and to our knowledge no one has previously included all these processes in the same model.

In this article we describe and apply the newly developed Aerosol Dynamics, gas- and particle-phase chemistry model for laboratory CHAMber studies (ADCHAM). As the name implies the model is primarily aimed to be used as a flexible tool for evaluation and design of controlled experiments in smog chambers (e.g. Nordin et al., 2013), thermodenuders (e.g. Riipinen et al., 2010), evaporation chambers (e.g. Vaden et al., 2011), flow-tube reactors (e.g. Jonsson et al., 2008) or hygroscopicity measurements set-ups (e.g. Svenningsson et al., 2006). However, the overall aim is to gain a better un- derstanding of which processes (e.g. gas-phase chemistry, particle-phase reactions, particle-phase state, aerosol water uptake, cloud droplet activation, and aerosol dynamics) are relevant for the aerosol properties and formation in the atmosphere.

In ADCHAM the secondary aerosol formation is modelled by combining the Master Chemical Mechanism version 3.2 (MCMv3.2) (Jenkin et al., 1997, 2003; Saunders et al., 2003) and an updated version of the aerosol dynamics and particle-phase chemistry module from ADCHEM (2-DLagrangian model for Aerosol Dynamics, gas-phase CHEMistry and radiative transfer) (Roldin et al., 2011a), which now considers acid-catalysed oligomerization; oxidation reactions in the particle phase (e.g. secondary ozonide formation); and the diffusion-limited transport of compounds between the gas phase, particle surface and particle bulk phase. In this work we test the capability of ADCHAM to simulate (1) the particle-size-dependent mass evaporation loss rates of liquid dioctyl phthalate (DOP) particles, (2) the slow and almost particle-size-independent evaporation of $\alpha$-pinene SOA particles (Vaden et al., 2011), (3) the mass-transfer-limited uptake of $\mathrm{NH}_{3}$ and formation of organic salts between ammonium and carboxylic acids (Na et al., 2007; Kuwata and Martin, 2012), and (4) the influence of heterogeneous reactions and chamber wall effects on the SOA formation and properties.

Regional- and global-scale chemistry transport models (e.g. the EMEP model (Bergström et al., 2012) rely on semi-empirical parameterizations for the SOA formation (e.g. VBS) derived from smog chamber experiments. This is one of many reasons why it is important to constrain the uncertainties related to specific chamber effects. Hence, as a final application, we illustrate how ADCHAM can be used to study the influence of chamber wall effects on the SOA mass formation, particle number size distribution and gasphase chemistry during an $m$-xylene oxidation experiment by Nordin et al. (2013).

\section{Model description}

\section{ADCHAM consists of}

1. a detailed gas-phase kinetic code (in this work with reactions from MCMv3.2);

2. an aerosol dynamics code (Roldin et al., 2011a) which includes Brownian coagulation, homogeneous nucleation, deposition to chamber walls and a detailed condensation/evaporation algorithm;

3. a novel particle-phase chemistry module which is closely connected to the condensation/evaporation algorithm; 
4. and a kinetic multilayer model which treats the diffusion of compounds between the particle surface and several bulk layers, analogous to Shiraiwa et al. (2012).

Figure 1 shows a schematic picture of the ADCHAM model structure. The model explicitly treats the bulk diffusion of all compounds (including oxidation agents $\left(Z_{\mathrm{ox}}\right)$ such as $\mathrm{OH}, \mathrm{O}_{3}$ and $\mathrm{NO}_{2}$ ) between different particle layers and bulk reactions. For all compounds except $Z_{\mathrm{ox}}$, the gas-surface partitioning is by default modelled as an absorption (dissolution) process with the condensation/evaporation equation (Eq. 1, Jacobson, 2005a). Equation (1) considers the gassurface diffusion limitations and potentially non-unity probability of adsorption (sticking) and dissolution into the particle surface-bulk layer (surface-bulk accommodation). The surface-bulk layer we define as the monolayer thick particle surface layer where the condensing compounds dissolve (absorb). In each particle layer the model considers acidcatalysed oligomerization, equilibrium reactions between inorganic and organic salts and their dissolved ions, and heterogeneous oxidation of SOA.

In ADCHAM the different processes are solved with separate modules using operator splitting. For each main model time step (in this work $10 \mathrm{~s}$ ), ADCHAM considers homogeneous nucleation, followed by deposition of particles (Sect. 2.2.3) and potentially gases, emissions of gases and particles, gas-phase chemistry (Sect. 2.1) and coagulation (Sect. 2.2.2). After this ADCHAM handles the condensation and evaporation of all organic and inorganic compounds (Sect. 2.2.1) and the reversible adsorption, diffusion and reactions of $Z_{\mathrm{ox}}$ in the different particle layers (Sect. 2.4.2). In between these processes ADCHAM uses operator splitting with a much shorter time step (in this work 1-10 ms). For the reversible adsorption, diffusion and reactions of the different oxidation agents in the particle phase, a kinetic multilayer model (Sect. 2.4.2) is used. This model consists of a coupled ordinary differential equation system which is solved using the MATLAB ode15s solver with adaptive and error-tolerance-controlled internal time steps. The gasparticle partitioning relies upon updated activity coefficients (Sect. 2.3.1), hydrogen ion concentrations (Sect. 2.3.2), water content, concentrations of inorganic and organic salts (Sect. 2.3.3) and their corresponding anion and cations. Therefore, the gas-particle partitioning is usually the most time demanding process in ADCHAM. Finally, the model considers the diffusion of organic and inorganic compounds between all particle layers (Sect. 2.4.1) and acid-catalysed oligomerization (Sect. 2.3.4).

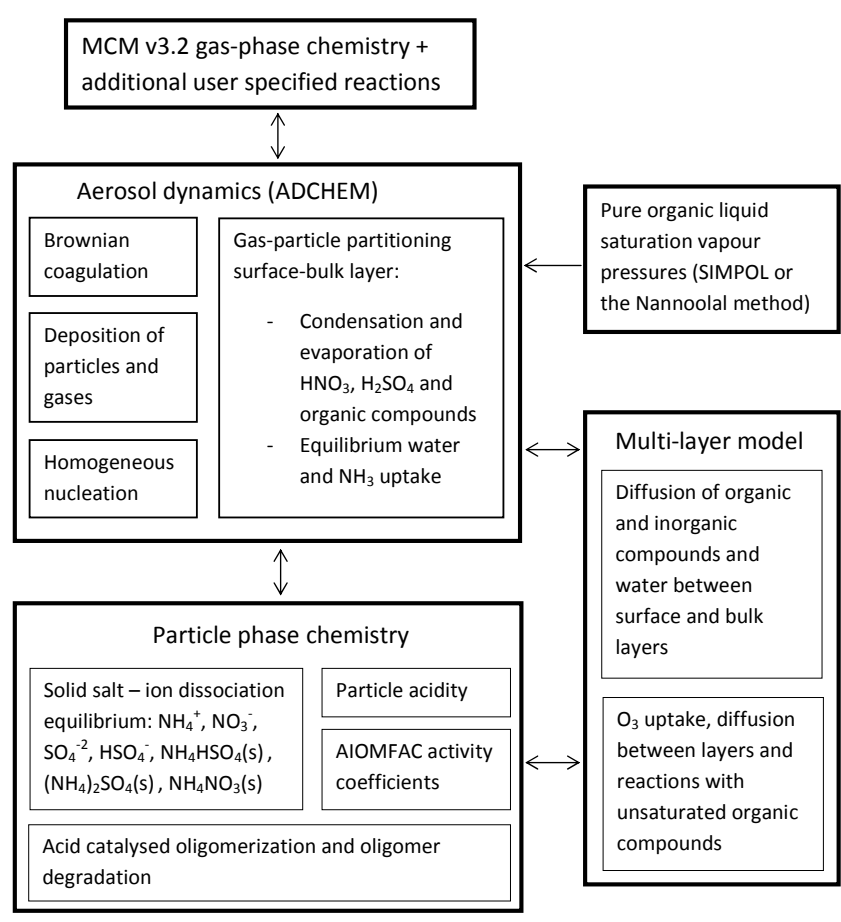

Figure 1. Schematic picture of the ADCHAM model structure.

\subsection{Gas-phase chemistry}

To be able to implement the detailed MCMv3.2 gas-phase chemistry together with user-specified reactions and reaction rates (e.g. chamber wall effects) in a computationally efficient way in MATLAB, we constructed a program which automatically creates a system of equations which can be used to calculate the concentrations of the user-specified compounds. The only required input to the program is the MCMv3.2 names of the compounds, which can be downloaded at http://mcm.leeds.ac.uk/MCM. The output from the program is a set of coupled ordinary differential equations (one for each compound) and the Jacobian matrix, which is used by the ode15s solver in MATLAB. The constructed code can either be used as a standalone code for separate gasphase chemistry simulations or used as a module in the ADCHEM or ADCHAM model. The ode 15s solver in MATLAB is intended to be used for stiff ordinary differential equation systems. The solver uses an adaptive and error-tolerancecontrolled internal time step in order to solve the gas-phase chemistry.

In Sects. 3.2 and 3.3 we simulate the SOA formation from ozonolysis of $\alpha$-pinene in the presence of $\mathrm{CO}$ or cyclohexane as an $\mathrm{OH}$ scavenger. We constructed an equation system consisting of all MCMv3.2 reactions involving inorganic gasphase chemistry and all oxidation products of $\alpha$-pinene and cyclohexane (in total 668 compounds and 2093 reactions). In Sect. 3.4 we also model the SOA formation oxidation of 
$m$-xylene with the MCMv3.2 gas-phase chemistry (273 compounds and 878 reactions).

\subsection{Aerosol dynamics}

The aerosol dynamics module in ADCHAM is based on the aerosol dynamics code from the ADCHEM model (Roldin et al., 2011a). A shorter description with focus on the important updates is given below.

\subsubsection{Condensation and evaporation}

In ADCHAM the gas-particle partitioning depends on the chemical composition in the particle surface-bulk layer. Analogous to Jacobson (2005b) the dissolution of ammonia into the particle surface-bulk layer water- and/or organic phase is treated as an equilibrium process, considered after the diffusion-limited condensation/evaporation of $\mathrm{HNO}_{3}$, $\mathrm{H}_{2} \mathrm{SO}_{4}$ and organic compounds (Eq. 1, Seinfeld and Pandis, 2006) (of which carboxylic acids influence the particle acidity and hence the ammonia dissolution).

$I_{i}=2 D_{i} D_{\mathrm{p}} f_{i}\left(K n_{i}, \alpha_{\mathrm{s}, i}\right)\left(C_{i, \infty}-C_{i, \mathrm{~s}}\right)$,

$f_{i}\left(K n_{i}, \alpha_{\mathrm{s}, i}\right)=\frac{0.75 \alpha_{\mathrm{s}, i}\left(1-K n_{i}\right)}{K n_{i}^{2}+K n_{i}+0.283 K n_{i} \alpha_{\mathrm{s}, i}+0.75 \alpha_{\mathrm{s}, i}}$

In Eq. (1) $I_{i}$ is the contributions of species $i$ to the particle molar growth rates, $f_{i}$ is the Fuchs-Sutugin correction factor in the transition region, $C_{i, \infty}$ is the gas-phase concentration of species $i$ far from the particle surface ( $\mathrm{mol} \mathrm{m}^{-3}$ air), $C_{i, \mathrm{~s}}$ is the saturation gas-phase concentration at the particle surface ( $\mathrm{mol} \mathrm{m}^{-3}$ air), $D_{i}$ is the gas-phase diffusion coefficient $\left(\mathrm{m}^{2} \mathrm{~s}^{-1}\right), D_{\mathrm{p}}$ is the particle diameter $(\mathrm{m}), K n_{i}$ is the nondimensional Knudsen number and $\alpha_{\mathrm{s}, i}$ is the surface-bulk accommodation coefficient.

In this work we estimate the pure-liquid saturation vapour pressures $\left(p_{0}\right)$ of the MCMv3.2 oxidation products using either the group contribution method SIMPOL (Pankow and Asher, 2008) or the method by Nannoolal et al. (2008) (here referred to as the Nannoolal method). The corresponding equilibrium vapour pressures $\left(p_{\mathrm{s}, i, j}\right)$ for each particle size bin $(j)$ are derived with Raoult's law, using the mole fractions of each organic compound $\left(x_{i, j}\right)$, the activity coefficients $\left(\gamma_{i, j}\right)$ calculated with the AIOMFAC thermodynamic model (Zuend et al., 2008, 2011) (Sect. 2.3.1), and the Kelvin effect $\left(C_{k_{i, j}}\right)$ (Eq. 2). The surface tension $\left(\sigma_{i}\right)$ of the organic compounds was assumed to be $0.05 \mathrm{~N} \mathrm{~m}^{-1}$ following Riipinen et al. (2010).

$p_{\mathrm{s}, i, j}=p_{0, i} x_{i, j} \gamma_{i, j} C_{k_{i, j}}, C_{k_{i, j}}=e^{\left(\frac{4 M_{i} \sigma_{i}}{R T \rho_{\mathrm{p}} D_{\mathrm{p}, j}}\right)}$

$T$ is the temperature in kelvin, $R$ is the universal gas constant $\left(\mathrm{J} \mathrm{mol}^{-1} \mathrm{~K}^{-1}\right), M_{i}$ is the molar mass of compound $i$ and $\rho_{\mathrm{p}}$ is the density of the phase which the compound partitions to.
The mole fraction for compound $i$ in Eq. (2) is the mole fraction of the organic compound in the surfacebulk layer organic phase which compound $i$ partitions into (dissolves). In this work we either treat all SOAs (monomers + dimers + organic salts) as one phase or as two completely separate phases, with monomers as one phase and the dimers and organic salts as a second phase. This phase separation is not modelled explicitly (as in Zuend and Seinfeld, 2012). Instead we simply assume that either the phase separation does occur or it does not. In future model applications, we intend to implement a simple approach to calculate liquid-liquid phase separation (e.g. Topping et al., 2013). If the described phase separation occurs, then the monomers will not dissolve in the phase made up of dimers and/or organic salts. Thus, their saturation vapour pressures are not lowered by dimerization or organic salt formation, which results in less SOA mass in the model compared to simulations without phase separation (Topping et al., 2013).

In this work the condensation and evaporation mechanism includes all organic compounds with modelled pure-liquid saturation vapour pressures less than $1 \mathrm{~Pa}$. For the $\alpha$-pinene oxidation experiments which we model in Sects. 3.2 and 3.3, this involves 154 non-radical MCMv3.2 organic compounds, while for the $m$-xylene SOA formation experiment modelled in Sect. 3.4, we consider 112 condensable organic MCMv3.2 compounds.

\subsubsection{Coagulation}

ADCHAM also includes a Brownian coagulation algorithm (Roldin et al., 2011a). The particle mass and number concentrations of the formed particles are split between the existing particle size bins using a fully stationary method. It still remains a challenge to combine the coagulation algorithm with the kinetic multilayer model when the number of particle layers depends on the particle size. In this first version of ADCHAM it is only possible to treat coagulation between particles composed of maximum three layers (e.g. a surface monolayer layer, a bulk layer and a seed aerosol core). When two particles composed of such a layer structure collide, the layers are simply assumed to merge together, forming a new spherical particle with a surface-bulk layer, a bulk layer and a seed aerosol core. Because the surface area of the formed particle is always less than the sum of the surface areas of the two original particles, the width of the surface-bulk layer increases. Hence, in order to keep the width of the surface-bulk layer at approximately the thickness of one monolayer, part of the surface-bulk layer material is transferred to the particle bulk.

\subsubsection{Deposition and chamber wall effects}

It is well known that deposition losses of particles onto the chamber walls have a large influence on many chamber experiments (see e.g. Pierce et al., 2008). A commonly used 
method (see e.g. Hildebrandt et al., 2009; Loza et al., 2012) is to scale the measured SOA mass with the measured relative seed aerosol (typically ammonium sulfate) loss rate. With this method it is assumed that the particles deposited on the chamber walls continue to take up condensable gasphase compounds as if they were still present in the gas phase. A second method which was also used by Hildebrandt et al. (2009) and Loza et al. (2012) is to assume that the gasparticle partitioning stops once the particles have deposited on the chamber walls. These two correction methods can be considered to be two extremes, where the first method gives an upper bound of the SOA mass formed during the experiments whereas the second method gives a lower bound of the SOA formed during the experiments (at least if the SOA particles on the chamber walls are not evaporating and the gas-phase losses directly to the chamber walls are negligible).

ADCHAM considers the deposition of particles onto chamber walls and also keeps track of the particles deposited on the walls. The model also treats the mass-transfer-limited gas-particle partitioning between the gas phase and the walldeposited particles. Hence, ADCHAM can be used to study the influence of chamber wall effects on the SOA mass formation and help to constrain the uncertainties of the formed SOA mass (SOA mass yield).

For non-charged particles, ADCHAM uses the indoor deposition loss rate model from Lai and Nazaroff (2000), which accounts for different deposition loss rates on upward, downward- and vertically facing surfaces. However, if a considerable fraction of the particles are charged (e.g. at Boltzmann charge equilibrium) the effective deposition loss rate of particles can be considerably enhanced (Pierce et al., 2008). Hence, in order to be able to model realistic deposition loss rates of charged particles, ADCHAM keeps track of the fraction of particles suspended in the air with zero, one, two or three elemental charges in each particle size bin. The first-order deposition loss rate $\left(\mathrm{s}^{-1}\right)$ due to charge $\left(k_{\text {charge }}\right)$ is calculated with Eq. (3), where $v_{\mathrm{e}}$ is the characteristic average deposition velocity due to electrostatic forces $\left(\mathrm{m} \mathrm{s}^{-1}\right)$ (McMurry and Rader, 1985). The deposition loss rates depend on the friction velocity and for charged particles also on the mean electrical field strength within the chamber $\left(E^{\prime \prime}\right)$. Unfortunately both of these parameters are usually poorly known and need to be constrained with model simulations of seed aerosol deposition experiments (see Sect. 3.4). McMurry and Rader (1985) found that $E^{\prime \prime}$ was $\sim 45 \mathrm{~V} \mathrm{~cm}^{-1}$ in an almost spherical $\sim 0.25 \mathrm{~m}^{3}$ Teflon chamber. On the chamber surfaces they measured a negative electrical field strength of $-300 \pm 150 \mathrm{~V} \mathrm{~cm}^{-1}$. They attributed the lower empirically derived electric field within the chamber to the fact that the particles in the chamber will be influenced by a net electrical field, which has contributions from all points on the chamber surfaces. Hence, the shape and size of the chamber will also influence the mean electrical field. $k_{\text {charge }}=\frac{A_{\text {chamber }} v_{\mathrm{e}}}{V_{\text {chamber }}}, v_{\mathrm{e}}=\frac{n e C_{\mathrm{c}} E^{\prime \prime}}{3 \pi \mu D_{\mathrm{p}}} ;$

$A_{\text {chamber }}$ is the chamber surface area, $V_{\text {chamber }}$ is the chamber volume, $n$ is the number of elemental charges of the particle, $e$ is the elementary charge, $C_{\mathrm{c}}$ is the Cunningham slip correction factor and $\mu$ is the dynamic viscosity of air.

The mass-transfer-limited uptake of gases to and from the chamber walls needs to be considered in order to take into account the potential uptake (dissolution) of organic compounds in the SOA particles deposited on the chamber walls (Hildebrandt et al., 2009), as well as direct uptake of gasphase molecules onto the Teflon chamber surfaces (Matsunaga and Ziemann, 2010). For the condensation uptake or evaporation of SOA from the particles deposited on the walls, we assume that the particles deposited on the walls behave as if they were still suspended in (direct contact with) a thin (by default $1 \mathrm{~mm}$ thick) air layer adjacent to the chamber walls. As more particles get deposited on the walls, the SOA concentration on the chamber wall will increase. The condensable organic compounds in the thin air layer next to the chamber walls then have an increased probability to dissolve into the organic particle phase on the walls. However, semi-volatile organic compounds may also evaporate from the particles on the walls when the gas-phase concentrations in the chamber are reduced. The gas-particle partitioning between the wall-deposited particles and the thin air layer next to the chamber walls is modelled with the condensation and evaporation module described in Sect. 2.2.1.

ADCHAM also considers the adsorption and desorption of condensable organic compounds onto the Teflon surface film. This is modelled as a reversible process in accordance with Matsunaga and Ziemann (2010). The adsorption of gas-phase organic compounds onto the chamber walls is represented by a first-order loss rate from the near-wall gas phase to the walls $\left(k_{\mathrm{g}, \mathrm{w}}\right)$. The desorption rate from the Teflon surfaces out to the thin layer next to the chamber walls $\left(k_{\mathrm{w}, \mathrm{g}, i}\right)$ depends on the pure-liquid saturation vapour pressures $\left(p_{0, i}\right)$ of the adsorbed compounds (Eq. 4) (Matsunaga and Ziemann, 2010). Equations (5) and (6) describe the rate of change of the organic compound $\left(X_{i}\right)$ (due to adsorption and desorption) on the chamber walls and in the air layer adjacent to the wall, respectively. $\left[X_{i, \mathrm{~g}, \mathrm{w}}\right]$ is the concentrations of compound $X_{i}$ in the thin layer adjacent to the chamber walls. The concentration at the chamber wall $\left(\left[X_{i, \mathrm{w}}\right]\right)$ is given as an effective chamber volume concentration (total number of $X_{i}$ molecules on the walls divided by the total chamber volume $\left.\left(V_{\text {chamber }}\right)\right) . V_{\text {wall }}$ is the air volume of the thin $(1 \mathrm{~mm})$ layer adjacent to the chamber walls, $C_{\mathrm{w}}$ is an effective wallequivalent mass concentration which the organic compounds can dissolve into, $M_{\mathrm{W}}$ is the average molar mass of the Teflon film, and $\gamma_{\mathrm{w}, i}$ is the activity coefficient of compound $i$ in the Teflon film. 
Because ADCHAM calculates the gas-wall uptake from the thin layer (volume) adjacent to the Teflon walls and not from the total chamber volume, the $k_{\mathrm{g}, \mathrm{w}}$ values used in the model need to be substantially larger than the (experimentally quantifiable) effective total chamber volume loss rate $k_{\mathrm{g}, \mathrm{w}}^{*}$ (e.g. from Matsunaga and Ziemann, 2010). If the mass transport across the laminar layer adjacent to the chamber walls does not pose a strong limitation on the gas-wall uptake $(\Delta x \approx 1 \mathrm{~mm})$, the $k_{\mathrm{g}, \mathrm{w}}$ value used in ADCHAM can be derived from the experimentally determined effective loss rate by scaling $k_{\mathrm{g}, \mathrm{w}}^{*}$ with the ratio between the total chamber volume and the air volume adjacent to the chamber walls $\left(V_{\text {chamber }} / V_{\text {wall }}\right)$. However, if $\Delta x$ is relatively large (e.g. $10 \mathrm{~mm}), k_{\mathrm{g}, \mathrm{w}}$ needs to be increased in order to match the experimentally derived gas-wall losses. In the supplementary material we illustrate this with a few examples. Here we also illustrate that the modelled gas-wall uptake is not sensitive to the absolute width of the thin air layer adjacent to the chamber walls as long as $k_{\mathrm{g}, \mathrm{w}}$ is scaled with $V_{\text {chamber }} / V_{\text {wall }}$ (see Supplement Fig. S1).

$k_{\mathrm{g}, \mathrm{w}}^{*}$ and $C_{\mathrm{w}} /\left(M_{\mathrm{w}} \gamma_{\mathrm{w}, i}\right)$ in Eq. (4) were experimentally determined by Matsunaga and Ziemann (2010) for a $5.9 \mathrm{~m}^{3}$ Teflon chamber. For $n$-alkanes, 1-alkenes, 2-alcohols and 2ketones, $C_{\mathrm{w}} /\left(M_{\mathrm{w}} \gamma_{\mathrm{w}, i}\right)$ was $9,20,50$ and $120 \mu \mathrm{mol} \mathrm{m}^{-3}$, respectively. $k_{\mathrm{g}, \mathrm{w}}^{*}$ varied between $1 / 3600$ and $1 / 480 \mathrm{~s}^{-1} \mathrm{de}-$ pending on the type of compound.

$k_{\mathrm{w}, \mathrm{g}, i}=\frac{k_{\mathrm{g}, \mathrm{w}}}{\left(R T / p_{0, i} C_{\mathrm{w}} /\left(M_{\mathrm{w}} \gamma_{\mathrm{w}, i}\right)\right.}$

$\frac{\mathrm{d}\left[X_{i, \mathrm{w}}\right]}{\mathrm{d} t}=\left(k_{\mathrm{g}, \mathrm{w}}\left[X_{i, \mathrm{~g}, \mathrm{w}}\right]-k_{\mathrm{w}, \mathrm{g}, i}\left[X_{i, \mathrm{w}}\right]\right) \frac{V_{\mathrm{wall}}}{V_{\text {chamber }}}$

$\frac{\mathrm{d}\left[X_{i, \mathrm{~g}, \mathrm{w}}\right]}{\mathrm{d} t}=-k_{\mathrm{g}, \mathrm{w}}\left[X_{i, \mathrm{~g}, \mathrm{w}}\right]+k_{\mathrm{w}, \mathrm{g}, i}\left[X_{i, \mathrm{w}}\right]$

According to Eq. (4), a compound with $p_{0}=2.5 \times 10^{-2} \mathrm{~Pa}$ and $C_{\mathrm{w}} /\left(M_{\mathrm{w}} \gamma_{\mathrm{w}, i}\right)=10 \mu \mathrm{mol} \mathrm{m}^{-3}$ partitions $\sim 50 \%$ to the gas phase and $\sim 50 \%$ to the chamber walls at equilibrium and room temperature. At equilibrium, compounds with a vapour pressure $<10^{-3} \mathrm{~Pa}$ and $C_{\mathrm{w}} /\left(M_{\mathrm{w}} \gamma_{\mathrm{w}, i}\right)>$ $10 \mu \mathrm{mol} \mathrm{m}{ }^{-3}$ will almost exclusively be found at the walls if they are not able to form SOA rapidly enough. Hence, the SOA formation in the smog chamber will depend on (1) the formation rate of condensable organic compounds, (2) the particle deposition losses, (3) the magnitude of the condensation sink to the particles in the air and onto the chamber walls, and (4) the diffusion-limited uptake onto the chamber walls and particles on the walls.

The concentration gradient in the laminar layer adjacent to the chamber walls generally drives condensable gas-phase components from the well-mixed chamber volume to the chamber walls (thin model layer next to the wall). We explicitly model this mass transfer with Fick's first law of diffusion, assuming a linear concentration gradient across the laminar layer next to the chamber wall (see Fig. 2).

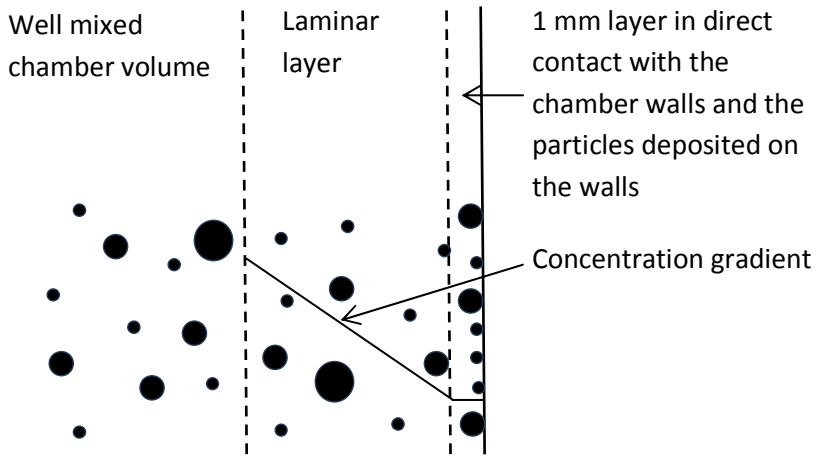

Figure 2. Schematic figure which illustrates how ADCHAM treats the diffusion-limited mass transfer of gas-phase compounds across a laminar layer next to the chamber walls. The thin $(1 \mathrm{~mm}$ thick $)$ air layer next to the chamber walls is treated as a separate volume which exchanges gas-phase compounds with the well-mixed chamber and the walls + wall-deposited particles.

In Sect. 3.4 we study how different values of the laminar layer width influence the model results. The gas-phase chemistry and the gas-particle mass transfer (condensation) in the well-mixed chamber volume and in the thin layer adjacent to the chamber wall were solved using operator splitting with a model time step of $10 \mathrm{~ms}$. The mass transfer between the well-mixed chamber volume and the thin layer next to the chamber wall was modelled with a time step of $0.1 \mathrm{~ms}$. The model needs to take short time steps because of the large condensation sink (or evaporation source) of the wall-deposited particles and the Teflon surfaces, which may rapidly alter the concentrations in the thin air layer next to the chamber walls.

In Sect. 3.2 we evaluate the potential influence of the reversible uptake of organic compounds to the smog chamber Teflon walls on the volatility and evaporation rates of SOA particles. In Sect. 3.4 we test the capability of ADCHAM to simulate the losses of organic compounds from the gas phase to the Teflon walls and wall-deposited particles.

\subsubsection{Size distribution structures}

Analogous to ADCHEM (Roldin et al., 2011a) ADCHAM include several methods (fully stationary, fully moving and moving centre) in order to treat the changes in the particle number size distribution upon condensation/evaporation or coagulation. These methods are all mass- and numberconserving and have different advantages and disadvantages (Korhonen, et al. 2004; Jacobson, 2005a; Roldin et al., 2011a). For all simulations performed in this article, we have used the fully moving method for condensation and evaporation. With this method the diameter grid moves with the particles. Hence, this method has no numerical diffusion problems when particles grow by condensation or shrink by evaporation. Homogeneous nucleation is considered by adding new particle size bins when new particles are formed 
(Sects. 3.2 and 3.3). For coagulation we use a fully stationary method in which the formed particles mass and number concentrations are split between the existing diameter bins (Sect. 2.2.2).

\subsection{Particle-phase chemistry}

\subsubsection{Activity coefficients and organic-inorganic interactions}

The AIOMFAC model is based on the UNIFAC (UNIquac Functional group Activity Coefficients) model for organic mixtures but also considers organic-inorganic interaction which allows us to study salt effects on the SOA formation. AIOMFAC (Aerosol Inorganic-Organic Mixtures Functional groups Activity Coefficients) considers interactions between 12 different ions (including $\mathrm{NH}_{4}^{+}, \mathrm{NO}_{3}^{-}, \mathrm{H}^{+}, \mathrm{SO}_{4}^{-2}$ and $\mathrm{HSO}_{4}^{-}$) and alkyls, hydroxyls, carboxyls, ketones, aldehydes, ethers, esters, alkenyls, aromatic carbon alcohols and aromatic hydrocarbons (Zuend et al., 2008, 2011). For other important functional groups, i.e. nitrates, nitros, PANs and peroxides, we only consider organic-organic functional group interactions. In total the model considers 52 different UNIFAC functional subgroups, with interaction parameters from Hansen et al. (1991), except for alcohols (Marcolli and Peter, 2005) and nitrates, PANs and peroxides, for which we use the parameterization from Compernolle et al. (2009). In ADCHAM, the activity coefficients are calculated before the condensation algorithm is used and when updating the hydrogen ion concentration $\left(\left[\mathrm{H}^{+}\right]\right)$for the acid-catalysed oligomerization.

\subsubsection{Acidity and dissociation of inorganic compounds in organic-rich phases}

The hydrogen ion concentration is calculated in the condensation algorithm and when considering acid-catalysed oligomerization. Analogous to the procedure in ADCHEM (Roldin et al., 2011a), $\left[\mathrm{H}^{+}\right]$in the particle water or particle water + organics phase is calculated by solving the ion balance equation (Eq. 7). In ADCHAM we have extended the ion balance equation with dissociation products of carboxylic acids $\left(\mathrm{RCOO}^{-}\right)$. In this work we assume that all carboxylic acids have identical dissociation constants (see Sect. 3.2). Hence, $\left[\mathrm{RCOO}^{-}\right]$in Eq. (7) represents the total concentration (mol kg-1 solvent) of dissociated carboxylic acids.

$$
\begin{array}{r}
{\left[\mathrm{H}^{+}\right]+\left[\mathrm{NH}_{4}^{+}\right]+\left[\mathrm{Na}^{+}\right]=\left[\mathrm{NO}_{3}^{-}\right]+2\left[\mathrm{SO}_{4}^{2-}\right]+\left[\mathrm{HSO}_{4}^{-}\right]} \\
+\left[\mathrm{Cl}^{-}\right]+\left[\mathrm{OH}^{-}\right]+\left[\mathrm{HCO}_{3}^{-}\right]+2\left[\mathrm{CO}_{3}^{2-}\right]+\left[\mathrm{RCOO}^{-}\right]
\end{array}
$$

In order to calculate $\left[\mathrm{H}^{+}\right]$, all concentrations except the hydrogen ion concentration in Eq. (7) are replaced with known equilibrium coefficients, activity coefficients from AIOMFAC, and the total concentration of dissolved dissociated and non-dissociated compounds, $\quad\left([\mathrm{RCOOH}]+\left[\mathrm{RCOO}^{-}\right]\right), \quad\left(\left[\mathrm{NH}_{3}(\mathrm{aq})\right]+\left[\mathrm{NH}_{4}^{+}\right]\right)$, $\left(\left[\mathrm{SO}_{4}^{2-}\right]+\left[\mathrm{HSO}_{4}^{-}\right]\right),\left(\left[\mathrm{HNO}_{3}\right]+\left[\mathrm{NO}_{3}^{-}\right]\right)$and $([\mathrm{HCl}(\mathrm{aq})]+$ $\left.\left[\mathrm{Cl}^{-}\right]\right)$. In this work the uptake of $\mathrm{CO}_{2}$ in the particles was treated as an equilibrium process. The $\mathrm{HCO}_{3}^{-}$and $\mathrm{CO}_{3}^{2-}$ concentrations depend on the hydrogen ion concentration and the $\mathrm{CO}_{2}$ partial pressure (390 ppbv). When all unknown ion concentrations have been replaced with the known parameters, Eq. (7) becomes an eight-order polynomial with $\left[\mathrm{H}^{+}\right]$as the only unknown variable. The hydrogen ion concentration is given by the maximum real root of this polynomial.

To treat the $\mathrm{CO}_{2}$ uptake as an equilibrium process may not be realistic if the particles are very viscous (see Sect. 1). However, the estimated diffusion coefficients of other small "guest" molecules (e.g. $\mathrm{O}_{3}, \mathrm{OH}$ and $\mathrm{H}_{2} \mathrm{O}$ ) in an amorphous glassy organic matrix is of the order of $10^{-10}-10^{-12} \mathrm{~cm}^{2} \mathrm{~s}^{-1}$ at room temperature (Koop et al., 2011; Zobrist et al., 2011). This gives corresponding e-folding times of equilibration for submicron particles in the range of seconds.

All experiments which we model in this paper were performed under dry conditions ( $\mathrm{RH} \leq 5 \%$ ). For the $\alpha$-pinene SOA experiments (Sects. 3.2-3.3), the modelled particle water mass content is only $\sim 0.4 \%$ at an RH of $5 \%$. For these particles the solvent will therefore mainly be the organic compounds and not water. Hence, in this work the concentrations of the inorganic ions (including $\mathrm{H}^{+}$) is not given for the aqueous phase but for the combined organics and water phase. Henry's law coefficients $\left(K_{\mathrm{H}}\right)$ of inorganic compounds and dissociation rates $\left(K_{\mathrm{a}}\right)$ of inorganic compounds and carboxylic acids are (if at all) usually only available for aqueous solutions. However, there is often a relationship between the $\Delta \mathrm{pK}_{\mathrm{a}}\left(-\log _{10}\left(K_{\mathrm{a} \text {,base }}\right)+\log _{10}\left(K_{\mathrm{a} \text {,acid }}\right)\right)$ and the proton transfer between the Brønsted acid and the Brønsted base in protic ionic liquids (Greaves and Drummond, 2008). Thus, for most of the simulations we will use the aqueous dissociation rates and Henry's law coefficients for the organic amorphous SOA and water mixtures, and take into account the non-ideal interactions between the ions, organic solvents and water using AIOMFAC (Sect. 2.3.1). However, we will also test to model the ammonium uptake with 10-times-lower Henry's law coefficients, which may be more appropriate for organic solvents.

With these assumptions in mind, the modelled absolute values of $\left[\mathrm{H}^{+}\right]$should be interpreted with caution. However, we believe that the model can give a realistic representation of the relative influence of different types of dissolved compounds on the particle acidity. For instance, carboxylic acids will most likely increase $\left[\mathrm{H}^{+}\right]$also in an organic-rich phase, while dissolved ammonia will decrease $\left[\mathrm{H}^{+}\right]$. For all other organic compounds except the carboxylic acids, the dissociation rates were assumed to be equal to that of pure water $\left(\mathrm{pK}_{\mathrm{a}}=14\right)$. Hence, equivalent to aqueous solutions, the 
acidity will mainly be governed by the carboxylic acids and inorganic compounds.

\subsubsection{Inorganic and organic salt formation}

In ADCHAM the inorganic salts $\left(\mathrm{NH}_{4}\right)_{2} \mathrm{SO}_{4}, \mathrm{NH}_{4} \mathrm{HSO}_{4}$ and $\mathrm{NH}_{4} \mathrm{NO}_{3}$ and the organic salts of ammonium and different carboxylic acids $\left(\mathrm{NH}_{4} \mathrm{RCOO}\right)$ can be considered to form. All these salts contain $\mathrm{NH}_{4}^{+}$, and which of these salts will be formed depends on the solubility constants, the ammonium concentration, the concentration of the different anions and the activity coefficients. Because all these salts contain ammonium, the salt which forms first will limit the formation of other salts. In this work, we only simulate experiments performed on pure organic particles or organic particles which take up $\mathrm{NH}_{3}(\mathrm{~g})$. Hence, $\mathrm{NH}_{4} \mathrm{RCOO}(\mathrm{s})$ was the only (solid) salt which was considered to be formed in the particle organics-water phase. The solid salt concentrations are updated iteratively at every time step in which the condensation/evaporation algorithm is used.

When updating the $\mathrm{NH}_{4} \mathrm{RCOO}(\mathrm{s})$ concentration, ADCHAM starts by estimating the activity coefficients and the hydrogen ion concentration (Eq. 7). After this, nonequilibrium $\mathrm{NH}_{4}^{+}$and $\mathrm{RCOO}^{-}$concentrations $\left(\left[\mathrm{NH}_{4}^{+}\right]^{*}\right.$ and $\left.\left[\mathrm{RCOO}^{-}\right]^{*}\right)$ can be derived, and the total concentrations of $\mathrm{NH}_{4}\left(\left[\mathrm{NH}_{4, \text { tot }}\right]=\left[\mathrm{NH}_{4}^{+}\right]^{*}+\left[\mathrm{NH}_{4} \mathrm{RCOO}_{t-1}\right)\right.$ and $\mathrm{RCOO}$ $\left(\left[\mathrm{RCOO}_{\mathrm{tot}}\right]=\left[\mathrm{RCOO}^{-}\right]^{*}+\left[\mathrm{NH}_{4} \mathrm{RCOO}\right]_{t-1}\right)$ are estimated. These values are then inserted into the solubility product equation (Eq. 8). Rearranging Eq. (8) gives a secondorder polynomial where the new $\mathrm{NH}_{4} \mathrm{RCOO}$ concentration $\left(\left[\mathrm{NH}_{4} \mathrm{RCOO}\right]_{t}\right)$ is given by the smallest positive real root. Finally the $\mathrm{NH}_{4}^{+}$and $\mathrm{RCOO}^{-}$concentrations are updated and the iteration starts from the beginning by deriving the hydrogen ion concentration again. The iteration proceeds until the relative change in the $\mathrm{NH}_{4}^{+}, \mathrm{RCOO}^{-}$and $\mathrm{H}^{+}$concentrations all are less than $10^{-3}$ within one iteration step. The activity coefficient of the dissociated carboxylic acids $\left(\gamma_{\mathrm{RCOO}}\right)$ was assumed to be equal to the activity coefficient of undissociated pinonic acid.

$$
\begin{aligned}
K_{\mathrm{NH}_{4} \mathrm{RCOO}}= & \gamma \mathrm{NH}_{4} \gamma_{\mathrm{RCOO}}\left[\mathrm{NH}_{4}^{+}\right]\left[\mathrm{RCOO}^{-}\right] \\
= & \gamma \mathrm{NH}_{4} \gamma_{\mathrm{RCOO}}\left(\left[\mathrm{NH}_{4, \mathrm{tot}}\right]-\left[\mathrm{NH}_{4} \mathrm{RCOO}\right]\right) \\
& \left(\mathrm{RCOO}_{\text {tot }}-\left[\mathrm{NH}_{4} \mathrm{RCOO}\right]\right)
\end{aligned}
$$

\subsubsection{Acid-catalysed oligomerization}

Any oligomerization mechanisms in the gas phase (g) or particle phase (p) (including different functional groups, ozonolysis, acid-catalysed reactions, and radicals) can easily be implemented in ADCHAM. For the applications in this work, we only consider the reactions between monomers which form dimers and not the possible reactions between dimers and dimers with monomers. The acid-catalysed formation rate of a dimer in the particle phase can generally be considered to be proportional to the hydrogen ion concentration (see e.g. schemes by Tolocka et al., 2004, and Iinuma et al., 2004). In contrast to thermodynamic equilibrium models (e.g. Barsanti and Pankow, 2004), ADCHAM explicitly treats the kinetics of reversible dimerization with separate Reactions (R1) and (R2) for the formation and the degradation of dimers back to monomers. Based on observations, several different particle-phase oligomerization mechanisms have been suggested. These include (i) esters formed from reactions between carboxylic acids and alcohols (e.g. Surratt et al., 2006), (ii) hemiacetal formation from reactions between carbonyls and alcohols (e.g. Iinuma et al., 2004), (iii) aldol reaction products formed from carbonyl-carbonyl reactions (Casale et al., 2007) and (iv) peroxyhemiacetals formed from reactions between hydroperoxides and carbonyls (e.g. Tobias and Ziemann, 2000). Dimers can also form when carbonyls react with ozone in the particle phase and form secondary ozonides (Reaction R3) which then rapidly react with other organic compounds and form dimers (Maksymiuk et al., 2009). Based on thermodynamic calculations of different organic mixtures, it has been suggested that ester formation (Barsanti and Pankow, 2006) and peroxyhemiacetal formation (DePalma et al., 2013) can be thermodynamically favourable, while hemiacetal formation is not (Barsanti and Pankow, 2004 and DePalma et al., 2013).

If peroxyhemiacetal and hemiacetal formation are thermodynamically favourable, then these mechanism are probably rapid enough to form substantial dimer mass on short timescales (minutes to hours). The second-order rate constants $\left(k_{\mathrm{f}}\right)$ for uncatalysed reactions of different hydroperoxides and aldehydes to form peroxyhemiacetals range from 0.5 to $70 \mathrm{M}^{-1} \mathrm{~h}^{-1}\left(2.3 \times 10^{-25}-3.2 \times\right.$ $10^{-23}$ molecules $^{-1} \mathrm{~cm}^{3} \mathrm{~s}^{-1}$ ) (Ziemann and Atkinson, 2012). According to Ziemann and Atkinson (2012) peroxyhemiacetal formation can probably be acid-catalysed. Thus, for acid particles, $k_{\mathrm{f}}$ may be larger than the values reported by Ziemann and Atkinson (2012). Shiraiwa et al. (2013a) found that in order for the KM-GAP model to capture the temporal evolutions of the SOA formation and shape of the particle number size distribution during an dodecane photooxidation experiment, the peroxyhemiacetal formation rate needs to be $12 \mathrm{M}^{-1} \mathrm{~s}^{-1}\left(2 \times 10^{-20}\right.$ molecules $\left.{ }^{-1} \mathrm{~cm}^{3} \mathrm{~s}^{-1}\right)$. This high formation rate can be attributed to the presence of carboxylic acids (Shiraiwa et al., 2013a). The formation of hemiacetal from the reaction between acetaldehyde and methanol is acid-catalysed with a third-order reaction-specific formation rate constant $\left(k_{\mathrm{f}, \mathrm{H}^{+}}\right)$equal to $4.9 \times 10^{6} \mathrm{M}^{-2} \mathrm{~h}^{-1}$ (Ziemann and Atkinson, 2012). With a pH of 4 , this corresponds to a $k_{\mathrm{f}}$ of $2.3 \times 10^{-22}$ molecules ${ }^{-1} \mathrm{~cm}^{3} \mathrm{~s}^{-1}$.

monomer $_{j}+$ monomer $_{i} \stackrel{\mathrm{H}^{+}}{\longrightarrow} \operatorname{dimer}_{j i}$

$\operatorname{dimer}_{j i} \longrightarrow$ monomer $_{j}+$ monomer $_{i}$

carbonyls $(\mathrm{p})+\mathrm{O}_{3}(\mathrm{p}) \longrightarrow$ secondary ozonides $(\mathrm{p})$

In the gas phase, low-volatility ROOR-type peroxide dimers can form when two peroxy radicals $\left(\mathrm{RO}_{2}\right)$ react 
(e.g. Kroll and Seinfeld, 2008; Ng et al., 2008) (Reaction R4). Recently, Ehn et al. (2014) also showed that extremely low volatility organic compounds (ELVOC) can form during ozonolysis of $\alpha$-pinene. The authors propose that ELVOC is formed from $\mathrm{RO}_{2}$, which rapidly takes up $\mathrm{O}_{2}$ after intramolecular hydrogen abstraction in several steps.

$\mathrm{RO}_{2}(\mathrm{~g})+\mathrm{RO}_{2}(\mathrm{~g}) \longrightarrow$ ROOR-type peroxides $(\mathrm{g})$

The acid-catalysed dimer formation rates in the particle phase $\left(F_{\mathrm{f}}(\mathrm{p})\right)$ between monomer (denoted by index $i$ and $j$ ) depend on the monomer concentrations, $k_{\mathrm{f}, \mathrm{H}^{+}}$ (molecules ${ }^{-2} \mathrm{~cm}^{6} \mathrm{~s}^{-1}$ ) and the hydrogen ion concentration $\left(c_{\mathrm{H}^{+}}\right)$(Eq. 9). If the dimerization process is uncatalysed, the formation rate depends on the monomer concentrations and a second-order rate constant $\left(k_{\mathrm{f}}\left(\right.\right.$ molecules $\left.\left.{ }^{-1} \mathrm{~cm}^{3} \mathrm{~s}^{-1}\right)\right)$. The degradation rate $\left(F_{\mathrm{d}}(\mathrm{p})\right.$ ) of a dimer (denoted by index $q$ ) simply depends on the dimer concentration and a dimer-specific first-order degradation reaction rate constant $\left(k_{\mathrm{d}}\left(\mathrm{s}^{-1}\right)\right)($ Eq. 10).

$F_{\mathrm{f}, i, j}(\mathrm{p})=k_{\mathrm{f}, \mathrm{H}^{+}}(\mathrm{p}) c_{\mathrm{H}^{+}}(\mathrm{p}) c_{\mathrm{m}, i}(\mathrm{p}) c_{\mathrm{m}, j}(\mathrm{p})$

$F_{\mathrm{d}, q}(\mathrm{p})=k_{\mathrm{d}}(\mathrm{p}) c_{\mathrm{d}, q}(\mathrm{p})$

The temporal evolution of the dimer and the monomer concentrations $\left(c_{\mathrm{d}}\right.$ and $\left.c_{\mathrm{m}}\right)$ in the particle bulk layers and surfacebulk layer are derived with a kinetic model. This code solves a coupled ordinary differential equation system, consisting of one ordinary differential equation for each SOA monomer (Eq. 11) and one ordinary differential for each dimer (Eq. 12). The equations are given by the sum of all dimer degradation and formation rates for the individual reactions which each monomer compound is involved in.

$$
\begin{aligned}
\frac{\mathrm{d} c_{\mathrm{m}, i}}{\mathrm{~d} t} & =\sum_{q=1}^{Z}\left(F_{\mathrm{d}, q} x_{\mathrm{m}, i, q}\right)-\sum_{j=1}^{N} F_{\mathrm{f}, i, j} \\
\frac{\mathrm{d} c_{\mathrm{d}, q}}{\mathrm{~d} t} & =-F_{\mathrm{d}, q}+\sum_{i=1}^{M}\left(\sum_{j=1}^{N} F_{\mathrm{f}, i, j}\right) x_{\mathrm{d}} \\
x_{\mathrm{m}, i, q} & =\sum_{j=1}^{N} F_{\mathrm{f}, i, j} / \sum_{i=1}^{M}\left(\sum_{j=1}^{N} F_{\mathrm{f}, i, j}\right)
\end{aligned}
$$

In order to not end up with an enormous coupled ordinary differential equation system, the different dimers are classified into different categories (types) depending on the dimerization mechanism (e.g. esters or peroxyhemiacetal formation). Secondary ozonide formation (Reaction R3) is treated by the kinetic multilayer module for heterogeneous oxidation (see Sect. 2.4.2). In order to be mass-conserving, the number of moles of dimer formed is corrected with the molar ratio $\left(x_{\mathrm{d}}\right)$ between the molar mass of the product(s) and the sum of the molar masses of the reacting compounds. In ADCHAM all dimers have by default a molar mass of $400 \mathrm{~g} \mathrm{~mol}^{-1}$.
When we lump the dimers into different categories, the information about their exact chemical composition and origin is lost. This can be a problem when considering the reversible reactions back to monomers. In this work we have assumed that a dimer is converted back to the monomers it is formed from, with fractions $\left(x_{\mathrm{m}}\right)$ corresponding to the (current time step) relative contribution of each monomer to the dimer formation (Eq. 13). This can be a reasonable assumption if the monomer SOA composition does not change substantially on a timescale longer than the lifetime of the dimer. However, if this is not the case it can distort the modelled particle composition. With this method we do not take into account that specific compounds of the same type of dimer (e.g. esters) may have substantially different formation and degradation rates, e.g. depending on other functional groups in the molecules (Ziemann and Atkinson, 2012). However, in principle the method still enables an unlimited number of different dimer types and dimer-specific formation and degradation rates.

The modelled relative amount and composition of oligomer SOA in each particle layer depends on (1) the monomer SOA composition, (2) the hydrogen ion concentration, (3) the dimer formation rates, (4) the oligomer degradation reaction rates, (5) possible evaporation and condensation of monomers and dimers (vapour pressures), (6) the mixing between different particle layers (diffusion coefficients of monomers and dimers), (7) the ozone uptake at the particle surface, (8) the ozone diffusion rate within the particle bulk phase, (9) the reaction rates of ozone with unsaturated organic compounds in the particle phase, and (10) the time of aging. Points 1-9 all bear large uncertainties which need to be constrained in order to represent oligomerization in an accurate way. For the model applications in this work we will not explicitly model the influence of particle acidity on the dimer formation rates because these values are very uncertain regardless.

\subsection{Kinetic multilayer model}

To be able to model the diffusion-limited mass transfer of ozone from the gas-particle interface to the particle core, and the reaction between ozone and the organic compounds in the particle phase, Shiraiwa et al. (2010) developed the kinetic multilayer model KM-SUB, which is based on the PRA (Pöschl-Rudich-Ammann) concept of gas-particle interactions (Pöschl et al., 2007; Ammann and Pöschl, 2007). This model divides the particles into a sorption layer, a quasistatic surface layer, near-surface bulk, and multiple bulk layers and considers the gas-surface transport, reversible adsorption, surface layer reactions, surface-bulk transport, bulk diffusion and bulk reactions. Recently, Shiraiwa et al. (2012) extended the kinetic multilayer model to also include condensation, evaporation and heat transfer (KM-GAP), thermodynamics (Shiraiwa et al., 2013b), and simplified gas- and particle-phase chemistry (Shiraiwa et al., 2013a). 
For the oxidation agents we model the uptake to the sorption layer as a reversible adsorption process, followed by diffusion to and from the particle surface-bulk and bulk layers. In this work, the partitioning of organic and inorganic compounds to and from the monolayer thick particle surfacebulk layer is modelled as a condensation/evaporation process (Eq. 1), taking into account the possibility of non-unity surface-bulk accommodation (Sect. 2.2.1). However, in principle ADCHAM could also model the gas-particle partitioning of organic and inorganic compounds as a reversible adsorption process. Analogous to KM-SUB and KM-GAP, ADCHAM explicitly treats the bulk diffusion of all compounds between the different layers using first-order mass transport rate equations.

The kinetic multilayer model in ADCHAM consists of two separate modules. The first module (Sect. 2.4.1) treats the diffusion of all organic and inorganic compounds (except $Z_{\text {ox }}$ ) between the different bulk layers. The second module (Sect. 2.4.2) considers the uptake, diffusion and reactions of $Z_{\mathrm{ox}}$ with the organic compounds in the particle phase. The main reason why these processes are treated by two separate modules is that the uptake, diffusion and reaction of $\mathrm{O}_{3}$ and other oxidation agents generally occur on substantially shorter timescales than the diffusion of the organic compounds.

\subsubsection{Diffusion of organic and inorganic compounds}

The transport velocity of compound $X_{i}$ between the bulk layers or the surface and first bulk layer is given by Eq. (14). $D_{X_{i}}$ is the diffusion coefficient of compound $X_{i}$, and $\delta_{k}$ and $\delta_{k+1}$ represent the width of the two adjacent layers $(k$ and $k+1)$ which $X_{i}$ is transported between.

$k_{k+1, k, X_{i}}=k_{k, k+1, X_{i}}=\frac{4 D_{\mathrm{X}_{i}}}{\pi\left(\delta_{k+1}+\delta_{k}\right) / 2}$

The transport of compound $\mathrm{X}_{i}$ between the particle layers (including the exchange between the surface- and first bulk layer) is modelled with Eq. (15). $A_{k}$ is the area of exchange between layer $k-1$ and $k$. $\left[V_{X_{i}}\right]_{k}$ is the absolute volume concentration $\left(\mathrm{m}^{3}\right)$ and $\left[X_{i}\right]_{k}$ is the relative volume concentration (volume fraction) of compound $X_{i}$ in layer $k$. The total volume of each particle layer $\left(V_{k}\right)$ is given by the sum of the absolute volume concentrations of all compounds. Equation (16) contains no terms for the chemical formation and degradation of $X_{i}$ because this is considered by separate modules for oligomerization (Sect. 2.3.4), heterogeneous oxidation (Sect. 2.4.2) and organic salt formation (Sect. 2.3.3).

$$
\begin{aligned}
\frac{\mathrm{d}\left[V_{X_{i}}\right]_{k}}{\mathrm{~d} t} & =\left(k_{k-1, k}\left[X_{i}\right]_{k-1}-k_{k, k-1}\left[X_{i}\right]_{k}\right) A_{k} \\
& +\left(-k_{k, k+1}\left[X_{i}\right]_{k}+k_{k+1, k}\left[X_{i}\right]_{k+1}\right) A_{k+1}
\end{aligned}
$$

The equations describing the concentration change of all compounds in all layers (Eq. 15) comprise a system of $N \times$

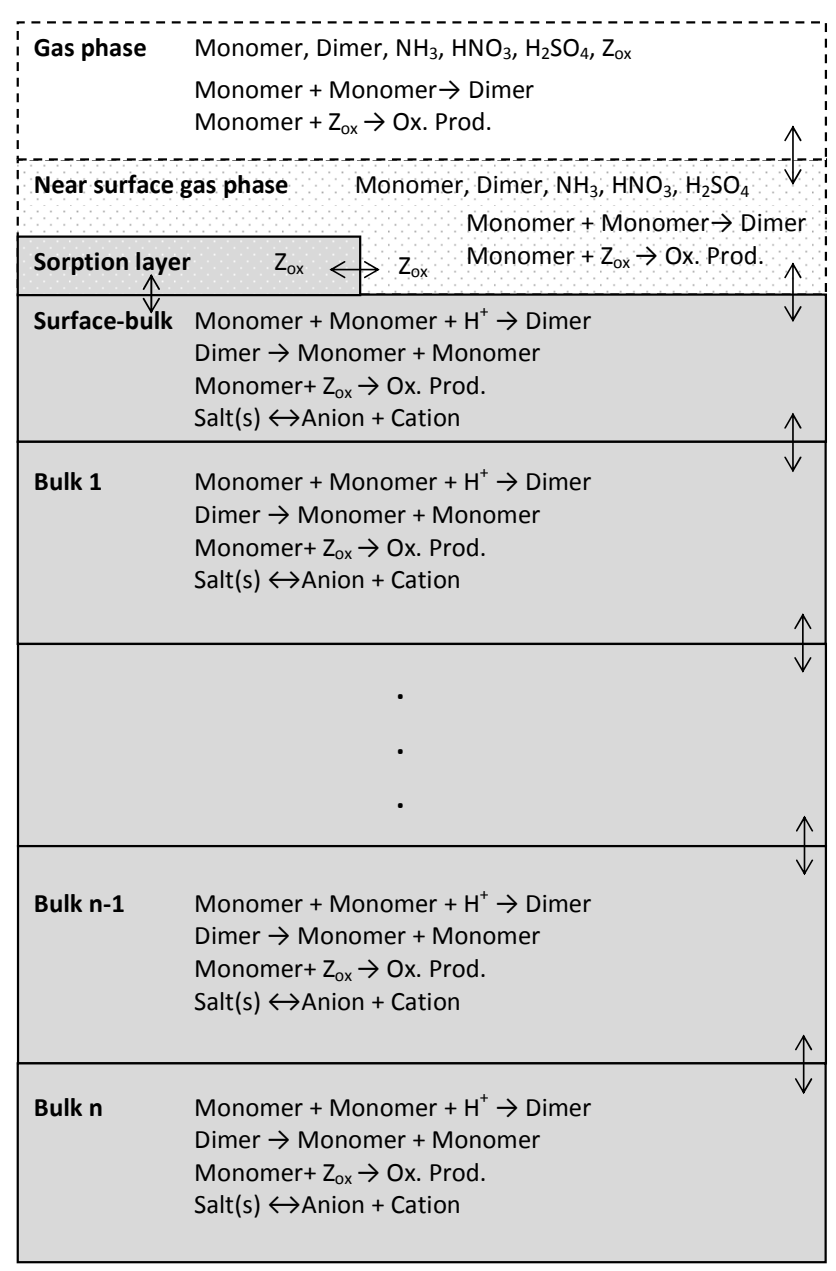

Figure 3. Schematic picture which illustrates the model structure and processes included in the kinetic multilayer model in ADCHAM. The double arrows represent the mass transport between the layers.

$N_{\mathrm{L}}$ coupled ordinary differential equations $\left(N_{\mathrm{L}}=\right.$ number of particle layers), which we solve with the ode15s solver in MATLAB.

Figure 3 shows a schematic picture of the kinetic multilayer module in ADCHAM. In contrast to the kinetic multilayer model by Shiraiwa et al. $(2010,2012)$, the number of particle layers increases when the particles grow. Hence, particles of different sizes are composed of different number of layers.

Once the depth of the surface-bulk layer becomes larger than $1.1 \mathrm{~nm}$, material is moved from this layer to the first bulk layer, leaving a $1 \mathrm{~nm}$ thick surface-bulk layer. If the first bulk layer becomes larger than a certain value (by default $3 \mathrm{~nm}$ thick) it is split into a first and second bulk layer with identical compositions, 1 and $2 \mathrm{~nm}$ thick, respectively.

Upon evaporation, material is lost from the surface-bulk layer, and if the layer thickness becomes less than $0.99 \mathrm{~nm}$, material is moved from the first bulk layer to the surface-bulk 
layer in order to keep the surface-bulk layer width intact. If the first bulk layer width becomes less than a certain value (by default $0.8 \mathrm{~nm}$ ), this layer is merged together with the second bulk layer, and together they form a new first bulk layer. The rest of the particle bulk is divided into layers with variable width. The layer width depends on the net mass transport to the adjacent layers and chemical reactions (e.g. between $\mathrm{O}_{3}$ and unsaturated hydrocarbons).

In each particle layer the model considers different oligomerization reactions and the equilibrium reactions between salts and their dissolved ions in the organic + water phase (Sects. 2.3.3 and 2.3.4). The formed oligomers and salts make up a particle volume fraction $\left(f_{\mathrm{p}}\right)$ with generally substantially lower diffusivity than the rest of the compounds. Hence, oligomerization and solid salt formation increases the viscosity, which also limits the diffusion of the liquid compounds according to the obstruction theory (Stroeve, 1975). The treatment of the oligomers as solid non-diffusing compounds which limit diffusion of the liquid compounds was adopted from Pfrang et al. (2011), who used KM-SUB to model degradation of an organic 12-component mixture with ozone.

According to the obstruction theory the diffusivity of compound $X_{i}\left(D_{X_{i}}\right)$ is a function of the fraction of solid or semisolid material and the diffusivity $\left(D_{0, X_{i}}\right)$ without any solid or semi-solid material (Eq. 16). The diffusivity of organic compounds can vary from $\sim 10^{-5} \mathrm{~cm}^{2} \mathrm{~s}^{-1}$ in a liquid to $\sim 10^{-20} \mathrm{~cm}^{2} \mathrm{~s}^{-1}$ in a solid organic matrix (Shiraiwa et al., 2011).

$D_{X_{i}}=D_{0, X_{i}}\left(2-2 f_{\mathrm{p}}\right) /\left(2+f_{\mathrm{p}}\right)$

\subsubsection{Diffusion of oxidation agents and reactions with SOA}

The diffusion of oxidation agents $\left(Z_{\mathrm{ox}}\right)$ between the particle bulk layers is similar to the treatment of other compounds (Eqs. 14 and 15), except that we do not consider that the dissolved $Z_{\mathrm{ox}}$ in the particle phase takes up a bulk volume of its own.

The uptake of $Z_{\mathrm{ox}}$ from the gas phase to the particle surface is treated as a reversible adsorption process (Fig. 3). This approach was adopted from Shiraiwa et al. (2010). The surface accommodation coefficient of $Z_{\text {ox }}$ is given by Eq. (17). $\theta_{s, Z_{\mathrm{ox}}}$ is the relative coverage of adsorbed $Z_{\mathrm{ox}}$ on the particle surface. The adsorption of $Z_{\mathrm{ox}}$ from the near-surface gas phase (gs) to the sorption layer (so) and the desorption from the sorption layer to the near-surface gas phase are given by Eqs. (18) and (19), respectively. $\omega_{Z_{\mathrm{ox}}}$ is the mean thermal velocity of $Z_{\mathrm{ox}}$ and $\tau_{\mathrm{d}, Z_{\mathrm{ox}}}$ is the desorption lifetime of $Z_{\mathrm{ox}}$.

The transport velocity of $Z_{\mathrm{ox}}$ from the surface-bulk layer to the sorption layer is given by Eq. (20). $\delta_{\mathrm{s}}$ is the width of the monolayer thick surface-bulk layer and $d_{Z_{\mathrm{ox}}}$ is the width of the sorption layer. Hence, $\left(\delta_{s}+d_{Z_{\mathrm{ox}}}\right) / 2$ in Eq. (20) represents the average travel distance between the sorption and surface-bulk layer. The transport velocity of $Z_{\mathrm{ox}}$ from the sorption layer to the surface-bulk layer can then be calculated from Eq. (21). $K_{\mathrm{H}, Z_{\mathrm{ox}}}$ is the Henry's law coefficient of $Z_{\text {ox }}$.

$\alpha_{\mathrm{s}, Z_{\mathrm{ox}}}=\alpha_{\mathrm{s}, 0, Z_{\mathrm{ox}}}\left(1-\theta_{\mathrm{s}, Z_{\mathrm{ox}}}\right), \theta_{\mathrm{s}, Z_{\mathrm{ox}}}=\frac{\left[Z_{\mathrm{ox}}\right]_{\mathrm{so}} d_{Z_{\mathrm{ox}}}^{2} \pi}{4}$

$J_{\mathrm{ads}, Z_{\mathrm{ox}}}=\left[Z_{\mathrm{ox}}\right]_{\mathrm{gs}} \omega_{Z_{\mathrm{ox}}} \alpha_{\mathrm{s}, Z_{\mathrm{ox}}} / 4$

$J_{\mathrm{des}, Z_{\mathrm{ox}}}=\tau_{\mathrm{d}, Z_{\mathrm{ox}}}^{-1}\left[Z_{\mathrm{ox}}\right]_{\mathrm{so}}$

$k_{\mathrm{su}, \mathrm{so}, Z_{\mathrm{ox}}} \approx \frac{4 D_{Z_{\mathrm{ox}}}}{\pi\left(\delta_{\mathrm{s}}+d_{Z_{\mathrm{ox}}}\right) / 2}$

$k_{\mathrm{so}, \mathrm{su}, Z_{\mathrm{ox}}}=\frac{4 k_{\mathrm{su}, \mathrm{so}, Z_{\mathrm{ox}}} K_{\mathrm{H}, Z_{\mathrm{ox}}} \tau_{\mathrm{d}, Z_{\mathrm{ox}}}^{-1}}{\alpha_{\mathrm{s}, Z_{\mathrm{ox}}} \omega_{Z_{\mathrm{ox}}}} T R$

Equations (22)-(24) form a differential equation system which describes the rate of change of the $Z_{\mathrm{ox}}$ concentration in the particle sorption layer, particle surface-bulk layer, and particle bulk layers. The chemical oxidation reactions between $Z_{\mathrm{ox}}$ and the organic compounds $\left(X_{i}\right)$ are represented by the last term in Eqs. (23) and (24), where the summation is over all compounds which react and consume $Z_{\mathrm{ox}}$ in the particle phase. The module also calculates the temporal evolution of the organic compounds $\left(X_{i}\right)$ consumed by $Z_{\mathrm{ox}}$ and the organic compounds formed from the oxidation reactions $\left(Y_{i}\right)$ (Eqs. 25 and 26). The diffusion of these compounds is treated by the kinetic multilayer module described in Sect. 2.4.1.

$$
\begin{aligned}
\frac{\mathrm{d}\left[Z_{\mathrm{ox}}\right]_{\mathrm{so}}}{\mathrm{d} t} & =J_{\mathrm{ads}, Z_{\mathrm{ox}}}-J_{\mathrm{des}, Z_{\mathrm{ox}}}-k_{\mathrm{so}, \mathrm{su}, Z_{\mathrm{ox}}}\left[Z_{\mathrm{ox}}\right]_{\mathrm{so}} \\
& +k_{\mathrm{su}, \mathrm{so}, Z_{\mathrm{ox}}}\left[Z_{\mathrm{ox}}\right]_{\mathrm{su}}
\end{aligned}
$$

$$
\begin{aligned}
\frac{\mathrm{d}\left[Z_{\mathrm{ox}}\right]_{\mathrm{su}}}{\mathrm{d} t} & =\left(k_{\mathrm{so}, \mathrm{su}}\left[Z_{\mathrm{ox}}\right]_{\mathrm{so}}-k_{\mathrm{su}, \mathrm{so}}\left[Z_{\mathrm{ox}}\right]_{\mathrm{su}}\right) \frac{A_{\mathrm{su}}}{V_{\mathrm{su}}} \\
& +\left(-k_{\mathrm{su}, \mathrm{b} 1}\left[Z_{\mathrm{ox}}\right]_{\mathrm{su}}+k_{\mathrm{b} 1, \mathrm{su}}\left[Z_{\mathrm{ox}}\right]_{\mathrm{b} 1}\right) \frac{A_{\mathrm{b} 1}}{V_{\mathrm{su}}} \\
& -\sum_{i=1}^{N} k_{\mathrm{Ox}, i}\left[X_{i}\right]_{\mathrm{su}}\left[Z_{\mathrm{ox}}\right]_{\mathrm{su}}
\end{aligned}
$$

$$
\begin{aligned}
\frac{\mathrm{d}\left[Z_{\mathrm{ox}}\right]_{\mathrm{bk}}}{\mathrm{d} t} & =\left(k_{\mathrm{bk}-1, \mathrm{bk}}\left[Z_{\mathrm{ox}}\right]_{\mathrm{bk}-1}-k_{\mathrm{bk}, \mathrm{bk}-1}\left[Z_{\mathrm{ox}}\right]_{\mathrm{bk}}\right) \frac{A_{\mathrm{bk}}}{V_{\mathrm{bk}}} \\
& +\left(-k_{\mathrm{bk}, \mathrm{bk}+1}\left[Z_{\mathrm{ox}}\right]_{\mathrm{bk}}+k_{\mathrm{bk}+1, \mathrm{bk}}\left[Z_{\mathrm{ox}}\right]_{\mathrm{bk}+1}\right) \frac{A_{\mathrm{bk}+1}}{V_{\mathrm{bk}}} \\
& -\sum_{i=1}^{N} k_{\mathrm{Ox}, i}\left[X_{i}\right]_{\mathrm{bk}}\left[Z_{\mathrm{ox}}\right]_{\mathrm{bk}}
\end{aligned}
$$

$\frac{\mathrm{d}\left[X_{i}\right]_{\mathrm{bk}}}{\mathrm{d} t}=-k_{\mathrm{Ox}, i}\left[X_{i}\right]_{\mathrm{bk}}\left[Z_{\mathrm{Ox}}\right]_{\mathrm{bk}}$

$$
\frac{\mathrm{d}\left[Y_{i}\right]_{\mathrm{bk}}}{\mathrm{d} t}=k_{\mathrm{Ox}, i}\left[X_{i}\right]_{\mathrm{bk}}\left[Z_{\mathrm{Ox}}\right]_{\mathrm{bk}}
$$


Table 1. Model parameters used in the multilayer module for $\mathrm{O}_{3}$ uptake, diffusion and reactions in the particle phase.

\begin{tabular}{lll}
\hline Parameter & Definition & Value \\
\hline$\alpha_{\mathrm{s}, 0, \mathrm{O}_{3}}$ & Surface accommodation coefficient of $\mathrm{O}_{3}$ on a free substrate & $1^{\mathrm{a}}$ \\
$\tau_{\mathrm{d}, \mathrm{O}_{3}}$ & $\mathrm{O}_{3}$ desorption lifetime & $10^{-9 \mathrm{a}}$ \\
$K_{\mathrm{H}, \mathrm{O}_{3}}\left(\mathrm{~mol} \mathrm{~m}^{3} \mathrm{~Pa}^{-1}\right)$ & Henry's law coefficient of $\mathrm{O}_{3}$ & $4.7 \times 10^{-3 \mathrm{a}, \mathrm{b}}$ \\
$D_{0, \mathrm{O}_{3}}\left(\mathrm{~cm}^{2} \mathrm{~s}^{-1}\right)$ & Bulk diffusion coefficient $\mathrm{O}_{3}$ without obstruction & Variable \\
$\omega_{\mathrm{O}_{3}}\left(\mathrm{~cm} \mathrm{~s}^{-1}\right)$ & Mean thermal velocity $\mathrm{O}_{3}$ & $3.6 \times 10^{4 \mathrm{a}}$ \\
$d_{\mathrm{O}_{3}}(\mathrm{~nm})$ & Effective diameter cross section $\mathrm{O}_{3}$ & $0.4^{\mathrm{a}}$ \\
$k_{\mathrm{O}_{3}}\left(\mathrm{~mol}^{-1} \mathrm{~cm}^{3} \mathrm{~s}^{-1}\right)$ & Reaction rate constant between $\mathrm{O}_{3}$ and organic comp. & Variable \\
\hline
\end{tabular}

a Values from Pfrang et al. (2011).

${ }^{\mathrm{b}}$ Different unit than in Pfrang et al. (2011).

Table 1 gives the values of different parameters used in the multilayer module for ozone uptake, diffusion and reactions within the particle phase. Most of the values were adopted from Table 1 in Pfrang et al. (2011).

The coupled ordinary differential equation system describing the temporal evolution of $Z_{\mathrm{ox}}$ and the concentration of compounds which are consumed or formed from the $Z_{\mathrm{ox}}$ oxidation is solved with the ode15s solver in MATLAB.

\section{Model applications}

In order to test and illustrate the capability of ADCHAM, we apply the model to four types of published experimental results. In Sect. 3.1 we model the evaporation experiments of liquid DOP particles presented in Vaden et al. (2011), which have been modelled by Shiraiwa et al. (2012) with the KMGAP model. In Sect. 3.2 we model the evaporation experiments of $\alpha$-pinene SOA particles by Vaden et al. (2011). In Sect. 3.3 we model the SOA formation, ammonia uptake, and organic salt $\left(\mathrm{NH}_{4} \mathrm{RCOO}\right)$ formation in the $\alpha$-pinene- $\mathrm{NH}_{3}-$ $\mathrm{O}_{3}$ experiments by $\mathrm{Na}$ et al. (2007). Finally, we apply ADCHAM to an $m$-xylene oxidation experiment from Nordin et al., 2013 (Sect. 3.4). These examples serve to illustrate the wide applicability of ADCHAM.

For the simulations in Sects. 3.2-3.3 we model the condensational growth of particles formed by homogeneous nucleation using the condensation module described in Sect. 2.2.1 using the fully moving method (see Sect. 2.2.4). We start with one particle size and add new particle size bins during the early stage of particle formation. The new particles are assumed to be composed of non-volatile SOA material and are introduced into the model at an initial diameter of $5 \mathrm{~nm}$. Hence, in this work we do not treat the initial activation and growth of the formed molecular clusters. The new particle formation rate $\left(J_{5 \mathrm{~nm}}\right)$ is assumed to be constant during the experiments. A new size bin is added for the time step when the smallest particle size grows larger than $10 \mathrm{~nm}$ in diameter. For the experiments which we simulate in this work, the SOA mass (condensation sink) increases rapidly during the early stage of SOA formation. This effectively prevents the newly formed particles from growing and thus generally keeps the number of model particle size bins down to $\sim 20$ (see Fig. S2 in the Supplement).

Table 2 summarizes the different processes and range of parameter values used for the different simulations in Sects. 3.1-3.4.

\subsection{Simulations of DOP particle evaporation}

Before modelling complex multicomponent SOA particle formation, growth and evaporation, we test ADCHAM on the evaporation experiments of single-component, liquid DOP particles (Vaden et al., 2011). In the study of Vaden et al. (2011), the particles were evaporated in a $7 \mathrm{~L}$ chamber with $1 \mathrm{~L}$ of activated charcoal at the bottom of the chamber. The particle number concentration was kept low $\left(\sim 150 \mathrm{~cm}^{-3}\right)$ in order to keep the gas-phase concentration close to zero. Before the aerosol was introduced into the chamber, it was passed through two charcoal denuders in order to remove most of the gas-phase DOP (Vaden et al., 2011).

Here we adopt the approach from Shiraiwa et al. (2012), who modelled the gas-phase loss to the charcoal denuder using Fick's first law, on a laminar layer $(\Delta x)$ adjacent to the charcoal denuder on the bottom of the chamber. Since the layer thickness is poorly known, we modelled the DOP $(\mathrm{g})$ loss rate using different $\Delta x$ values. Coagulation and particle wall losses were not considered. In this small chamber, the wall losses can be substantial; however particles deposited on the chamber walls not coated with charcoal will likely continue to evaporate and contribute to the gas-phase DOP. Neglecting the particle wall losses has the same effect as assuming that the particles deposited on the walls continue to take up vapours as if they were still suspended in the air (Sect. 2.2.3)

Vaden et al. (2011) and Shiraiwa et al. (2012) used a binary diffusion coefficient for DOP in air of $4.4 \times 10^{-2} \mathrm{~cm}^{2} \mathrm{~s}^{-1}$ from Ray et al. (1988). This value was measured at a pressure of 98 Torr $(0.13 \mathrm{~atm})$, which is lower than the pressure used in experiments. We have therefore estimated the diffusion coefficient ( $\left.D_{\mathrm{DOP}}\right)$ with Eq. (27) (Jacobson, 2005a) and with Eq. (28) (Chapman and Cowling, 1970, in accordance 
Table 2. Summary of the processes and parameter values that were used for the simulations presented in Sects. 3.1 to 3.4.

\begin{tabular}{|c|c|c|c|c|}
\hline Parameter (unit) & Sect. 3.1 & Sect. 3.2 & Sect. 3.3 & Sect. 3.4 \\
\hline Gas-wall losses & Yes & Yes & No & Yes \\
\hline$\Delta x(\mathrm{~cm})$ & ${ }^{\mathrm{a}} 0.1$ & $\mathrm{~b}_{0.1}$ & - & 0.1 or 1 \\
\hline$V_{\text {chamber }}\left(\mathrm{m}^{3}\right)$ & - & 0.1 & - & $\mathrm{c}_{6}$ \\
\hline$V_{\text {wall }}\left(\mathrm{m}^{3}\right)$ & - & - & - & $\mathrm{d}_{0.02}$ \\
\hline$k_{\mathrm{g}, \mathrm{w}}\left(\mathrm{s}^{-1}\right)$ & - & - & - & $0-1 / 6$ \\
\hline$k_{\mathrm{g}, \mathrm{w}}^{*}\left(\mathrm{~s}^{-1}\right)$ & - & $0-1 / 500$ & - & - \\
\hline$C_{\mathrm{w}} /\left(M_{\mathrm{w}} \gamma_{\mathrm{w}, i}\right)\left(\mu \mathrm{mol} \mathrm{m}^{-3}\right)$ & - & 100 & - & 100 \\
\hline Particle-wall deposition & No & No & No & Yes \\
\hline$E^{\prime \prime}\left(\mathrm{V} \mathrm{cm}^{-1}\right)$ & - & - & - & 50 or Eq. (30) \\
\hline$u^{*}\left(\mathrm{~m} \mathrm{~s}^{-1}\right)$ & - & - & - & 0.01 or 0.05 \\
\hline Coagulation & No & No & No & Yes \\
\hline Homogeneous nucleation & No & ${ }^{\mathrm{e}}$ Yes & ${ }^{\mathrm{e}}$ Yes & No \\
\hline Organic salt formation & No & No & Yes (Table 3) & No \\
\hline Condensation/evaporation & Yes & Yes & Yes & Yes \\
\hline$\alpha_{\mathrm{S}}$ & 1 & 1 & 1 & 1 \\
\hline$\sigma\left(\mathrm{N} \mathrm{m}^{-1}\right)$ & 0.05 & 0.05 & 0.05 & 0.05 \\
\hline Kinetic multilayer model & Yes & Yes & Yes & 3-layer model \\
\hline$D_{0, \text { monomer }}\left(\mathrm{cm}^{2} \mathrm{~s}^{-1}\right)$ & 0 or $10^{-10}$ & $5 \times 10^{-17}-10^{-13}$ & $0-10^{-15}$ & $5 \times 10^{-17}$ \\
\hline$D_{0, \text { dimer }}\left(\mathrm{cm}^{2} \mathrm{~s}^{-1}\right)$ & - & $0-10^{-15}$ & - & 0 \\
\hline$D_{0, \text { ammonium }}\left(\mathrm{cm}^{2} \mathrm{~s}^{-1}\right)$ & - & - & $0-10^{-13}$ & - \\
\hline$D_{0, \mathrm{NH}_{4} \mathrm{RCOO}}\left(\mathrm{cm}^{2} \mathrm{~s}^{-1}\right)$ & - & - & 0 & - \\
\hline$D_{0, \mathrm{O}_{3}}\left(\mathrm{~cm}^{2} \mathrm{~s}^{-1}\right)$ & - & - & - & $10^{-7}$ or $10^{-8}$ \\
\hline$D_{0, \mathrm{NO}_{2}}\left(\mathrm{~cm}^{2} \mathrm{~s}^{-1}\right)$ & - & - & - & $10^{-7}$ \\
\hline Heterogeneous oxidation & No & No & No & Yes \\
\hline$k_{\mathrm{O}_{3}}\left(\mathrm{molec}^{-1} \mathrm{~cm}^{3} \mathrm{~s}^{-1}\right)$ & - & - & - & $0-10^{-16}$ \\
\hline$k_{\mathrm{NO}_{2}}\left(\mathrm{molec}^{-1} \mathrm{~cm}^{3} \mathrm{~s}^{-1}\right)$ & - & - & - & 0 or $10^{-15}$ \\
\hline Particle-phase dimerization & No & Yes & No & Yes \\
\hline$k_{\mathrm{f}}$ peroxyhemiacetals $\left(\mathrm{mol}^{-1} \mathrm{~cm}^{3} \mathrm{~s}^{-1}\right)$ & - & $10^{-24}-10^{-21}$ & - & $0-10^{-21}$ \\
\hline$k_{\mathrm{f}}$ hemiacetal $\left(\mathrm{mol}^{-1} \mathrm{~cm}^{3} \mathrm{~s}^{-1}\right)$ & - & - & - & $0-10^{-21}$ \\
\hline$k_{\mathrm{d}}$ peroxyhemiacetals $\left(\mathrm{h}^{-1}\right)$ & - & $1 / 40-30$ & - & 0 \\
\hline$k_{\mathrm{d}}$ hemiacetal $\left(\mathrm{h}^{-1}\right)$ & - & - & - & 0 \\
\hline
\end{tabular}

a Value used for the gas uptake onto the charcoal denuder.

b Same value used for the charcoal denuder and the Teflon chamber walls.

${ }^{\mathrm{c}}$ Initial value. During the experiments $V_{\text {chamber }}$ gradually decreases.

$\mathrm{d}$ Derived with the assumption that the width of the thin air layer adjacent to the chamber walls is $1 \mathrm{~mm}$.

${ }^{\mathrm{e}}$ Represented by adding new size bins with an initial particle diameter of $5 \mathrm{~nm}$ (see Sect. 3).

with Zhang et al., 1993). Equation (27) gives a $D_{\text {DOP }}$ of $1.5 \times 10^{-2} \mathrm{~cm}^{2} \mathrm{~s}^{-1}$, while with the Chapman-Enskog theory, utilizing a value of 1.34 for the collision integral $\left(\Omega_{\mathrm{DOP}, \text { air }}^{(1,1)}\right)$ (Hirschfelder et al., 1954), yields $2.9 \times 10^{-2} \mathrm{~cm}^{2} \mathrm{~s}^{-1}$ for $D_{\text {DOP }}$ at $1 \mathrm{~atm}$ and $296 \mathrm{~K}$.

$$
\begin{aligned}
D_{i} & =\frac{5}{16 N_{\mathrm{a}} d_{i}^{2} \rho_{\text {air }}} \sqrt{\frac{\mathrm{RTM}_{\mathrm{air}}\left(\frac{M_{i}+M_{\mathrm{air}}}{M_{i}}\right)}{2 \pi}} \\
D_{i} & =\frac{3}{8 \pi \Omega_{i, \text { air }}^{(1,1)} p d_{i, \text { air }}^{2}} \sqrt{\frac{\pi k_{\mathrm{b}}^{3} T^{3}\left(m_{i}+m_{\mathrm{air}}\right)}{2 m_{i} m_{\text {air }}}}, \\
d_{i, \text { air }} & =\frac{d_{i}+d_{\text {air }}}{2}
\end{aligned}
$$

In the above, $N_{\mathrm{a}}$ is Avogadro's number, $\rho_{\text {air }}$ is the density of air, $M_{\text {air }}$ is the molar mass of air, $M_{i}$ is the molar mass of compound $i\left(M_{\mathrm{DOP}}=390.56 \mathrm{~g} \mathrm{~mol}^{-1}\right), d_{i}$ is the collision diameter of compound $i\left(d_{\mathrm{DOP}}=1.012 \mathrm{~nm}\right.$; Ray et al., 1979), $d_{i, \text { air }}$ is the collision diameter for binary collisions between compound $i$ and air molecules $\left(d_{\mathrm{air}}=0.362 \mathrm{~nm}\right), m_{\text {air }}$ is the molecular mass of air, $m_{i}$ is the molecular mass of compound $i, k_{\mathrm{b}}$ is the Boltzmann constant and $p$ is the total pressure.

When we use Eq. (27), a laminar layer of $0.1 \mathrm{~cm}$ adjacent to the charcoal denuder wall and unity $\alpha_{\mathrm{s}, \mathrm{DOP}}$, the model is in good agreement with the observed evaporation rates for all particle sizes. Similar results are also achieved when using Eq. (28), unity $\alpha_{\mathrm{s}, \mathrm{DOP}}$ and a laminar layer of $0.6 \mathrm{~cm}$ adjacent to the charcoal denuder (Fig. 4).

In Sect. 3.2 we compare the modelled and measured $\alpha$ pinene SOA evaporation rates using the same evaporation chamber. Based on the DOP evaporation experiments the 


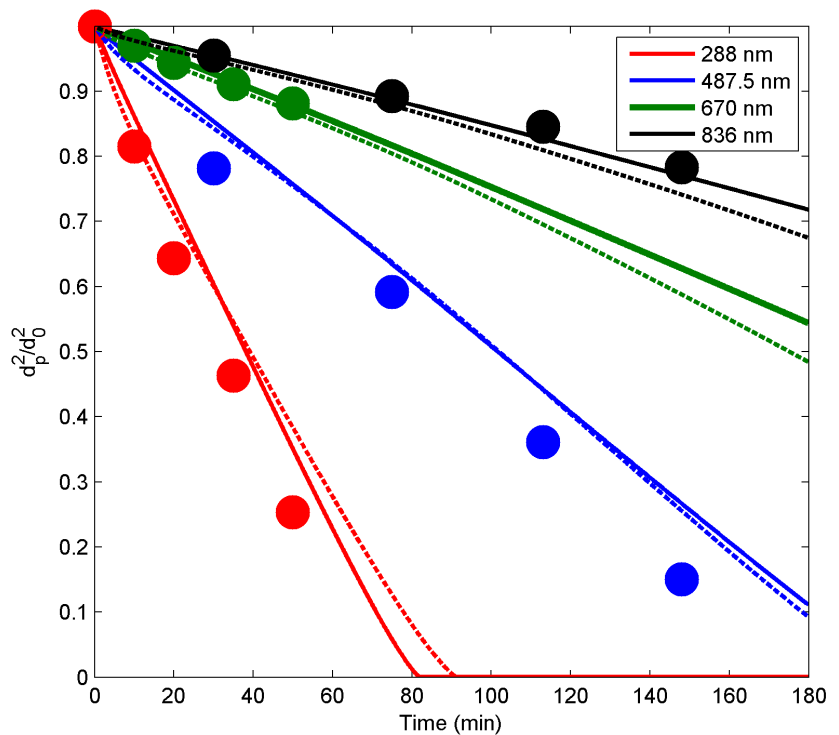

Figure 4. Modelled and measured (Vaden et al., 2011) evaporation losses of DOP particles of different initial diameters. The model results are from simulations with (1) Eq. (30) and a laminar layer width of $0.1 \mathrm{~cm}$ adjacent to the charcoal denuder (solid lines) and (2) Eq. (31) and a laminar layer of $0.6 \mathrm{~cm}$ (dashed lines). The measurements are given by the solid circles. In the model the DOP mass accommodation coefficient was 1 .

simulations of the $\alpha$-pinene SOA particle experiments were performed with a $\Delta x$ of $0.1 \mathrm{~cm}$, binary diffusion coefficients calculated with Eq. (27), and unity surface-bulk accommodation coefficients.

\subsection{Evaporation of $\alpha$-pinene SOA}

Here we use ADCHAM to explore which processes are responsible for the slow and nearly size-independent evaporation loss rates of $\alpha$-pinene SOA particles observed by Vaden et al. (2011). $\alpha$-pinene SOA particles were produced by homogeneous nucleation in a $0.1 \mathrm{~m}^{3}$ Teflon chamber under dark conditions with $\sim 200 \mathrm{ppb} \alpha$-pinene, $\sim 250 \mathrm{ppm}$ cyclohexane as an $\mathrm{OH}$ scavenger and $\sim 500 \mathrm{ppb} \mathrm{O}_{3}$. Once SOA particles stopped growing (approximately after $1.5 \mathrm{~h}$, fresh particles), monodisperse aerosol particles were selected with a differential mobility analyser (DMA), passed through two charcoal denuders (residence time $\sim 2 \mathrm{~min}$ ), and introduced at low concentration $\left(\sim 10-200 \mathrm{~cm}^{-3}\right)$ into the evaporation chamber described in Sect. 3.1 (Vaden et al., 2011). Alternatively, the particles were aged for 10-15 h (aged particles) in the Teflon chamber before being transferred into the evaporation chamber.

Vaden et al. (2011) showed that the evaporation rate of the pure $\alpha$-pinene SOA particles is more than 100 times slower than expected from modelled evaporation rates of liquid-like monomer SOA, and that it consists of two stages. Around $50 \%$ of the particle mass evaporates during the first $100 \mathrm{~min}$ at relatively slow rate, followed by a second stage with even slower mass loss rate, in which and additional $\sim 25 \%$ of the initial mass is lost in $24 \mathrm{~h}$. Another interesting finding is that the fractional volume loss by evaporation is almost sizeindependent. Vaden et al. (2011) concluded that the nearly size-independent evaporation loss rates indicate that these type of SOA particles are not liquid-like, which was later verified with measurements by Abramson et al. (2013).

Here we use ADCHAM to examine how the processes listed below influence the $\alpha$-pinene SOA evaporation rates. Note that while the model includes various specific mechanisms, the conclusions should be taken in terms that are more general:

1. vapour pressures of the condensable monomers (pureliquid saturation vapour pressure method);

2. slow and imperfect mixing within semi-solid amorphous SOA particles;

3. dimerization in the particle phase, and the reversible decomposition back to monomers;

4. accumulation of low-volatility dimers at the particle surface, creating a coating material which prevents the more volatile SOA monomers from evaporating;

5. wall deposition losses of the $\alpha$-pinene oxidation products in the Teflon chamber.

For all simulations presented in this section, the monomer SOA surface-bulk accommodation coefficients were assumed to be unity. The simulations were conducted for $23^{\circ} \mathrm{C}$, an $\mathrm{RH}$ of $5 \%$ and a pressure of $1 \mathrm{~atm}$. The laminar layer width adjacent to the charcoal denuder in the evaporation chamber was assumed to be $0.1 \mathrm{~cm}$ (see motivation in Sect. 3.1). Pure-liquid saturation vapour pressures were estimated with the SIMPOL model, except where otherwise noted. Particles of different sizes were formed by homogeneous nucleation and were allowed to grow in the presence of each other. After $1.5 \mathrm{~h}$ or $12 \mathrm{~h}$ of aging (fresh or aged aerosol) size-selected particles with concentrations $\sim 100 \mathrm{~cm}^{-3}$ were introduced into the modelled charcoal denuder chamber and allowed to evaporate by continuous removal of the gas-phase compounds. The gas-wall partitioning to the Teflon chamber walls was modelled with an effective gas-wall loss rate $\left(k_{\mathrm{g}, \mathrm{w}}^{*}\right)$ in the range of $0-1 / 1000 \mathrm{~s}^{-1}$ and $C_{\mathrm{w}} /\left(M_{\mathrm{w}} \gamma_{\mathrm{w}, i}\right)$ equal to $100 \mu \mathrm{mol} \mathrm{m}^{-3}$ (see Sect. 2.2.3). For each model application in Sect. 3.2, we test how sensitive the model results are to the value of $k_{\mathrm{g}, \mathrm{w}}^{*}$. Particle wall losses were not considered (see discussion in Sects. 3.1 and 3.4). The dimer and monomer SOA compounds were assessed to form one organic phase (no phase separation).

\subsubsection{Evaporation of pure monomer SOA particles}

Cappa and Wilson (2011) did not find any substantial differences in chemical composition of $\alpha$-pinene SOA particles 
upon evaporation in a thermodenuder. Hence, according to their study these particles do not seem to obey absorptive partitioning theory upon evaporation. This could possibly be explained by a diffusion-limited transport of the organic compounds within an amorphous (glassy) particle phase (Cappa and Wilson, 2011). However, in a similar study, Kuwata et al. (2011) observed a substantial change of the CCN properties of $\alpha$-pinene SOA particles after thermodenuder treatment, which indicates a relative enrichment of low-volatility oligomers after evaporation. In Vaden et al. (2011) it is noted that the mass spectral peak at $m / z=201$ rapidly disappears on evaporation and that the only other change is a gradual increase in relative intensity of peaks at higher $m / z$. Thus, their study also suggests an increase in the relative oligomer content, which could indicate that the smaller, higher vapour pressure molecules evaporate and oligomerization continues at a slow rate during evaporation, consistent with the observed SOA hardening (Abramson et al. 2013).

To set the stage, we start by calculating whether the evaporation rates can be explained by the volatility distribution of the condensing monomers formed in the gas phase, in combination with non-perfect mixing within a semi-solid amorphous particle phase. The evaporation of the more volatile organic compounds will then be controlled by the evaporation rate of the least volatile organic compounds enriched in the particle surface-bulk layer, and not by their own speciesspecific saturation vapour pressures. The measured mass spectra and densities of small and large SOA particles formed by ozonolysis of $\alpha$-pinene are undistinguishable (Zelenyuk et al., 2008). Despite this fact, we use the model to evaluate whether it gives a relative enrichment of the least volatile monomer SOA compounds in the smaller particles during their formation and growth (see e.g. Roldin et al., 2011b), and whether this can explain the observed size-independent SOA evaporation.

The pure-liquid saturation vapour pressures were calculated with the SIMPOL (Pankow and Asher, 2008); the Nannoolal et al. (2008) vapour pressure methods; or with the semi-empirical seven-product model (VBS) parameterization from Pathak et al. (2007), which was also used by Vaden et al. (2011). Here we evaluate its influence on the modelled evaporation rates of $\sim 160$ and $\sim 250 \mathrm{~nm}$ particles. The model results presented in Fig. 5 are from simulations with $k_{\mathrm{g}, \mathrm{w}}^{*}=1 / 2000 \mathrm{~s}^{-1}$ and liquid-like SOA $\left(D_{\text {monomer }}=\right.$ $\left.10^{-10} \mathrm{~cm}^{2} \mathrm{~s}^{-1}\right)$ or solid-like SOA particles with negligible mixing $\left(D_{\text {monomer }}=0 \mathrm{~cm}^{2} \mathrm{~s}^{-1}\right)$. In Fig. 5a the results are from simulations with the VBS from Pathak et al. (2007), Fig. $5 \mathrm{~b}$ shows the results when we use SIMPOL and Fig. 5c results from simulations with the Nannoolal method. In Supplement Fig. S3 we compare the modelled evaporation losses for simulations with or without reversible gas-wall partitioning onto the smog chamber Teflon walls. The figure illustrates that the uptake of $\alpha$-pinene oxidation products onto the smog chamber walls lowers the volatility of the formed
SOA particles. But this does not substantially improve the agreement between the modelled and measured evaporation rates.

In all model runs except with the Nannoolal method and solid-like amorphous particles, the evaporation rates are orders of magnitude faster than the observations. According to the curve fitted to the measurements, only $\sim 3 \%$ of the SOA mass is lost during the first $2 \mathrm{~min}$. In the model runs 7-80\% is lost, depending on the vapour pressure method used, the particle size, the value of $k_{\mathrm{g}, \mathrm{w}}^{*}$ and if the SOA is treated as liquid- (1) or solid- (s) like.

Another difference is that the observed evaporation loss rate is almost linear for the first $30 \mathrm{~min}$ while in all model runs the loss rate is first very rapid and then gradually slows down. This is because in the model the SOA is composed of molecules with different volatility. Hence, the most volatile molecules are lost early and the remaining compounds that are less volatile evaporate later and slower, inconsistent with observations by Cappa and Wilson (2011) and Vaden et al. (2011). Moreover, all calculated evaporation rates are size-dependent, similarly inconsistent with the observed SOA evaporation (Vaden et al., 2011; Zelenyuk et al., 2012).

When the SOA is treated as a solid, the evaporation rates are much slower with the Nannoolal method compared to the other two methods, even though most of the other SOA mass (without wall losses) is somewhat more volatile than with the SIMPOL method (see Supplement Fig. S4). This is mainly because of two low-volatility MCMv3.2 compounds called $\mathrm{C} 922 \mathrm{OOH}$ and $\mathrm{C} 813 \mathrm{OOH}$, which before evaporation together make up $10 \pm 3$ and $7.5 \pm 2 \%$ of the particle mass in the 160 and $250 \mathrm{~nm}$ particles, respectively (see modelled mass spectrum in Supplement Fig. S5). These compounds have vapour pressures of $4.8 \times 10^{-8}$ and $5.3 \times 10^{-8} \mathrm{~Pa}$ (at 296 K) when calculated with the Nannoolal method, while according to SIMPOL their vapour pressures are $1.7 \times 10^{-6}$ and $1.8 \times 10^{-6} \mathrm{~Pa}$ (at $296 \mathrm{~K}$ ). Hence, if the SOA particles are considered to be solid or semi-solid, and the Nannoolal method is used, these compounds accumulate in the particle surface-bulk layer upon evaporation and limit the loss of other more volatile compounds.

From the discrepancies between the model and measurement results in Fig. 5, we can conclude that it is unlikely that the observed evaporation rates can be explained purely by incomplete mixing and the vapour-pressure-controlled evaporation of SOA monomers. We note, however, that when a nearly non-volatile component is introduced and the SOA is treated as solid-like, the evaporation rate significantly decreases.

\subsubsection{Evaporation governed by mass-transport-limited mixing and dimer degradation}

Here we evaluate a hypothesis where dimers comprise a significant fraction $(\sim 50 \%)$ of the particles' mass prior to the 
$\mathrm{C} 922 \mathrm{OOH}, \mathrm{C} 97 \mathrm{OOH}$ and $\mathrm{C} 813 \mathrm{OOH}$ ), which all contain at least one carbonyl and one hydroperoxide functional group. With this assumption, the dimer particle content is $\sim 50 \%$ for particles aged $1.5 \mathrm{~h}$. The dimer mass fraction is nearly the same for all particle sizes (see Supplement Fig. S6). Thus, for the results presented in this section we will assume that only these four monomers contribute to the dimer formation.

For the diffusion coefficients of monomers and dimers we assume that $D_{\text {dimer }}$ are 2 orders of magnitude smaller than $D_{0, \text { monomer }}$, and calculate $D_{\text {monomer }}$ with the obstruction theory. The dimers and monomers were assumed to be composed of one well-mixed organic phase.

In order to fit the model to the observed evaporation rates we varied $D_{0, X_{i}}$ for the monomers and dimers in the range of $1 \times 10^{-16}-1 \times 10^{-13} \mathrm{~cm}^{2} \mathrm{~s}^{-1}$ and $1 \times 10^{-18}-1 \times$ $10^{-15} \mathrm{~cm}^{2} \mathrm{~s}^{-1}$, respectively. With these values of $D_{0, X_{i}}$ the dimers are enriched in the particle surface-bulk layer upon evaporation, but mass-transport-limited monomer evaporation across the viscous surface-bulk layer is still possible. The dimer formation and degradation rate was varied in the range of $10^{-22}-10^{-24}$ molecules ${ }^{-1} \mathrm{~cm}^{3} \mathrm{~s}^{-1}$ and $1 / 20$ $1 \mathrm{~h}^{-1}$, respectively. We also tested to run the model with or without gas-wall partitioning to the smog chamber walls $\left(k_{\mathrm{g}, \mathrm{w}}^{*}=1 / 2000 \mathrm{~s}^{-1}\right.$ or $\left.k_{\mathrm{g}, \mathrm{w}}^{*}=0 \mathrm{~s}^{-1}\right)$.

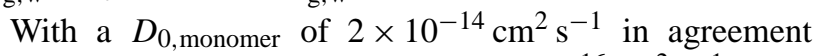
with Zhou et al. (2013), $D_{\text {dimer }}$ of $2 \times 10^{-16} \mathrm{~cm}^{2} \mathrm{~s}^{-1}, k_{\mathrm{f}}$ of $10^{-23}$ molecules $^{-1} \mathrm{~cm}^{3} \mathrm{~s}^{-1}, k_{\mathrm{d}}$ of $1 / 10 \mathrm{~h}^{-1}$, no phase separation and $k_{\mathrm{g}, \mathrm{w}}^{*}$ of $1 / 2000 \mathrm{~s}^{-1}$, the model reproduced the main features of the observed evaporation behaviour of fresh SOA particles (Fig. 6). However, other combinations of values of these parameters reproduces the observations equally well (e.g. with $D_{\text {monomer }} \approx 2 \times 10^{-15} \mathrm{~cm}^{2} \mathrm{~s}^{-1}, D_{\text {dimer }} \approx 2 \times$ $10^{-15} \mathrm{~cm}^{2} \mathrm{~s}^{-1}, k_{\mathrm{f}} \approx 10^{-23}$ molecules ${ }^{-1} \mathrm{~cm}^{3} \mathrm{~s}^{-1}$ and $k_{\mathrm{d}} \approx$ $1 / 20 \mathrm{~h}^{-1}$ ). For aged particles, the model somewhat underestimates the evaporation losses. This is because the relative dimer content in the particles increases with aging. This effect is most pronounced when considering chamber wall losses in the smog chamber (Supplement Fig. S6). Thus, when we run the model without reversible gas-wall partitioning to the smog chamber Teflon walls, the aging effect on the modelled evaporation rates is negligible (Supplement Fig. S7).

In the simulations the early evaporation rate is governed by the monomer diffusion rate to the surface. The small particles have a shorter characteristic time of mass transport than the large particles (see Sect. 1). This is the reason why the loss rate during the first hour is somewhat larger for the $\sim 160 \mathrm{~nm}$ particles than the $\sim 250 \mathrm{~nm}$ particles. When most of the monomers have evaporated (after $\sim 3 \mathrm{~h}$ for the modelled $160 \mathrm{~nm}$ particles and $\sim 6 \mathrm{~h}$ for the $250 \mathrm{~nm}$ particles) (Supplement Fig. S8), the second, slow evaporation-stage begins. This stage is determined by dimer degradation and formation and by the diffusion of monomer to the particle surface-bulk layer. Again, because of the shorter characteris-

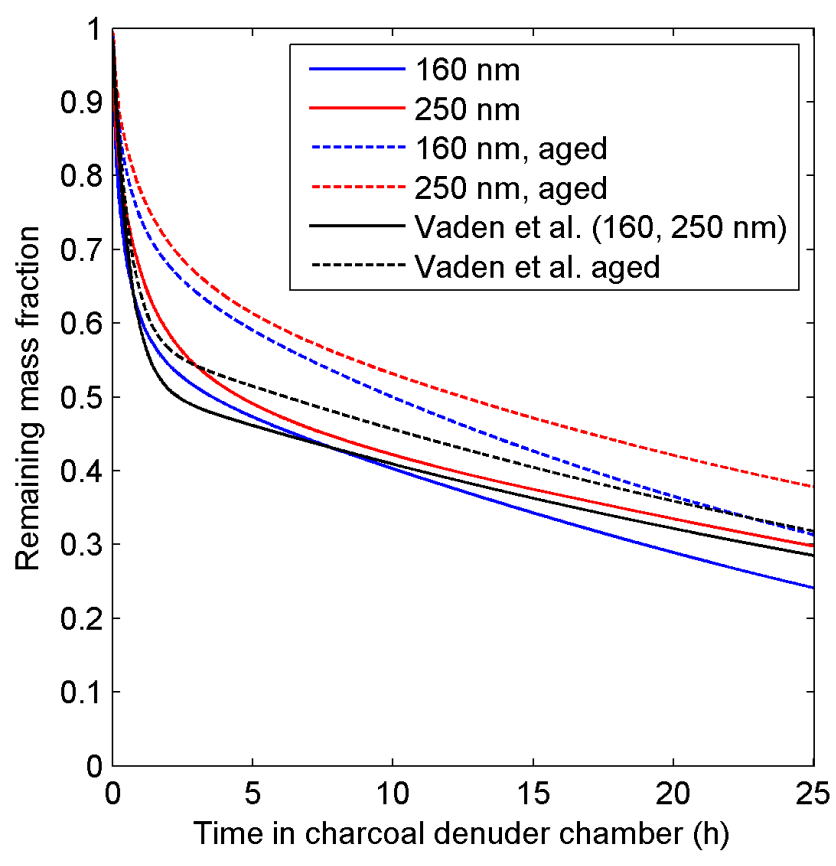

Figure 6. Measured (Vaden et al., 2011) and modelled evaporation losses for particles composed of approximately equal amount of dimer and monomer SOA prior to introduction to the charcoal denuder chamber. The saturation vapour pressures were calculated with SIMPOL, $D_{0 \text {, monomer }}=2 \times 10^{-14} \mathrm{~cm}^{2} \mathrm{~s}^{-1}$, $D_{\text {dimer }}=2 \times 10^{-16} \mathrm{~cm}^{2} \mathrm{~s}^{-1}, k_{\mathrm{f}}=10^{-23}$ molecules ${ }^{-1} \mathrm{~cm}^{3} \mathrm{~s}^{-1}$, $k_{\mathrm{d}}=1 / 10 \mathrm{~h}^{-1}$, no phase separation and $k_{\mathrm{g}, \mathrm{w}}^{*}=1 / 2000 \mathrm{~s}^{-1}$. The results are given both for fresh and aged particles with a diameter of $\sim 160$ and $\sim 250 \mathrm{~nm}$, respectively.

tic time of mass transport for the small particles, the evaporation losses of the small particles are somewhat larger (steeper slope of the curves in Fig. 6). This is not completely consistent with the measurements.

From these simulations we can conclude that the model can reproduce the main features of the observed evaporation rates for fresh and aged $\alpha$-pinene SOA particles if the reversible gas-wall partitioning in the smog chamber only has a small influence on the particle composition. However, the observed nearly size-independent evaporation rates can probably not be explained by an particle-phase mass-transferlimited evaporation of the monomer SOA, followed by a slow decomposition of the remaining ( $\sim 50 \%$ by mass) oligomer SOA.

\subsubsection{Evaporation controlled by the degradation of short- and long-lived dimers in semi-solid tar-like SOA particles}

Here we examine whether the observed slow evaporation rate can be explained by nearly solid-like SOA in combination with two types of dimers: the first being relatively shortlived (lifetime of a few minutes) and a second long-lived 
(lifetime of more than a day). For this paradigm the dimers will accumulate and stay in the particle surface-bulk layer upon evaporation. Thus, the size-independent evaporation rates will mainly be controlled by the decomposition rate of dimers back to monomers in the surface-bulk layer. We also test whether gas-wall losses can contribute to an enrichment of dimers in the particle surface-bulk layer already in the smog chamber, thus helping to explain the observed relatively slow and size-independent first evaporation stage of $\alpha$ pinene SOA. The evaporation is then first controlled by the degradation of the relatively short-lived dimers, which are gradually replaced by long-lived but less numerous dimers from the particle bulk.

In order to test the general mechanism principle, we consider that the dimers are peroxyhemiacetals, which, as in Sect. 3.2.2, are formed from the monomers $\mathrm{C} 108 \mathrm{OOH}$, $\mathrm{C} 922 \mathrm{OOH}, \mathrm{C} 97 \mathrm{OOH}$ and $\mathrm{C} 813 \mathrm{OOH}$. However, the longlived dimer is only assumed to be formed from the least volatile MCMv.3.2 oxidation products $\mathrm{C} 922 \mathrm{OOH}$. With this assumption and because of the Kelvin effect, the relative amount of long-lived dimer increases with decreasing particle sizes (Supplement Fig. S9). For the short-lived dimers we varied the values of $k_{\mathrm{f}}$ and $k_{\mathrm{d}}$ in the range of $1 \times 10^{-22}-1 \times 10^{-24}$ molecules $^{-1} \mathrm{~cm}^{3} \mathrm{~s}^{-1}$ and $30-6 \mathrm{~h}^{-1}$, respectively. For the long-lived dimer we used a $k_{\mathrm{f}}$ of $1 \times$ $10^{-22}$ molecules ${ }^{-1} \mathrm{~cm}^{3} \mathrm{~s}^{-1}$ and varied the $k_{\mathrm{d}}$ values in the range of $1 / 20-1 / 40 \mathrm{~h}^{-1}$. The monomer SOA was treated as a semi-solid tar-like mixture $\left(D_{0, \text { monomer }}=5 \times 10^{-17} \mathrm{~cm}^{2} \mathrm{~s}^{-1}\right)$ according to Abramson et al. (2013) and the dimer SOA as solid $\left(D_{\text {dimer }}=0 \mathrm{~cm}^{2} \mathrm{~s}^{-1}\right)$. The gas-wall partitioning was modelled with $k_{\mathrm{g}, \mathrm{w}}^{*}$ in the range of $0-1 / 500 \mathrm{~s}^{-1}$ and $C_{\mathrm{w}} /\left(M_{\mathrm{w}} \gamma_{\mathrm{w}, i}\right)$ equal to $100 \mu \mathrm{mol} \mathrm{m}^{-3}$.

In Fig. 7, we compare the modelled and observed evaporation rates of fresh and aged $\alpha$-pinene SOA particles for simulations with $k_{\mathrm{f}}$ and $k_{\mathrm{d}}$ values of $1 \times 10^{-23}$, $1 \times 10^{-22}$ molecules $^{-1} \mathrm{~cm}^{3} \mathrm{~s}^{-1}$ and $12,1 / 30 \mathrm{~h}^{-1}$ for the short- and long-lived dimers, respectively. $k_{\mathrm{g}, \mathrm{w}}^{*}$ was set to $1 / 1000 \mathrm{~s}^{-1}$. During the first $\sim 20 \mathrm{~min}$ of evaporation, before the surface-bulk layer has been entirely filled with a mixture of short- and long-lived dimers, the modelled evaporation rates are size-dependent. However, once the surface-bulk layer has been filled with dimers, the evaporation is controlled by the dimer degradation and becomes nearly sizeindependent. After $\sim 2 \mathrm{~h}$ of evaporation almost all shortlived dimers in the surface-bulk layer are lost and replaced by the long-lived dimers (see Supplement Fig. S9). This is when the second, slow evaporation stage starts. If the longlived dimer mass fraction had been size-independent, a substantially larger mass fraction of the small particles would have needed to evaporate before they reach this stage. Thus, in order for the model to capture the observed nearly sizeindependent evaporation, the long-lived dimers need to be formed from the least volatile monomers or formed in the gas

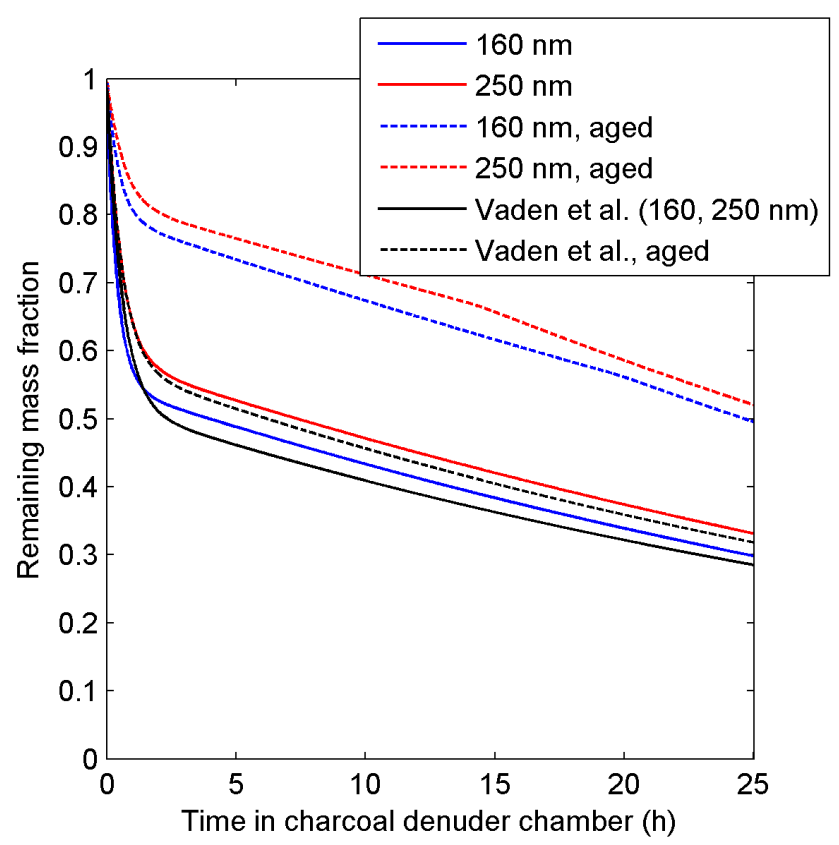

Figure 7. Measured (Vaden et al., 2011) and modelled evaporation loss rates for semi-solid tar-like particles $\left(D_{0 \text {, monomer }}=5 \times\right.$ $10^{-17} \mathrm{~cm}^{2} \mathrm{~s}^{-1}$ and $\left.D_{\text {oligomer }}=0 \mathrm{~cm}^{2} \mathrm{~s}^{-1}\right)$. The fresh SOA particles are composed of short-lived dimers $(\sim 20$ mass \%) and longlived dimers ( 2.19 and 1.44 mass $\%$ for 160 and $250 \mathrm{~nm}$ particles, respectively) (see Fig. S9) before they are introduced into the charcoal evaporation chamber. The saturation vapour pressures were calculated with SIMPOL and $k_{\mathrm{g}, \mathrm{w}}^{*}=1 / 1000 \mathrm{~s}^{-1}$.

phase (e.g. by peroxy radical termination reactions or hydrogen abstraction; see Sect. 2.3.4).

For the aged particles the model substantially underestimates the early-stage evaporation losses. This is because of the modelled gas-wall losses in the smog chamber. In Supplement Fig. S10 we compare the modelled evaporation losses with or without chamber wall losses $\left(k_{\mathrm{g}, \mathrm{w}}^{*}=0\right.$ or $1 / 1000 \mathrm{~s}^{-1}$ ) and with or without aging. Without chamber wall losses the effect of aging in the smog chamber becomes negligible, but at the same time the model substantially overestimates the mass fraction loss during the first evaporation stage. This is because (for this set-up) the bulk mass fraction of long-lived dimers is too small and $\sim 65$ mass $\%$ instead of the desired $\sim 50$ mass $\%$ needs to evaporate before the longlived dimer has formed a monolayer thick surface-bulk layer coverage. With a doubling of the long-lived dimer content, this model and measurement discrepancy disappears.

From these simulations we can conclude that ADCHAM is able to reproduce the main features of the measured nearly size-independent evaporation losses of SOA particles from Vaden et al. (2011) in the following cases:

1. If relatively short-lived dimers are present in and near the particle surface-bulk layer before the particles are introduced into the evaporation chamber. 
2. If a relatively small mass fraction of long-lived dimers accumulate in the particle surface-bulk layer upon evaporation.

3. If the long-lived dimer mass fraction is higher in the small particles compared to the large ones. As illustrated by the model simulations, this is possible (because of the Kelvin effect) if the dimer preferentially is formed from the least volatile monomer compounds. But it could also be explained by ELVOC (e.g. dimers) formed in the gas phase.

4. The reversible gas-wall losses to the smog chamber Teflon walls have only small influences on the particle composition.

\subsection{Modelling of organic salt formation between carboxylic acids and ammonia}

Here we model the SOA formation in the $\alpha$-pinene- $\mathrm{NH}_{3}-$ $\mathrm{O}_{3}$ experiments by $\mathrm{Na}$ et al. (2007) in a dark indoor $18 \mathrm{~m}^{3}$ Teflon chamber. In the experiments CO $(\sim 200 \mathrm{ppm})$ was used as an $\mathrm{OH}$ scavenger. The chamber was operated at a temperature of $21 \pm 1{ }^{\circ} \mathrm{C}$ and under dry conditions. For the simulations we use an $\mathrm{RH}$ of $5 \%$ and a temperature of $21^{\circ} \mathrm{C}$. Once the $\alpha$-pinene and $\mathrm{NH}_{3}$ initial target concentrations were reached, the experiments started with injection of $\mathrm{O}_{3}$ for approximately 20 min to produce an $\mathrm{O}_{3}$ concentration of $200 \pm 5 \mathrm{ppb}$. In the model, emissions corresponding to $250 \mathrm{ppb}$ unreacted $\mathrm{O}_{3}$ were added during the first $20 \mathrm{~min}$ in order to simulate the experimental target $\mathrm{O}_{3}$ concentrations.

In the experiments $\mathrm{Na}$ et al. (2007) observed a substantially higher $\mathrm{SOA}$ formation when $\mathrm{NH}_{3}(\mathrm{~g})$ was present. The authors also performed experiments on cis-pinonic acid (a common $\alpha$-pinene oxidation product) and found a dramatic increase in particle number and volume concentration when $\mathrm{NH}_{3}$ was added to the system. From these experiments they concluded that most of the observed SOA mass enhancement in the presence of $\mathrm{NH}_{3}$ could be explained by acid-base reactions, which drive the carboxylic acids into the particle phase. Similar organic salt formation in the presence of $\mathrm{NH}_{3}$ was observed both under dry and humid conditions $(\mathrm{RH}=50 \%)$.

Several experiments were performed at initial $\mathrm{NH}_{3}(\mathrm{~g})$ concentration between 0 and $400 \mathrm{ppb}$ and an $\alpha$-pinene concentration of $\sim 220 \mathrm{ppb}$ (see Table 1 in $\mathrm{Na}$ et al., 2007). The formed aerosol particle mass increased when more $\mathrm{NH}_{3}$ was added. However, when the ammonia concentration exceeded $200 \mathrm{ppb}$, no substantial additional mass formation was observed. The reason for this could be that, in principle, all gas-phase carboxylic acids already had formed particle mass at $200 \mathrm{ppb} \mathrm{NH}_{3}$ (Na et al., 2007).

Recently, Kuwata and Martin (2012) conducted experiments with an aerosol mass spectrometer (AMS) on SOA formed from ozonolysis of $\alpha$-pinene at low and high relative humidity ( $\mathrm{RH}<5 \%$ and $\mathrm{RH}>94 \%)$. In these experi- ments, the $\alpha$-pinene SOA particles were formed under dry conditions before they were exposed to varying degrees of humidification and ammonia (see Fig. 1 in Kuwata and Martin, 2012). An $\sim 10$ times greater uptake of ammonia was observed at high RH compared to low RH, which was attributed to a more rapid diffusion uptake of ammonia in the less viscous humidified aerosol particles. Because the gas phase was not removed from the aerosol between the generation and the exposure to ammonia, part of the ammonia uptake could be attributed to reactive uptake of $\mathrm{NH}_{3}$ and organic acids from the gas phase (Kuwata and Martin, 2012).

In this work, we model the organic salt formation between ammonium and carboxylic acids as a process occurring in the particle surface-bulk layer and particle bulk, analogous to inorganic salt formation (e.g. $\mathrm{NH}_{4} \mathrm{NO}_{3}$ ). The partitioning of carboxylic acids and ammonia between the gas phase and particle surface-bulk layer are modelled as separate $\mathrm{pH}$-dependent dissolution processes using the condensation/evaporation module (Sect. 2.2.1). The amount of organic acids, ammonia/ammonium and organic salts which exists in the particles depends on the pure-liquid saturation vapour pressures or Henry's law constant $\left(K_{\mathrm{H}}\right)$, acid dissociation constants $\left(K_{\mathrm{a}}\right)$, activity coefficients, surface tension (Barsanti et al., 2009) and the solubility product of the formed salts $\left(K_{\mathrm{S}}\right)$ (Reactions R5-R9). The aerosol particle formation will be favoured by low pure-liquid saturation vapour pressures of the carboxylic acids, the large solubility (Henry's law coefficient) of $\mathrm{NH}_{3}$, the large difference between the carboxylic acids and $\mathrm{NH}_{4}^{+} K_{\mathrm{a}}$ values (Greaves and Drummond, 2008) and the low solubility of the formed salts $\left(K_{\mathrm{S}}\right)$.

$\mathrm{RCOOH}(\mathrm{g}) \leftrightarrow \mathrm{RCOOH}(\mathrm{l})$

$$
\begin{aligned}
& \mathrm{RCOOH}(\mathrm{l}) \leftrightarrow \mathrm{RCOO}^{-}+\mathrm{H}^{+}, K_{\mathrm{a}} \\
& =\frac{\left[\mathrm{RCOO}^{-}\right]\left[\mathrm{H}^{+}\right] \gamma_{\mathrm{H}^{+}} \gamma_{\mathrm{RCOO}^{-}}}{[\mathrm{RCOOH}] \gamma_{\mathrm{RCOOH}}}
\end{aligned}
$$

$\mathrm{NH}_{3}(\mathrm{~g}) \leftrightarrow \mathrm{NH}_{3}(\mathrm{l}), K_{\mathrm{H}}=\frac{\left[\mathrm{NH}_{3}(\mathrm{l})\right] \gamma_{\mathrm{NH}_{3}}}{p_{\mathrm{NH}_{3}}}$

$\mathrm{NH}_{3}(\mathrm{l})+\mathrm{H}^{+} \leftrightarrow \mathrm{NH}_{4}^{+}$,

$$
\frac{1}{K_{\mathrm{a}, \mathrm{NH}_{4}^{+}}}=K_{\mathrm{NH}_{3}}=\frac{\left[\mathrm{NH}_{4}^{+}\right] \gamma_{N H_{4}^{+}}}{\left[\mathrm{NH}_{3}(\mathrm{l})\right]\left[\mathrm{H}^{+}\right] \mathrm{NH}_{3} \gamma_{H^{+}}}
$$

$\mathrm{NH}_{4}^{+}+\mathrm{RCOO}^{-} \leftrightarrow \mathrm{NH}_{4} \mathrm{RCOO}(\mathrm{s})$,

$K_{\mathrm{S}}=\left[\mathrm{NH}_{4}^{+}\right]\left[\mathrm{RCOO}^{-}\right] \gamma_{\mathrm{NH}_{4}^{+}} \gamma_{\mathrm{RCOO}^{-}}$

Table 3 lists different model parameter values used for the base case simulations in this section. The $K_{\mathrm{a}}$ values are unknown for most carboxylic acids, even in aqueous solutions. However, for two major ozonolysis products (cis-pinic acid) 
and (cis-pinonic acid) (Hallquist et al., 2009), aqueous $\mathrm{pK}_{\mathrm{a}}$ values were found in the literature (see e.g. Hyder et al., 2012 and Barsanti et al., 2009). These acids have nearly the same $\mathrm{pK}_{\mathrm{a}}$ values $(\sim 4.6)$. Hence, in this work we assume that all carboxylic acids from $\alpha$-pinene ozonolysis which partition into the particle organic-rich phase have $\mathrm{pK}_{\mathrm{a}}$ values equal to 4.6. The carboxylic acid and ammonia dissociation rate coefficients and the Henry's law coefficient of $\mathrm{NH}_{3}$ are valid for dilute water solutions (see Sect. 2.3.2). Thus, as a sensitivity test we also tested to model the $\mathrm{NH}_{3}$ uptake with a 10-times-lower Henry's law coefficient, which may be more appropriate for organic solvents.

Unfortunately we could not find any values of solubility products between carboxylic acids and ammonium in the literature. Hence, we decided to define an effective solubility product $\left(K_{s}^{*}\right)$ as the product between the ammonium concentration and the total deprotonated carboxylic acid concentration $\left(\left[\mathrm{RCOO}^{-}\right]_{\text {tot }}\right)($ Eq. 29$) . K_{\mathrm{s}}^{*}$ was the only parameter which we systematically varied in order to find the best possible agreement between the model and measurements.

$K_{\mathrm{s}}^{*}=\left[\mathrm{NH}_{4}^{+}\right]\left[\mathrm{RCOO}^{-}\right]_{\text {tot }}$

If not otherwise specified, the pure-liquid saturation vapour pressures of the organic compounds were estimated with the SIMPOL method, $K_{\mathrm{s}}^{*}$ was set to $0.1 \mathrm{~mol}^{2} \mathrm{~m}^{-6}$, and the $\mathrm{NH}_{4} \mathrm{RCOO}$ salts were mixed with the other organic compounds (no separate phase). Because the interactions between the $\mathrm{NH}_{4} \mathrm{RCOO}$ and other organic compounds and inorganic ions are unknown (see Sect. 2.3.1), $\mathrm{NH}_{4} \mathrm{RCOO}$ was not considered to influence the activity coefficients of the other compounds. However, for a second extreme condition, we performed simulations where we treated $\mathrm{NH}_{4} \mathrm{RCOO}$ and the other organic compounds + inorganics as two completely separate phases (liquid-liquid phase separated or $\mathrm{NH}_{4} \mathrm{RCOO}$ as crystalline salts; see Sect. 1). The diffusion coefficients for monomer SOA and ammonia/ammonium were estimated with the Stokes-Einstein relationship using a viscosity of $\sim 10^{8}$ Pa s (Abramson et al., 2013). Because the viscosity of the SOA is uncertain and depends on the experimental conditions and time of aging, we also performed simulations with less viscous particles $\left(D_{0, \text { monomer,SOA }}=10^{-15} \mathrm{~cm}^{2} \mathrm{~s}^{-1}\right.$, $D_{0, \text { ammonium }}=10^{-13} \mathrm{~cm}^{2} \mathrm{~s}^{-1}$ ).

In Table 4 we have listed the measured and model initial concentrations, concentration change of ozone $\left(\Delta\left[\mathrm{O}_{3}\right]=\left[\mathrm{O}_{3}\right]_{\max }-\left[\mathrm{O}_{3}\right]_{t=6 \mathrm{~h}}\right)$ and $\alpha$-pinene $\Delta[\alpha$-pin. $]$, and SOA yields. Figure 8 shows the modelled temporal evolution of the $\alpha$-pinene, $\mathrm{O}_{3}, \mathrm{NH}_{3}$ and $\mathrm{OH}$ concentrations in the gas phase. The $\mathrm{O}_{3}$ concentration rises during the first $20 \mathrm{~min}$ while $\mathrm{O}_{3}$ is continuously applied to the chamber. The $\mathrm{OH}$ concentration reaches a maximum of $\sim 10^{6}$ molecules $\mathrm{cm}^{-3}$ at the same time as the maximum $\mathrm{O}_{3}$ concentration. Hence, according to the model, the experiments with $\mathrm{CO}$ as an $\mathrm{OH}$ scavenger are not pure $\mathrm{O}_{3}$ oxidation experiments, but a fraction of the $\alpha$-pinene and the oxidation products are also oxidized with OH. Supplement Fig. S11 shows the cumulative

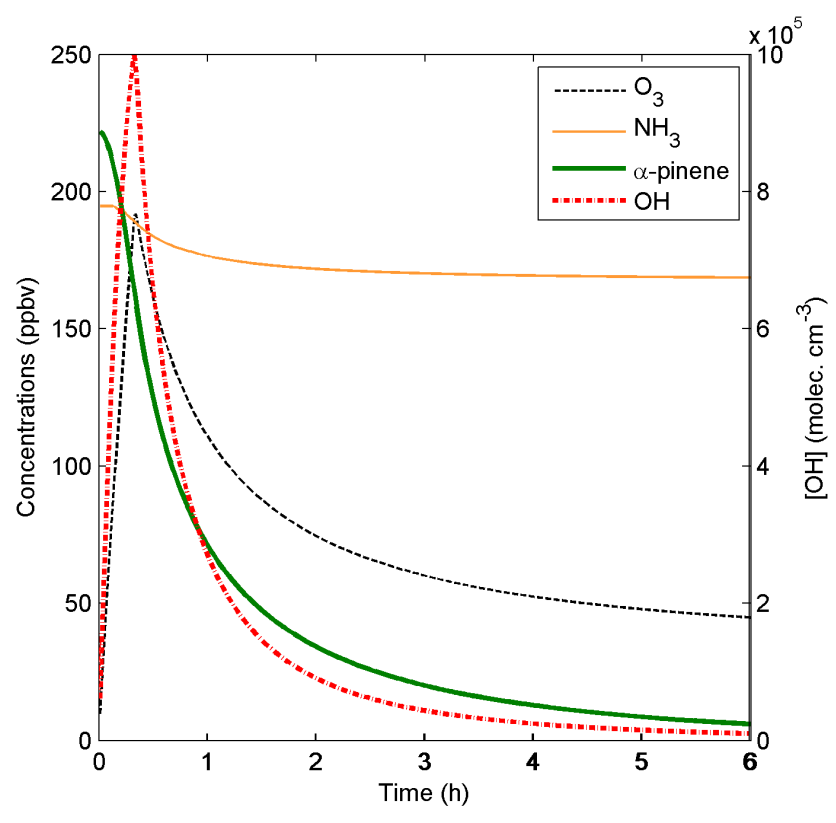

Figure 8. Modelled $\mathrm{NH}_{3}(\mathrm{~g}), \mathrm{O}_{3}(\mathrm{~g}), \alpha$-pinene $(\mathrm{g})$ and $\mathrm{OH}(\mathrm{g})$ concentrations for the $\alpha$-pinene oxidation experiments by $\mathrm{Na}$ et al. (2007).

fraction of reacted $\alpha$-pinene which was oxidized by $\mathrm{O}_{3}$ during the evolution of the experiment. At the beginning of the experiment only $86 \%$ of the consumed $\alpha$-pinene was oxidized by $\mathrm{O}_{3}$, while at the end of the experiment $92 \%$ of the consumed $\alpha$-pinene was oxidized by $\mathrm{O}_{3}$.

In Fig. 9 we compare the modelled and measured SOA yields from experiments conducted with approximately $220 \mathrm{ppb} \alpha$-pinene, $200 \mathrm{ppb} \mathrm{O}_{3}$ and varying initial $\mathrm{NH}_{3}$ concentrations. The model results in Fig. 9a are from the base case simulation set-up (Table 3). Figure 9b shows model results from simulations performed with pure-liquid saturation vapour pressures from Nannoolal et al. (2008). The results in Fig. 9c are from model runs with unity activity coefficients (Raoult's law for ideal solution), and Fig. 9d shows results from simulations with less viscous particles $\left(D_{0, \text { monomer,SOA }}=10^{-15} \mathrm{~cm}^{2} \mathrm{~s}^{-1}, D_{0, \text { ammonium }}=\right.$ $10^{-13} \mathrm{~cm}^{2} \mathrm{~s}^{-1}$ and $D_{0, \mathrm{NH}_{4} \mathrm{RCOO}}=0 \mathrm{~cm}^{2} \mathrm{~s}^{-1}$ ). For a particle with a diameter of $250 \mathrm{~nm}$, these values of the diffusion coefficients give an expected e-folding time of equilibration of $2.6 \mathrm{~min}$ for ammonium and $4.4 \mathrm{~h}$ for SOA monomers (Seinfeld and Pandis, 2006). However, since a substantial fraction of the ammonium can be bound into $\mathrm{NH}_{4} \mathrm{RCOO}$, the actual e-folding time can be longer.

For the base case simulations the agreement between the modelled and measured SOA mass and SOA yields are surprisingly good, both with and without addition of $\mathrm{NH}_{3}$. One reason for this is that the organic salt effective solubility product (Eq. 29) was used as a model-fitting parameter. However, in order for the model to agree with the measurements, the amount of semi-volatile carboxylic acids formed from the $\alpha$-pinene oxidation still needs to be reasonably well 
Table 3. Base case model set-up values for the simulation of organic salt formation between carboxylic acids and dissolved ammonium ions.

\begin{tabular}{lll}
\hline Parameter & Definition & Value $^{\mathrm{a}}$ \\
\hline $\mathrm{pK}_{\mathrm{a}, \mathrm{COOH}}$ & Logarithm of carboxylic acid dissociation constant & 4.6 \\
$\mathrm{pK}_{\mathrm{a}, \mathrm{NH}_{3}}$ & Logarithm of $\mathrm{NH}_{4}^{+}$dissociation constant & $9.25^{\mathrm{b}}$ \\
$K_{\mathrm{s}}^{*}\left(\mathrm{~mol}^{2} \mathrm{~m}^{-6}\right)$ & Effective solubility product (see Eq. 32) & 0.1 \\
$K_{\mathrm{H}}\left(\mathrm{mol} \mathrm{m}^{-3} \mathrm{~atm}^{-1}\right)$ & Henry's law coefficient for $\mathrm{NH}_{3}$ & $57.6^{\mathrm{c}}$ \\
$p_{0, i}$ & Pure-liquid saturation vapour pressure comp. $i$ & SIMPOL \\
$\gamma_{i}$ & Activity coefficient for compound $i$ & AIOMFAC \\
$D_{0, \text { monomer,SOA }\left(\mathrm{cm}^{2} \mathrm{~s}^{-1}\right)}$ & Diffusion coefficient for SOA monomers & $5 \times 10^{-17 \mathrm{~d}}$ \\
$D_{0, \text { ammonium }}\left(\mathrm{cm}^{2} \mathrm{~s}^{-1}\right)$ & Diffusion coefficient for $\mathrm{NH}_{3} / \mathrm{NH}_{4}^{+}$ & $1.3 \times 10^{-16 \mathrm{~d}}$ \\
$D_{\mathrm{NH}_{4} \mathrm{RCOO}}\left(\mathrm{cm}^{2} \mathrm{~s}^{-1}\right)$ & Diffusion coefficient of organic salts & 0 \\
\hline
\end{tabular}

${ }^{a}$ Base case simulation value.

$\mathrm{b}$ Lide (2008) (CRC Handbook of Chemistry and Physics) at $298 \mathrm{~K}$.

c Jacobson (2005a).

${ }^{\mathrm{d}}$ Based on the Stokes-Einstein relationship and an SOA viscosity of $10^{8}$ Pa s (Abramson et al., 2013).

Table 4. Initial conditions and results from the $\alpha$-pinene- $-\mathrm{O}_{3}-\mathrm{NH}_{3}-\mathrm{CO}$ experiments (Na et al., 2007) and base case model simulations.

\begin{tabular}{lrrrrrrrrr}
\hline Date & $\begin{array}{r}\text { Initial } \\
{[\alpha \text {-pin. }]} \\
\text { exp. }(\mathrm{ppb})\end{array}$ & $\begin{array}{r}\text { Initial } \\
\mathrm{NH}_{3} \\
(\mathrm{ppb})\end{array}$ & $\begin{array}{r}\Delta\left[\mathrm{O}_{3}\right] \\
\text { exp. } \\
(\mathrm{ppb})\end{array}$ & $\begin{array}{r}\Delta[\alpha \text {-pin. }] \\
\text { exp. }\end{array}$ & $\begin{array}{r}\text { Yield } \\
\text { exp. }(\%)\end{array}$ & $\begin{array}{r}\text { Initial } \\
{[\alpha \text {-pin. }]} \\
\text { model }(\mathrm{ppb})\end{array}$ & $\begin{array}{r}\Delta\left[\mathrm{O}_{3}\right] \\
\text { model } \\
(\mathrm{ppb})\end{array}$ & $\begin{array}{r}\Delta[\alpha \text {-pin. } \\
\text { model } \\
(\mathrm{ppb})\end{array}$ & $\begin{array}{r}\text { Yield } \\
\text { model } \\
(\%)\end{array}$ \\
\hline $25 / 01 / 05$ & 221 & & 130 & 218 & 54.3 & 222 & 149 & 216 & 57.5 \\
$11 / 01 / 05$ & 221 & 50 & 150 & 203 & 60.3 & 222 & 149 & 216 & 63.6 \\
$10 / 01 / 05$ & 223 & 100 & 150 & 206 & 64.0 & 222 & 149 & 216 & 65.4 \\
$06 / 01 / 05$ & 224 & 200 & 151 & 220 & 65.3 & 222 & 149 & 216 & 67.0 \\
\hline
\end{tabular}

predicted, which seems to be the case. It is also important to mention that for these model simulations we did not consider any chamber wall losses. Supplement Fig. S12 shows the modelled temporal evolution of the total carboxylic acid concentration (gas + particle phase).

We find the largest difference between the model runs, as well as between the model and measurements, when we use the pure-liquid saturation vapour pressure method from Nannoolal et al. (2008) instead of SIMPOL (Pankow and Asher, 2008) (Fig. 9b). The model then underestimates the SOA mass with $\sim 200 \mu \mathrm{g} \mathrm{m}^{-3}(\sim 30 \%)$, irrespective of the amount of $\mathrm{NH}_{3}$ added.

Supplement Fig S4 shows a comparison of the VBS parameterization from Pathak et al. (2007) and VBS parameterizations which we have derived from the MCMv3.2 condensable $\alpha$-pinene oxidation products using either the method from Nannoolal et al. (2008) or SIMPOL. The MCMv3.2 $\alpha$ pinene oxidation product VBS parameterizations are given both for $\mathrm{CO}$ and cyclohexane as an $\mathrm{OH}$ scavenger. The VBS parameterizations show large differences both between the vapour pressure methods and the type of $\mathrm{OH}$ scavenger used. By comparing the VBS parameterizations we can conclude that SIMPOL gives the largest SOA mass at high $\alpha$-pinene concentrations (this work). However, at low (atmospherically more realistic) $\alpha$-pinene concentrations the Nannoolal method will give the least volatile SOA and highest SOA mass.
Barley and McFiggans (2010) showed that the uncertainties of the calculated pure-liquid saturation vapour pressures are large, especially for low-volatility compounds with several functional groups. However, because of other large uncertainties, e.g. oligomerization processes and gas-phase chemistry mechanisms (see Sect. 1), we cannot predict which of the two liquid saturation vapour pressure methods gives the most realistic vapour pressures. In Sect. 3.2 we illustrated how the estimated volatility of the $\alpha$-pinene gas-phase oxidation products can have substantial effects on the particle evaporation loss rates.

In contrast to the vapour pressures, the modelled activity coefficients have only a small influence on the simulated SOA mass formation (compare Fig. 9a and c). This is consistent with the conclusions from McFiggans et al. (2010) and Zuend and Seinfeld (2012) for conditions without dissolved inorganic ions and low relative humidity. The mass difference between the model runs ([OA ideal $\left.]-\left[\mathrm{OA}_{\text {activity }}\right]\right)$ is small without added $\mathrm{NH}_{3}$, but increases when the free particle ammonium concentration increases. The reason for this is that the dissolved ammonium ions generally increase the organic molecule activity coefficients (salting-out effect). At atmospherically more realistic relative humidities $(>30 \%)$, salt effects, which either cause liquid-liquid phase separation or drive the organic compounds out from the particles, may have large effects on SOA formation (see e.g. Zuend and Seinfeld, 2012). 

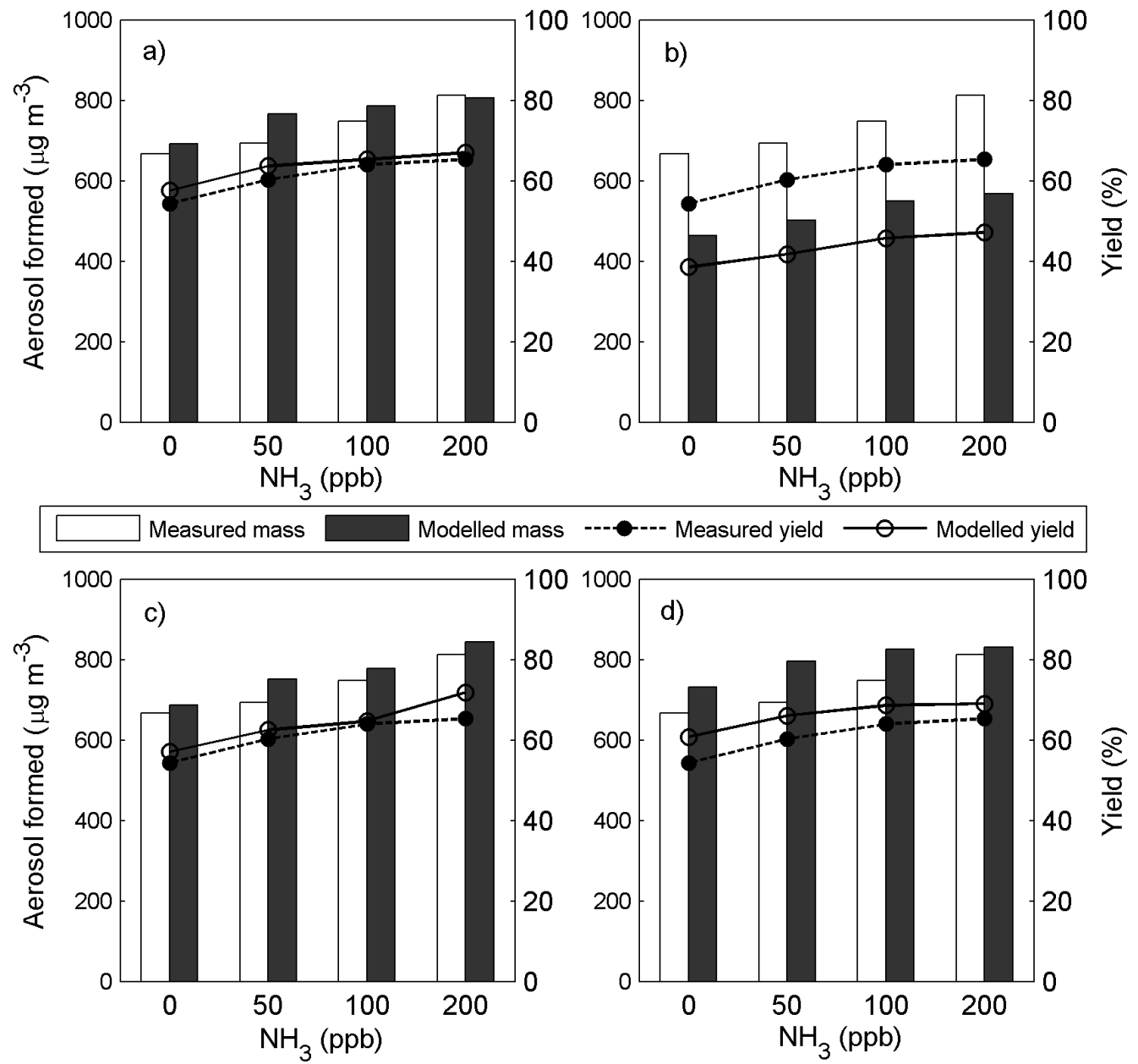

Figure 9. Comparison of modelled and measured SOA mass and mass yields at different initial levels of $\mathrm{NH}_{3}(\mathrm{~g})$. In (a) the model results are from simulations with vapour pressures from SIMPOL, activity coefficients from AIOMFAC and very slow mixing between the particle layers (base case); in (b) the results are from simulations with vapour pressures from Nannoolal et al. (2008), activity coefficients from AIOMFAC and very slow mixing between particle layers; in (c) the results are from simulations with vapour pressures from SIMPOL, unity activity coefficients (ideal solution) and very slow mixing between the particle layers; and in (d) the model results are from simulations with vapour pressures from SIMPOL, activity coefficients from AIOMFAC and semi-solid less viscous particles with $D_{0, \text { monomer, } \mathrm{SOA}}=10^{-15} \mathrm{~cm}^{2} \mathrm{~s}^{-1}$, $D_{0, \text { ammonium }}=10^{-13} \mathrm{~cm}^{2} \mathrm{~s}^{-1}$ and $D_{0, \mathrm{NH}_{4} \mathrm{RCOO}}=0 \mathrm{~cm}^{2} \mathrm{~s}^{-1}$.

If we assume that the SOA is less viscous (Fig. 9d), then the mass yields are slightly larger $(60.7 \%$ compared to $57.5 \%$ without $\mathrm{NH}_{3}$ addition, and $69.1 \%$ compared to $67.0 \%$ when $200 \mathrm{ppb} \mathrm{NH}_{3}$ is added at the start of the experiments).

Figure S13 in the Supplement shows the total SOA mass and $\mathrm{NH}_{4} \mathrm{RCOO}$ mass for varying initial $\mathrm{NH}_{3}$ concentration, $K_{\mathrm{s}}^{*}=0.01$ or $0.1 \mathrm{~mol}^{2} \mathrm{~m}^{-6}$ and semi-solid SOA particles. As expected, the $\mathrm{NH}_{4} \mathrm{RCOO}$ mass concentration and the total particle mass increase when $K_{\mathrm{s}}^{*}$ is lowered. However, for $200 \mathrm{ppb} \mathrm{NH}_{3}$ the difference becomes negligible since almost all carboxylic acids are found in the particle phase regardless. The results also reveal a moderate salting-out effect of the ammonium on the SOA (see the decrease in the total particle mass with increasing $\mathrm{NH}_{3}$ when $K_{\mathrm{s}}^{*}=0.01 \mathrm{~mol}^{2} \mathrm{~m}^{-6}$ ).
We also performed simulations with 10-times-lower Henry's law coefficients and $K_{\mathrm{s}}^{*}=0.01$ or $0.1 \mathrm{~mol}^{2} \mathrm{~m}^{-6}$ (Supplement Figs. S14 and S15). With $K_{\mathrm{s}}^{*}=0.1 \mathrm{~mol}^{2} \mathrm{~m}^{-6}$, no $\mathrm{NH}_{4} \mathrm{RCOO}$ is formed even if $200 \mathrm{ppb} \mathrm{NH}_{3}$ is added. However, the added $\mathrm{NH}_{3}$ still contributes to an enhanced dissociation and uptake of the carboxylic acids. When $200 \mathrm{ppb} \mathrm{\textrm {NH } _ { 3 }}$ is added and $K_{\mathrm{s}}^{*}$ is $0.1 \mathrm{~mol}^{2} \mathrm{~m}^{-6}$, the model gives an SOA mass increase of $11 \%$ and the measurements an increase of $22 \%$. If we decrease $K_{\mathrm{s}}^{*}$ to $0.01 \mathrm{~mol}^{2} \mathrm{~m}^{-6}$, a substantial amount of $\mathrm{NH}_{4} \mathrm{RCOO}$ is formed and the model is nearly able to capture the observed SOA mass increase with increasing $\mathrm{NH}_{3}$ concentrations (a $17 \%$ increase in mass when $200 \mathrm{ppb} \mathrm{NH}_{3}$ is added) (Supplement Fig. S15).

In order to test which processes are responsible for the observed $\mathrm{NH}_{3}$ uptake in $\alpha$-pinene SOA particles (Kuwata 


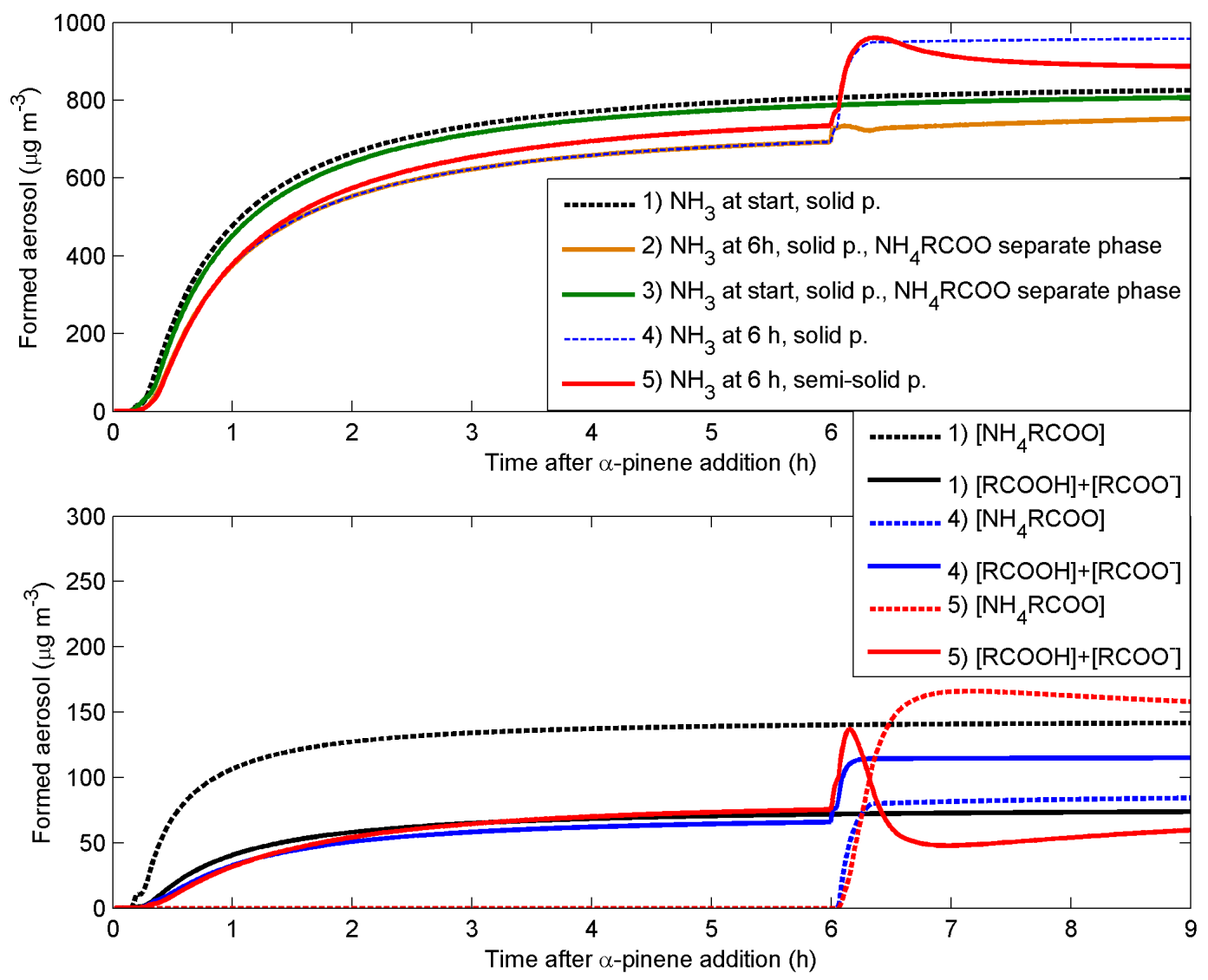

Figure 10. Modelled SOA mass formation for $\alpha$-pinene- $\mathrm{O}_{3}-\mathrm{NH}_{3}-\mathrm{CO}$ experiments with $200 \mathrm{ppb} \mathrm{NH}_{3}$ added at the start or after $6 \mathrm{~h}$ of aging. For all simulations, SIMPOL was used to estimate the vapour pressures of the organic compounds. The SOA particles were either treated as completely solid (no mixing between particle layers) (simulation 1-4) or semi-solid with $D_{0, \text { monomer,SOA }}=10^{-15} \mathrm{~cm}^{2} \mathrm{~s}^{-1}$, $D_{0, \text { ammonium }}=10^{-13} \mathrm{~cm}^{2} \mathrm{~s}^{-1}$ and $D_{0, \mathrm{NH}_{4} \mathrm{RCOO}}=0 \mathrm{~cm}^{2} \mathrm{~s}^{-1}$ (simulation 5). For simulations 2 and 3 we assume that the $\mathrm{NH}_{4} \mathrm{RCOO}$ salts form a separate phase which other organic compounds cannot dissolve into.

and Martin, 2012; Na et al., 2007), we also performed simulations where the SOA particles were allowed to age for $6 \mathrm{~h}$ before they were exposed to $200 \mathrm{ppb} \mathrm{NH}_{3}(\mathrm{~g})$. To test the effect of mass-transfer-limited uptake of $\mathrm{NH}_{3}$, the particles were either treated as glassy solids (no mixing) or semisolid and less viscous $\left(D_{0, \text { monomer, SOA }}=10^{-15} \mathrm{~cm}^{2} \mathrm{~s}^{-1}\right.$, $D_{0, \text { ammonium }}=10^{-13} \mathrm{~cm}^{2} \mathrm{~s}^{-1}$ ).

In Fig. 10a the temporal evolution of the modelled SOA mass from these simulations is shown. As a comparison, the results from simulations with $200 \mathrm{ppb} \mathrm{NH}_{3}(\mathrm{~g})$ added at the start of the experiments are also plotted. After the addition of $\mathrm{NH}_{3}$, the SOA mass increases rapidly both with and without mass-transfer-limited diffusion uptake in the particles (semisold or solid particles). This indicates that the rapid uptake of $\mathrm{NH}_{3}(\mathrm{~g})$ by the particles is mainly caused by reactive uptake of carboxylic acids $(\mathrm{g})$ and $\mathrm{NH}_{3}(\mathrm{~g})$ and not by the diffusion of $\mathrm{NH}_{3} / \mathrm{NH}_{4}^{+}$into the particle bulk. However, the temporal evolution of the formed $\mathrm{NH}_{4} \mathrm{RCOO}$ salts and dissociated and non-dissociated carboxylic acids (Fig. 10b) reveals that the mass of $\mathrm{NH}_{4} \mathrm{RCOO}$ salts formed in the semi-solid particles is twice as high, and the carboxylic acid mass concentration is substantially lower than if treating the SOA as solid. This difference is attributed to the mass-transfer-limited uptake and reaction of $\mathrm{NH}_{3} / \mathrm{NH}_{4}^{+}$with the carboxylic acids found in the semi-solid particle bulk interior.

However, although the $\mathrm{NH}_{4} \mathrm{RCOO}$ concentration becomes higher if the particles are semi-solid (less viscous), the total aerosol mass $3 \mathrm{~h}$ after the addition of ammonium is lower than if the particles are solid (compare simulation 4 and 5 in Fig. 10a). The reason for this is the salting-out effect of $\mathrm{NH}_{4}^{+}$, which causes the nonpolar organic compounds to evaporate. For these simulations, the salting-out effect is mainly important if both the $\mathrm{NH}_{3} / \mathrm{NH}_{4}^{+}$and the organic compounds can be transported between the bulk and particle surface-bulk layer. In the laboratory experiments (see Fig. 2a in Na et al., 2007), no SOA mass loss could be seen after the $\mathrm{NH}_{4} \mathrm{RCOO}$ formation. This experiment continued less than $1 \mathrm{~h}$ after the addition of $\mathrm{NH}_{3}$, but it at least indicates that the mixing of organic compounds within the particle phase is mass-transfer-limited and/or that the $\mathrm{NH}_{4} \mathrm{RCOO}$ salts form a separate phase, which 
a)

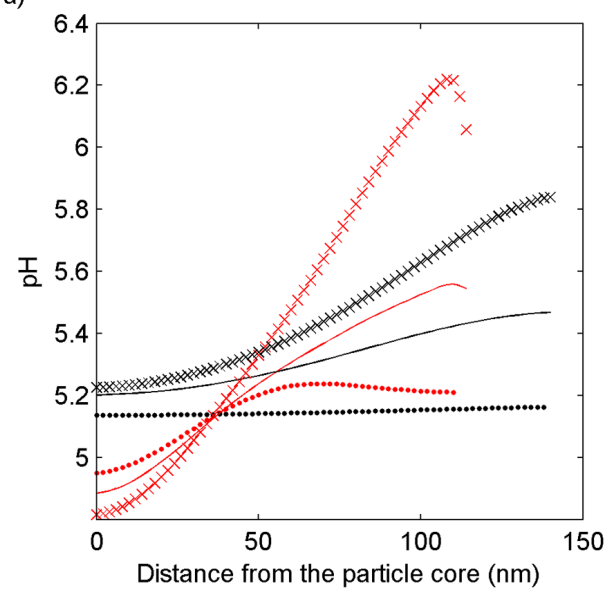

b)

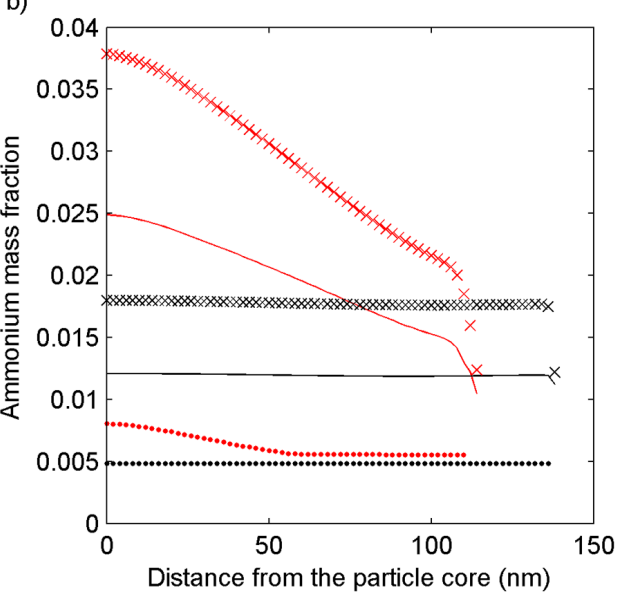

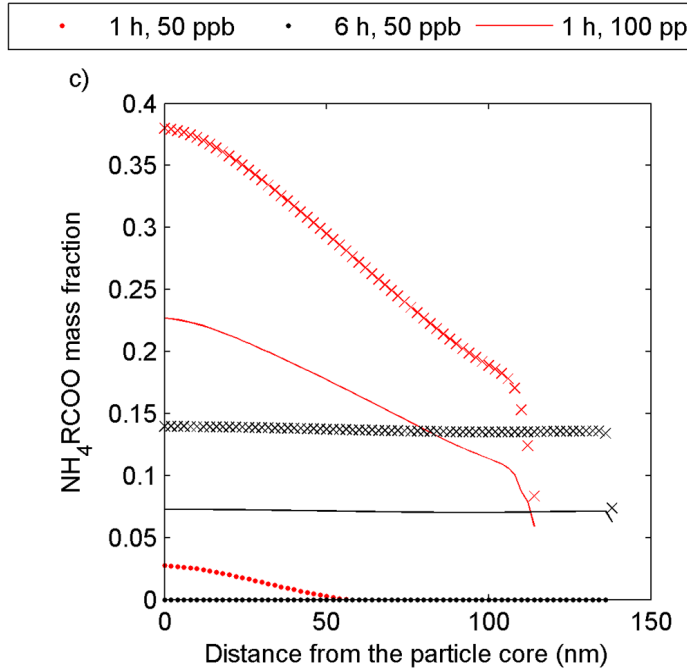

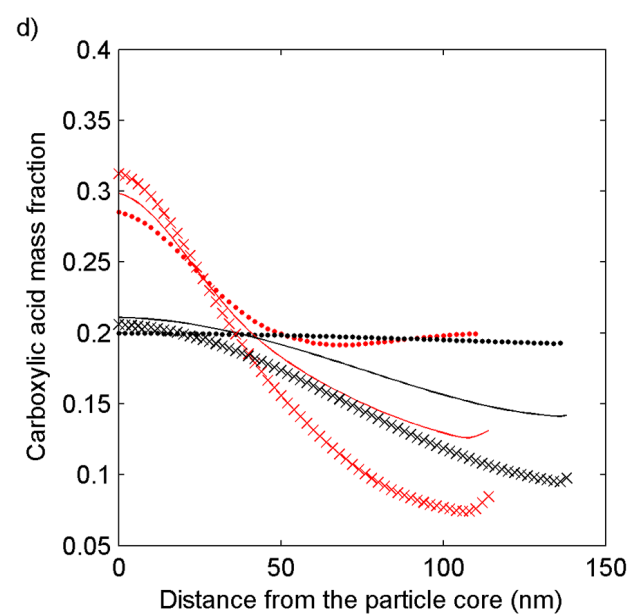

Figure 11. Modelled (a) $\mathrm{pH}$, (b) ammonium $\left(\mathrm{NH}_{4}^{+}+\mathrm{NH}_{3}(\mathrm{l})+\mathrm{NH}_{4}\right.$ in $\left.\mathrm{NH}_{4} \mathrm{RCOO}\right)$ mass fractions, (c) $\mathrm{NH}_{4} \mathrm{RCOO}$ mass fractions and (d) carboxylic acid $\left(\mathrm{COOH}+\mathrm{COO}^{-}\right)$mass fractions at different distances from the particle core for $\alpha$-pinene SOA particles with a diameter of approximately $240 \mathrm{~nm}$ after $1 \mathrm{~h}$ and $280 \mathrm{~nm}$ after $6 \mathrm{~h}$ of aging. The model results are from three different simulations with an initial $\left[\mathrm{NH}_{3}(\mathrm{~g})\right]$ of 50, 100 or $200 \mathrm{ppb}$. The SOA particles were assumed to be semi-solid with $D_{0, \text { monomer,SOA }}=10^{-15} \mathrm{~cm}^{2} \mathrm{~s}^{-1}, D_{0, \text { ammonium }}=$ $10^{-13} \mathrm{~cm}^{2} \mathrm{~s}^{-1}$ and $D_{0, \mathrm{NH}_{4} \mathrm{RCOO}}=0 \mathrm{~cm}^{2} \mathrm{~s}^{-1}$.

limits the salting-out of other SOA compounds from the particles to the gas phase.

Figure 10a also shows the simulated SOA mass formation when we treat the $\mathrm{NH}_{4} \mathrm{RCOO}$ salts as a separate phase (e.g. crystalline salt) which other condensable organic compounds cannot dissolve into. When $\mathrm{NH}_{3}(\mathrm{~g})$ is added during the start of the experiments the difference between the model runs with and without a separate $\mathrm{NH}_{4} \mathrm{RCOO}$ phase is relatively small. However, if the $\mathrm{NH}_{3}(\mathrm{~g})$ is added after the solid SOA particles have formed, only a moderate SOA mass increase is accomplished $(\sim 9 \%)$. This is in sharp contrast to the results from the simulations with solid particles and only one organic phase (mass increase of $\sim 39 \%$ ). The reason for this is that the ammonium salts are enriched in the particle surface-bulk layer, and if no other compounds can dissolve into this phase their uptake is limited. On the other hand, if $\mathrm{NH}_{4} \mathrm{RCOO}$ is part of a single amorphous organic phase, it will lower the mole fractions of the other compounds and hence increase (at least for ideal conditions) the uptake of them (see Eq. 2). This is the reason why the total SOA mass increase is larger $\left(\sim 270 \mu \mathrm{g} \mathrm{m}^{-3}, \sim 39 \%\right)$ than the increase explained purely by the carboxylic acids and $\mathrm{NH}_{4} \mathrm{RCOO}\left(46+84=130 \mu \mathrm{g} \mathrm{m}^{-3}\right.$, $\left.\sim 19 \%\right)$ (see simulation 4 in Fig. 10a and b). Na et al. (2007) observed a mass increase of $15 \%$ when $1000 \mathrm{ppb} \mathrm{NH}_{3}$ was added after the $\alpha$-pinene SOA particle mass formation had ceased. This increase is larger than the modelled increase when considering complete phase separation between $\mathrm{NH}_{4} \mathrm{RCOO}$ and the other condensable organic compounds but substantially smaller than for the simulations with only one organic phase. 
This may indicate that, in reality, there will neither be perfect (ideal) mixing between $\mathrm{NH}_{4} \mathrm{RCOO}$ and the other condensable organic compounds nor a complete phase separation.

Figure 11 shows (a) the modelled $\mathrm{pH}$, (b) the total ammonium mass fraction (free and bonded in ammonium salts), (c) the $\mathrm{NH}_{4} \mathrm{RCOO}$ mass fraction and (d) the carboxylic acid mass fraction $\left(\left[\mathrm{RCOO}^{-}\right]+[\mathrm{RCOOH}]\right)$ for a semi-solid SOA particle at different distances from the particle core. The figure includes results from the three simulations with initial $\mathrm{NH}_{3}(\mathrm{~g})$ concentrations of 50, 100 and $200 \mathrm{ppb}$, respectively, and at 1 or $6 \mathrm{~h}$ of aging. A large fraction of the SOA formed early during the experiments are due to condensation of carboxylic acids. This explains the large mass fractions of carboxylic acids and the lower $\mathrm{pH}$ in the particle cores (Fig. 11a and b). For the simulations with $200 \mathrm{ppb} \mathrm{NH}_{3}$, a large fraction of the carboxylic acids and ammonium form salts (Fig. 11c), while when only $50 \mathrm{ppb} \mathrm{NH}_{3}$ is added, ammonium salts are only present during the early stage of particle formation, when the carboxylic acid mass fraction is large. Because of the assumed relatively rapid mixing of ammonium (e-folding time of a few minutes), the free ammonium concentration (not bound in organic salts) is almost constant in all particle layers. Hence, the differences in the $\mathrm{NH}_{4} \mathrm{RCOO}$ concentrations between different layers are largely caused by differences in the carboxylic acid concentrations, which even after $6 \mathrm{~h}$ of aging are not uniformly mixed.

It has been suggested that organic salt formation between carboxylic acids and $\mathrm{NH}_{3}$ or ammines could possibly be responsible for the early growth of nanometre-sized particles in the atmosphere (e.g. Smith et al., 2008; Barsanti et al, 2009; Smith et al., 2010; Yli-Juuti et al., 2013). In order to be able to draw any conclusions from our simulations concerning the potential effect of $\mathrm{NH}_{4} \mathrm{RCOO}$ formation in the atmosphere, we performed simulations where we decreased the $\alpha$-pinene concentration to $50 \mathrm{ppb}$ and varied the $\mathrm{NH}_{3}$ concentration in the range $0-2 \mathrm{ppb}$. We used $50 \mathrm{ppb} \alpha$-pinene, because in the model $\sim 30 \mathrm{ppb} \alpha$-pinene needs to react before the particles with an initial diameter of $5 \mathrm{~nm}$ start to grow. Furthermore, the model simulations do not consider inorganic salt formation between $\mathrm{NH}_{3}$ and the strong acids $\mathrm{H}_{2} \mathrm{SO}_{4}$ or $\mathrm{HNO}_{3}$. YliJuuti et al. (2013) showed that, for typical conditions over boreal forest, $\mathrm{NH}_{3}$ will preferentially form inorganic salts with $\mathrm{H}_{2} \mathrm{SO}_{4}$ and not with carboxylic acids. In our simulations, very little $\mathrm{NH}_{4} \mathrm{RCOO}$ is formed even if the $\mathrm{NH}_{3}$ concentration is $2 \mathrm{ppb}$ and the average growth rate between 5 and $20 \mathrm{~nm}$ is only amplified by $\sim 7 \%$ (see Supplement Fig. S16).

From the simulations in this section we can conclude that ADCHAM (with the pure-liquid saturation vapour pressures from SIMPOL and activity coefficients from AIOMFAC) is able to reproduce the observed SOA formation at different concentrations of $\mathrm{NH}_{3}(\mathrm{~g})$. With $\mathrm{NH}_{3}$ present during the formation, reactive uptake of carboxylic acids contributes substantially to the modelled early growth of the particles formed by homogeneous nucleation. However, this is proba- bly not the case for atmospherically more relevant $\mathrm{NH}_{3}$ and $\alpha$-pinene concentrations.

\subsection{SOA formation from oxidation of $m$-xylene}

Here we model the SOA formation from an $m$-xylene oxidation experiment (experiment P2 in Nordin et al., 2013). The experiment was conducted in a $6 \mathrm{~m}^{3}$ Teflon chamber in the Aerosol Laboratory at Lund University. The experiment started with dark conditions by adding $\left(\mathrm{NH}_{4}\right)_{2} \mathrm{SO}_{4}$ seed aerosol into the chamber $\left(\sim 20 \mu \mathrm{g} \mathrm{m}^{-3}\right)$, followed by $\sim 40 \mathrm{ppb} \mathrm{NO}$ and $\sim 240 \mathrm{ppb} m$-xylene. Approximately $30 \mathrm{~min}$ before the UV lights were turned on $(\sim 90 \mathrm{~min}$ after the start of the experiment), $\left(\mathrm{NH}_{4}\right)_{2} \mathrm{SO}_{4}$ particles were added a second time in order to achieve the target $\left(\mathrm{NH}_{4}\right)_{2} \mathrm{SO}_{4}$ mass of $\sim 20 \mu \mathrm{g} \mathrm{m}^{-3}$.

The seed aerosol was formed by nebulizing an $\left(\mathrm{NH}_{4}\right)_{2} \mathrm{SO}_{4}$-water solution and then drying the droplets. Before the dry $\left(\mathrm{NH}_{4}\right)_{2} \mathrm{SO}_{4}$ particles were introduced into the chamber they were passed through a bipolar charger in order to achieve a well-defined nearly Boltzmann-distributed charge distribution (Wiedensohler et al., 2012). The experiment was performed at a temperature of $22^{\circ} \mathrm{C} \pm 2{ }^{\circ} \mathrm{C}$, under dry conditions (RH of 3-5\%) and in the presence of UV light with an experimentally derived $\mathrm{NO}_{2}$ photolysis rate of $0.2 \mathrm{~min}^{-1}$. The experimental set-up has been described in detail by Nordin et al. (2013). The measured UV-light spectrum $(320-380 \mathrm{~nm})$ is given in the supplementary material of Nordin et al. (2013).

In the model we used a temperature of $21^{\circ} \mathrm{C}$ and an $\mathrm{RH}$ of $5 \%$. The photolysis rates were calculated with the recommended cross sections and quantum yields from MCMv3.2 and the measured $1 \mathrm{~nm}$ resolution UV spectrum from Nordin et al. (2013), with a total light intensity of $23 \mathrm{~W} \mathrm{~m}^{-2}$, which gives a $\mathrm{NO}_{2}$ photolysis rate of $0.20 \mathrm{~min}^{-1}$.

\subsubsection{Particle deposition loss rates}

To be able to quantify the effect of deposition on the estimated SOA formation from chamber experiments, the deposition losses of particles to the chamber walls need to be evaluated. The deposition depends on the friction velocity $\left(u^{*}\right)$, the particle size and charge distributions, the mean electrical field strength $\left(E^{\prime \prime}\right)$ in the chamber, and the chamber surfacearea-to-volume ratio (see Sect. 2.2.3). $E^{\prime \prime}$ and $u^{*}$ are commonly not known, but can be estimated by fitting the model to particle number size distribution measurements. For this purpose an experiment was performed with $\left(\mathrm{NH}_{4}\right)_{2} \mathrm{SO}_{4}$ seed particles but without condensable organic compounds.

As the experiments in the chamber proceed, the chamber surface-area-to-volume ratio increased because of instrument sampling and leakage out from the chamber due to a small over pressure inside the chamber (see Nordin et al., 2013). We estimate the chamber volume loss rates $(\Delta V / \Delta t)$ during the experiments to be $0.8 \pm 0.2 \mathrm{~m}^{3} \mathrm{~h}^{-1}$. 

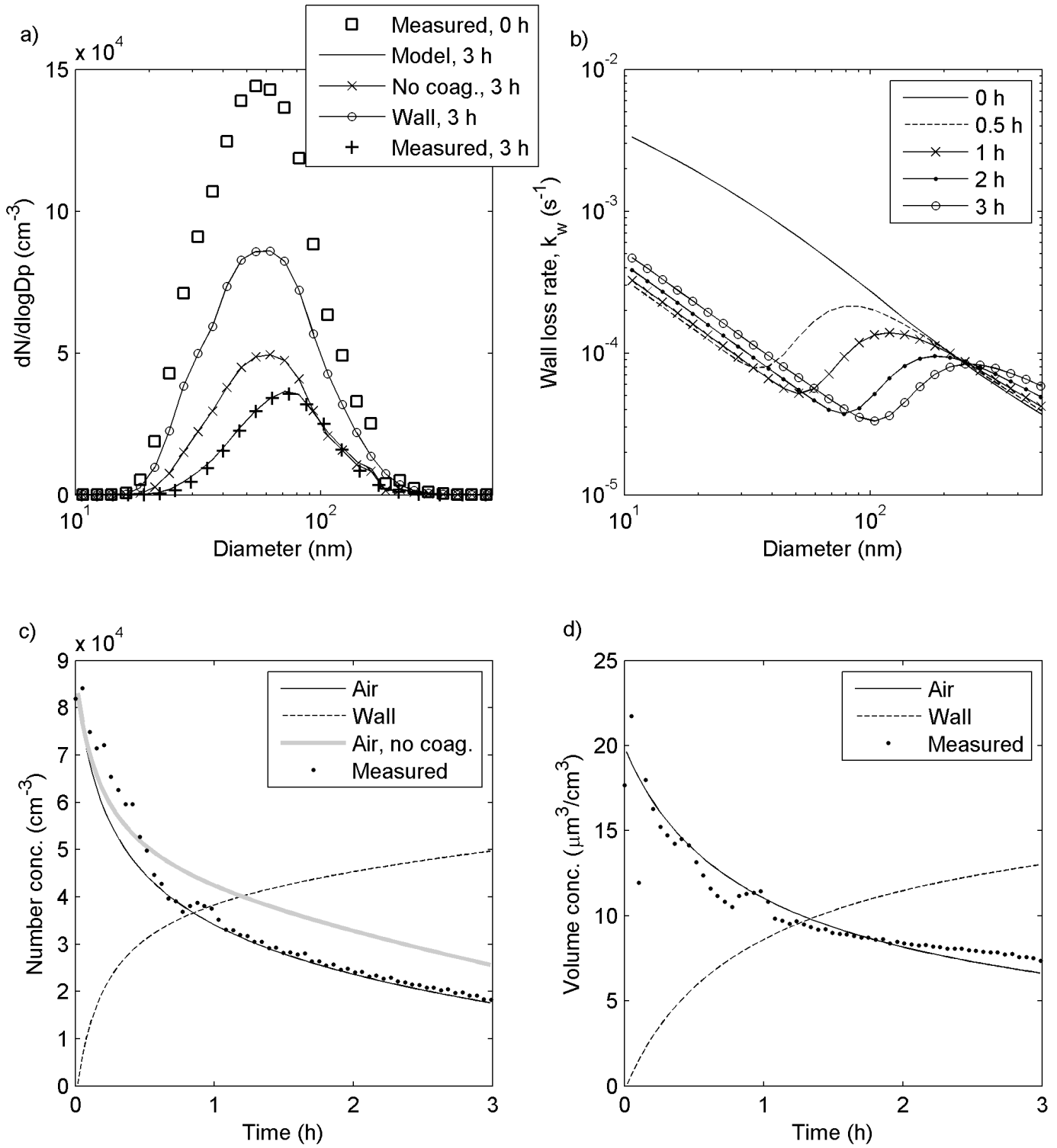

Figure 12. Modelled deposition and coagulation losses of $\left(\mathrm{NH}_{4}\right)_{2} \mathrm{SO}_{4}$ seed aerosol particles in the Lund University $6 \mathrm{~m}^{3}$ Teflon chamber. We used a friction velocity of $0.05 \mathrm{~m} \mathrm{~s}^{-1}$ and a mean electrical field strength of $50 \mathrm{~V} \mathrm{~cm}^{-1}$. The chamber volume loss rate was set to $0.8 \mathrm{~m}^{3} \mathrm{~h}^{-1}$. The shown model results are both for the particle concentrations in the air (with or without coagulation) and on the particle walls. (a) shows the modelled and measured particle number size distributions, (b) effective wall loss rates (modelled), (c) number concentration and (d) volume concentration.

In Supplement Fig. S17 we compare the modelled and measured temporal evolution of the particle number concentration and particle volume concentration for simulations with different values of $E^{\prime \prime}$ and $u^{*}$. With a $\Delta V / \Delta t$ of $0.8 \mathrm{~m}^{3} \mathrm{~h}^{-1}$, and an $E^{\prime \prime}$ of $50 \mathrm{~V} \mathrm{~cm}^{-1}$ and a $u^{*}$ of $0.05 \mathrm{~m} \mathrm{~s}^{-1}$, ADCHAM is able to nearly reproduce the measured $\left(\mathrm{NH}_{4}\right)_{2} \mathrm{SO}_{4}$ particle number size distributions (Fig. 12a), the temporal evolution of the total particle number (Fig. 12c) and volume concentrations (Fig. 12d). The coagulation has no direct influence on the particle volume concentration but is important for the particle number con- centration at the end of the experiment. At the beginning of the experiment the charged smallest particles are rapidly deposited to the chamber walls, resulting in a high effective wall deposition loss rate $\left(k_{\mathrm{w}}\left(\mathrm{s}^{-1}\right)\right)$ (Fig. 12b). But, as the experiment proceeds, the fraction of charged particles (especially the small ones) decreases in the air. At the same time the surface-area-to-volume ratio increases in the chamber, which in turn increases the deposition loss rates of all particle sizes (see the gradual upward displacement of the curves in Fig. 12b). Recharging of particles by collision with air ions was not considered in the model. 
After the tuning of the deposition loss rates on the pure seed aerosol experiments, we used ADCHAM to simulate the SOA formation experiment with $m$-xylene as a precursor (Nordin et al., 2013). However, if we use the same $(\Delta V / \Delta t)$, $E^{\prime \prime}$ and $u^{*}$ as in the pure seed particle deposition experiment, the model underestimates the seed aerosol mass loss (especially during the first $2 \mathrm{~h}$ after the UV lights are turned on), but substantially overestimates the particle number concentration losses before the UV lights are turned on.

The heating of the air by the UV lights and the air condition units which blow on the outer chamber walls can produce an increased mixing within the chamber. Therefore, before the UV lights are turned on, $u^{*}$ may be smaller. By decreasing $u^{*}$ to $0.01 \mathrm{~m} \mathrm{~s}^{-1}$ before the UV lights are turned on, the model better captures the measured initial particle number concentration losses.

Another important difference between the pure seed particle experiment and the $m$-xylene precursor experiment is that the latter experiment was performed over almost twice the length of time $(\sim 6 \mathrm{~h})$. Hence, the effect of particle recharging when colliding with air ions may be more important to consider. Furthermore, the chamber volume during the end of the $m$-xylene experiment was substantially smaller (1.5$2 \mathrm{~m}^{3}$ ). This might have increased the effective mean electrical field strength within the chamber (see Sect. 2.2.3). In the model we try to account for this by calculating $\overline{E_{t}}$ (at time $t)$ as the quotient between the initial mean electrical field strength $\overline{E_{0}}\left(50 \mathrm{~V} \mathrm{~cm}^{-1}\right)$ and the relative change of the approximate distance between the roof and ceiling $(h)$ of the chamber $\left(h_{t} / h_{0}\right)$ (which is approximately equal to the relative chamber volume change $\left.\left(V_{t} / V_{0}\right)\right)$ (Eq. 30).

$\overline{E_{t}}=\frac{\overline{E_{0}}}{h_{t} / h_{0}} \approx \frac{\overline{E_{0}}}{V_{t} / V_{0}}$

Figure S18 in the Supplement compares the modelled and measured (with AMS and scanning mobility particle sizer (SMPS)) temporal evolution of the sulfate seed particle mass concentration, particle number concentration and particle number size distribution, and the modelled initial and final effective deposition loss rates. The model results are from simulations with $\overline{E_{t}}=50 \mathrm{~V} \mathrm{~cm}^{-1}$ and $u^{*}=0.05 \mathrm{~m} \mathrm{~s}^{-1}$ or $\overline{E_{t}}$ calculated with Eq. (30) and with $u^{*}=0.01 \mathrm{~m} \mathrm{~s}^{-1}$ before the UV lights are turned on. With the latter values the model shows substantially better agreement with the measured temporal evolutions of the sulfate seed aerosol mass concentration. However, the model still overestimates the particle number concentration loss rates (especially after the UV lights are turned on). For the model simulations presented below we will use Eq. (30) to estimate $\overline{E_{t}}$, and $u^{*}=0.01 \mathrm{~m} \mathrm{~s}^{-1}$ before the UV lights are turned on, and $u^{*}=0.05 \mathrm{~m} \mathrm{~s}^{-1}$ after the UV lights are turned on.

\subsubsection{Gas-particle partitioning and heterogeneous reactions}

Since the $m$-xylene experiment was performed under dry conditions, the $\left(\mathrm{NH}_{4}\right)_{2} \mathrm{SO}_{4}$ seed particles will initially be in a solid crystalline phase. Therefore, we assume that no material is mixed between the crystalline solid salt cores and the SOA coating (see e.g. Fig. 1a in Bertram et al., 2011). Hence, in the model there will be no salting-out effect (increase of the nonpolar organic compound activity coefficients caused by $\mathrm{NH}_{4}^{+}, \mathrm{SO}_{4}^{-2}$ and $\mathrm{HSO}_{4}^{-}$from the seed aerosol particles) (see discussion in Sect. 3.3 on possible salting-out effects of $\mathrm{NH}_{4}^{+}$).

In total we considered 112 potentially condensable $\left(p_{0}<\right.$ $1 \mathrm{~Pa}$ ) non-radical organic MCMv3.2 compounds. The pureliquid saturation vapour pressures were calculated with either SIMPOL (Pankow and Asher, 2008) or the method from Nannoolal et al. (2008). We also used a third (semiempirical) method to model the SOA formation. This method considers a total of three oxidation products with vapour pressures and molar-based stoichiometric yields $\left(\alpha_{i}\right)$ derived from the parameterizations for low and high NO conditions from $\mathrm{Ng}$ et al. (2007). For this we assume that the condensable organic compounds have a molar mass of $200 \mathrm{~g} \mathrm{~mol}^{-1}$. The two most volatile compounds $\left(p_{0,1}=6.4 \times\right.$ $10^{-6} \mathrm{~Pa}, \alpha_{1}=0.021$ and $\left.p_{0,2}=1.7 \times 10^{-4} \mathrm{~Pa}, \alpha_{2}=0.061\right)$ represent the volatility distribution of the condensable oxidation products formed through the $\mathrm{RO}_{2}+\mathrm{NO}$ pathway. The third non-volatile product $\left(p_{0,3}=0 \mathrm{~Pa}, \alpha_{3}=0.245\right)$ represent the generally less volatile organic compounds formed through the $\mathrm{RO}_{2}+\mathrm{HO}_{2}$ pathway. The gas phase was still modelled with the MCMv3.2. The fraction of condensable organic compounds which was formed through the $\mathrm{RO}_{2}+\mathrm{HO}_{2}$ pathway (product 3) was derived with the ratio $\left(k_{\mathrm{RO} 2+\mathrm{HO}_{2}}\left[\mathrm{HO}_{2}\right] /\left(k_{\mathrm{RO}_{2}+\mathrm{NO}}[\mathrm{NO}]+k_{\mathrm{RO}_{2}+\mathrm{HO}_{2}}\left[\mathrm{HO}_{2}\right]\right)\right.$ as proposed by $\mathrm{Ng}$ et al. (2007).

The partitioning of the condensable organic compounds to the wall-deposited particles and the Teflon walls was modelled according to the procedure described in Sect. 2.2.3. The uptake onto the Teflon film and the particles deposited on the chamber walls depends on the laminar layer width adjacent to the chamber walls $(\Delta x)$. The uptake (adsorption) on the Teflon film also depends on the first-order loss rate from the near-wall gas phase to the walls $\left(k_{\mathrm{g}, \mathrm{w}}\right)$ and the desorption rate from the Teflon surfaces out to the thin layer next to the chamber walls $\left(k_{\mathrm{w}, \mathrm{g}, i}\right)$ (Eq. 4). In Sect. 3.4.4 we test different values of $\Delta x, k_{\mathrm{g}, \mathrm{w}}$ and $k_{\mathrm{w}, \mathrm{g}, i}$ in order to find the best possible agreement between the modelled and the measured SOA formation.

Because coagulation has a considerable influence on the modelled particle number size distribution (see Fig. 12), we will consider this process as well. However, with the current version of ADCHAM coagulation cannot be combined with the complete kinetic multilayer model (see Sect. 2.2.2). Hence, for the simulations presented in this section, the 
particles were only divided into a solid seed particle core and a second (well-mixed) bulk layer and a surface monolayer, which are composed of the condensable organic compounds. Additionally (if specified) we also consider the adsorption and desorption of $\mathrm{O}_{3}$ and $\mathrm{NO}_{2}$, the mass-transfer-limited diffusion of $\mathrm{O}_{3}$ and $\mathrm{NO}_{2}$ from the sorption layer into the particle bulk, and the particle-phase reactions between $\mathrm{O}_{3}$ and unsaturated organic compounds (see Sect. 2.4.2) or between $\mathrm{NO}_{2}$ and oxidized aromatic compounds (see Sect. 3.4.3).

Table 1 in Sect. 2.4.2 gives the model parameter values used for $\mathrm{O}_{3}$ uptake. For the simulations presented here, the diffusion coefficient of ozone $\left(D_{0, \mathrm{O}_{3}}\right)$ was set to values between $10^{-7}$ and $10^{-8} \mathrm{~cm}^{2} \mathrm{~s}^{-1}$ (semi-solid SOA (see e.g. Table 1 in Shiraiwa et al., 2011), and the reaction rate constants between ozone and the unsaturated (non-aromatic carbon-carbon double bond) organic compounds $\left(k_{\mathrm{O}_{3}}\right)$ were varied between $10^{-16}$ and $10^{-17}$ molecules ${ }^{-1} \mathrm{~cm}^{3} \mathrm{~s}^{-1}$. This can be compared with the measured $k_{\mathrm{O}_{3}}$ of $10^{-16}$ molecules ${ }^{-1} \mathrm{~cm}^{3} \mathrm{~s}^{-1}$ for the heterogeneous ozonolysis of oleic and palmitoleic acid (Huff Hartz et al., 2007). Berkemeier et al. (2013) used the KMSUB model to constrain the kinetic parameter values which limit the ozonolysis of oleic acid. According to their model simulations, $k_{\mathrm{O}_{3}}$ should be somewhere in the range of $1.7 \times 10^{-15}-1.7 \times 10^{-17}$ molecules ${ }^{-1} \mathrm{~cm}^{3} \mathrm{~s}^{-1}$. The formed particle-phase oxidation products were assumed to be nonvolatile, which is likely an acceptable assumption if the oxidation products rapidly react and form dimer SOA (see e.g. Maksymiuk et al., 2009). Apart from increasing the SOA mass formation and changing the chemical composition of the SOA, these heterogeneous reactions may also serve as an additional ozone sink (which is not accounted for by the MCMv3.2 gas-phase chemistry mechanism).

Additionally, we will also test peroxyhemiacetal and hemiacetal dimer formation in the particle phase.

\subsubsection{Gas-phase chemistry and influence from chamber walls and heterogeneous reactions}

Bloss et al. (2005a, b) have previously shown that the MCMv3.1 (without particle SOA formation and particlephase chemistry) generally overestimates the ozone concentration and underestimates the $\mathrm{OH}$ concentration during oxidation of light aromatic compounds (e.g. xylene and toluene). Hence, for these systems MCM also tends to underestimate the $\mathrm{NO}$ and hydrocarbon oxidation (loss) rates. In order to account for the missing $\mathrm{OH}$ source, Bloss et al. (2005b) had to include an artificial $\mathrm{OH}$ source of $4 \times$ $10^{8}$ molecules $\mathrm{cm}^{-3} \mathrm{~s}^{-1}$ when modelling a toluene oxidation experiment from the EUPHORE chamber.

Conversion of $\mathrm{NO}_{2}$ to $\mathrm{HONO}$ on the organic particle surfaces may partly explain the discrepancy between the modelled and measured particle-phase chemistry (Bloss et al., 2005b). These reactions have been observed on diesel exhaust particles (Gutzwiller et al., 2002) and on organic aerosol surfaces, for example, by George et al. (2005). Metzger et al. (2008) instead proposed that the $\mathrm{NO}_{2}$ is primarily converted to HONO on the Teflon chamber walls.

In this work we will test the heterogeneous $\mathrm{NO}_{2}$-to-HONO conversion mechanism. Bloss et al. (2005b) modelled this mechanism using a constant reaction probability $\left(\gamma_{\mathrm{HONO}}\right)$ of 0.025 for the $\mathrm{NO}_{2}$ molecules which collide with a particle. In this work we model this proposed mechanism in a more detailed way by considering the adsorption, diffusion and reaction of $\mathrm{NO}_{2}$ with specific organic compounds in the particle phase. $\mathrm{NO}_{2}$ has approximately the same Henry's law coefficient for dissolution in water (Seinfeld and Pandis, 2006) and molecule size as $\mathrm{O}_{3}$. Hence, for these simulations, we will use the same parameter values for $\mathrm{NO}_{2}$ (e.g. Henry's law coefficient and diffusion coefficient) as specified for $\mathrm{O}_{3}$ in Sect. 3.4.2 and in Table 1.

Gutzwiller et al. (2002) suggested that the organic compounds which react with $\mathrm{NO}_{2}$ in the particle phase and form HONO are oxygenated aromatics (e.g. 2-methoxyphenol). Hence, we assume that it is only the compounds that contain an aromatic ring which will be oxidized by $\mathrm{NO}_{2}$ and form HONO. The organic oxidation products formed from these heterogeneous reactions were assumed to be non-volatile.

The $\mathrm{NO}_{2}$ to HONO conversion mechanism was considered both on the particles deposited on the chamber walls and in the air. We will also test an additional photo-enhanced background reactivity caused by HONO release from the chamber walls (Rohrer et al., 2005). The strength of the HONO emissions (from the walls to the near-surface gas phase) in the Lund Teflon chamber (Nordin et al, 2013) was estimated to be $4.6 \times 10^{8}$ molecules $\mathrm{cm}^{-2} \mathrm{~s}^{-1}$. This value is based on the estimated HONO wall production rate of $9.1 \times 10^{6}$ molecules $\mathrm{cm}^{-3} \mathrm{~s}^{-1}$ in Metzger et al. (2008) and their chamber volume to surface area characteristics (Paulsen et al., 2005).

Analogous to the MCM light aromatic model simulations by Bloss et al. (2005a, b), we underestimate the $\mathrm{OH}$ and overestimate the maximum $\mathrm{O}_{3}$ concentration without tuning the MCM gas-phase chemistry (Fig. 13). MCMv3.2 also underestimate the initial $\mathrm{O}_{3}$ formation rate, the amount of reacted $m$-xylene, and the rapid NO-to- $\mathrm{NO}_{2}$ conversion which starts approximately $20 \mathrm{~min}$ after the UV lights were turned on. Therefore, analogous to Bloss et al. (2005b), we decided to include an artificial $\mathrm{OH}$ source, in our case with a rate of $10^{8} \mathrm{~cm}^{-3} \mathrm{~s}^{-1}$ from $20 \mathrm{~min}$ after the UV lights were turned on until the end of the experiment. This substantially improves the agreement between the modelled and measured $\mathrm{NO}, \mathrm{NO}_{2}, \mathrm{O}_{3}$ and $m$-xylene concentrations. However, the model still substantially overestimates the maximum $\mathrm{O}_{3}$ concentration.

The poor agreement between the modelled and measured $\mathrm{NO}_{2}$ in the latter half of the experiment (Fig. 13b) is because of the interference from peroxyacyl nitrates (PAN), $\mathrm{HNO}_{3}$, $\mathrm{HONO}, \mathrm{N}_{2} \mathrm{O}_{5}$ and other nitrate-containing compounds in the 


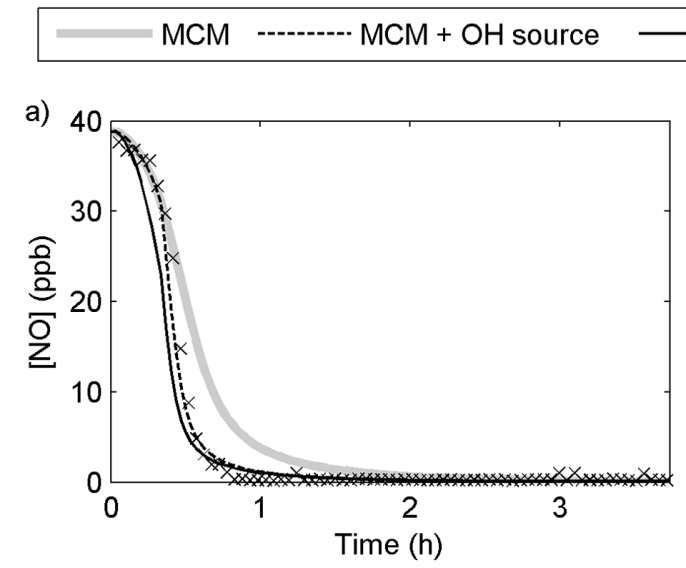

$\mathrm{MCM}+\mathrm{OH}$ source $+\mathrm{HONO}$ wall $\quad \times$ Measured
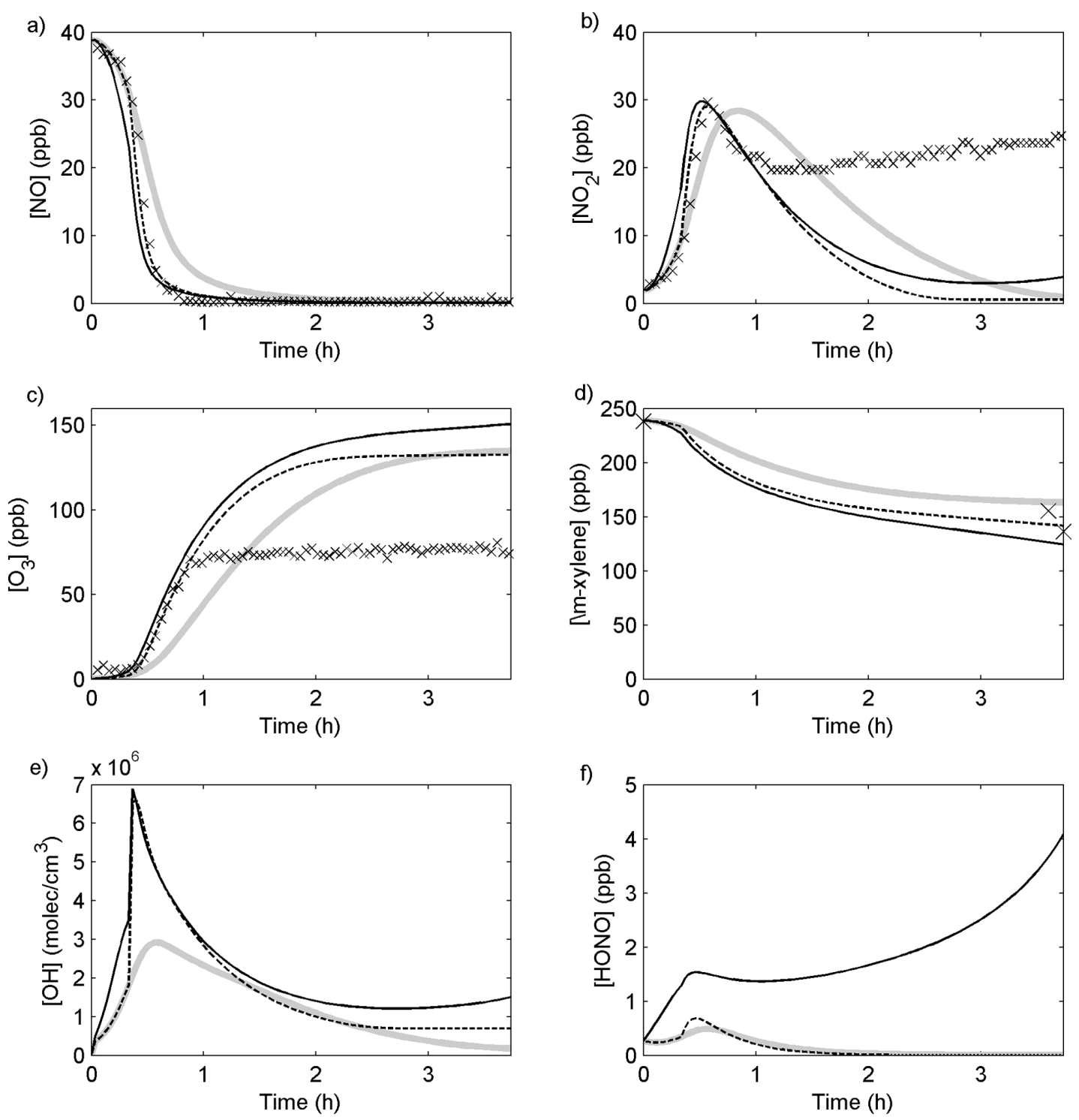

Figure 13. Modelled and measured gas-phase concentrations from the $m$-xylene oxidation experiment by Nordin et al. (2013). (a-d) give the modelled and measured $\mathrm{NO}, \mathrm{NO}_{2}, \mathrm{O}_{3}$ and $m$-xylene concentration, respectively. (e-f) show the modelled $\mathrm{OH}$ and $\mathrm{HONO}$ concentrations. The model results are from simulations with (1) the original MCMv3.2 gas-phase chemistry, (2) with MCMv3.2 gas-phase chemistry and an artificial $\mathrm{OH}$ source of $10^{8} \mathrm{~cm}^{3} \mathrm{~s}^{-1}$, and (3) with MCMv3.2 gas-phase chemistry, the artificial OH source and wall emissions of HONO.

chemiluminescence instrument used (see Nordin et al., 2013, and references therein).

Figure 13 also shows the results from a simulation where we additionally include HONO emissions from the chamber walls. Because the surface-area-to-volume ratio increases during the experiments ( $\sim 5$ times) these emissions have an increasing influence on the modelled gas-phase chemistry. With HONO emissions and the $\mathrm{OH}$ source, the $\mathrm{OH}$ concentration at the end of the model run is $1.5 \times 10^{6} \mathrm{~cm}^{-3}$, while without these emissions but with the $\mathrm{OH}$ source the concen- tration is $7 \times 10^{5} \mathrm{~cm}^{-3}$. Hence, with HONO wall emissions, more $m$-xylene reacts in the simulation than what is indicated by the gas chromatography-mass spectrometry (GCMS) measurements. Additionally, the model $\mathrm{O}_{3}$ concentration becomes even higher.

In order to be able to compare the modelled and measured SOA formation during the experiment, it is crucial that we are able to accurately simulate both the amount of $m$ xylene which is consumed and the fraction of $\mathrm{RO}_{2}$ which reacts with $\mathrm{HO}_{2}$ and $\mathrm{NO}$ (see e.g. Ng et al., 2007 and Kroll 
and Seinfeld, 2008). Hence, if not otherwise specified, we included the artificial $\mathrm{OH}$ source but not any HONO emissions from the chamber walls. With this model set-up, the cumulative fraction of the $m$-xylene first-generation $\mathrm{RO}_{2}$ oxidation products which have reacted with $\mathrm{HO}_{2}$ at the end of the experiment is about $\sim 65 \%$. When we also include $\mathrm{HONO}$ wall emissions this value is $\sim 50 \%$, and with the non-tuned MCMv3.2 chemistry we get a value of $\sim 35 \%$ (see Supplement Fig. S19).

In order to test whether HONO formation from heterogeneous reactions between $\mathrm{NO}_{2}$ and oxidized aromatic compounds can improve the agreement between the modelled and measured $\mathrm{O}_{3}$ concentration, we performed a simulation with what we believe are upper estimates of the reaction rates between $\mathrm{NO}_{2}$ and the oxidized aromatic compounds and the $\mathrm{NO}_{2}$ diffusion coefficient $\left(k_{\mathrm{NO}_{2}}=10^{-15}\right.$ molecules ${ }^{-1} \mathrm{~cm}^{3} \mathrm{~s}^{-1}$ and $D_{0, \mathrm{NO}_{2}}=$ $10^{-7} \mathrm{~cm}^{2} \mathrm{~s}^{-1}$ ). With these values, $\sim 60 \%$ of the aromatic SOA was oxidized by $\mathrm{NO}_{2}$. The formed (in the model nonvolatile) oxidation products comprise $20 \%$ of the total SOA mass at the end of the simulation (Supplement Fig. S20a). Still, this has only a moderate influence on the HONO concentration (Supplement Fig. S20b) and the $\mathrm{NO}_{2}$ and $\mathrm{O}_{3}$ decrease is equal to or less than $\sim 1 \%$ (Fig. S20c-d).

Figure S20d also shows the modelled $\mathrm{O}_{3}(\mathrm{~g})$ concentration when including heterogeneous reactions between $\mathrm{O}_{3}$ and the unsaturated organic compounds $\left(k_{\mathrm{O}_{3}}=\right.$ $10^{-16}$ molecules $^{-1} \mathrm{~cm}^{3} \mathrm{~s}^{-1}$ and $D_{0, \mathrm{O}_{3}}=10^{-7} \mathrm{~cm}^{2} \mathrm{~s}^{-1}$ ). For this simulation, $\sim 98 \%$ of the unsaturated organic compounds in the particle phase were oxidized by $\mathrm{O}_{3}$ and the formed non-volatile SOA products comprise $37 \%$ of the total SOA mass. However, comparable to the heterogeneous $\mathrm{NO}_{2}$ to $\mathrm{HONO}$ conversion, this has a very small influence on the modelled $\mathrm{O}_{3}(\mathrm{~g})$ concentration $(\sim 1 \%$ decrease). Hence, we can conclude that it seems unlikely that heterogeneous reactions between $\mathrm{NO}_{2}$ and oxidized aromatic compounds and/or between $\mathrm{O}_{3}$ and the unsaturated organic compounds can explain why measurements generally give much lower $\mathrm{O}_{3}(\mathrm{~g})$ concentrations than MCM. However, as will be shown in Sect. 3.4.4, these heterogeneous reactions can still be important for the amount and type of SOA which is formed.

\subsubsection{SOA formation, properties and the potential influence from chamber wall effects and heterogeneous reactions}

In Fig. 14 we compare the modelled and measured particle volume concentrations during the $m$-xylene experiment. The model results are from simulations with the SIMPOL vapour pressure method. The desorption of condensable organic compounds from the chamber walls was modelled with $C_{\mathrm{w}} /\left(M_{\mathrm{w}} \gamma_{\mathrm{w}, i}\right)$ in Eq. (4) equal to $100 \mu \mathrm{mol} \mathrm{m}{ }^{-3}$. This value is between those measured by Matsunaga and Ziemann (2010) for 2-alcohols and 2-ketones (see Sect. 2.2.3). For the model results in Fig. 14a we used a $\Delta x$ of $0.1 \mathrm{~cm}$ and $k_{\mathrm{g}, \mathrm{w}}$ was set to $1 / 20 \mathrm{~s}^{-1}$, while for the results in Fig. $14 \mathrm{~b}$ we used a $\Delta x$ of $1.0 \mathrm{~cm}$ and $k_{\mathrm{g}, \mathrm{w}}$ was set to $1 / 6 \mathrm{~s}^{-1}$. Hence, the model simulation in Fig. 14a represents conditions with only relatively small mass transfer limitations for the gas exchange between the air and the chamber walls and particles on the walls, and a relatively slow uptake of organic compounds directly onto the Teflon walls. The model simulation in Fig. 15b instead represents conditions where the mass transfer limitations between the air and the chamber walls and particles on the walls are substantial while the uptake of gases directly onto the Teflon walls is relatively effective.

The simulations were performed both with and without heterogeneous oxidation of unsaturated organic compounds using $k_{\mathrm{O}_{3}}$ and $D_{0, \mathrm{O}_{3}}$ as model-fitting parameters. The oxidation products (ox. prod.) from these reactions were assumed to form one organic semi-solid phase together with the other organic compounds $\left(D_{0, \text { monomer }}=5 \times 10^{-17} \mathrm{~cm}^{2} \mathrm{~s}^{-1}\right.$ and $D_{\text {ox. prod. }}=0 \mathrm{~cm}^{2} \mathrm{~s}^{-1}$ ).

In the model simulations presented in Fig. 14 it is shown that the model is able to capture the volume loss rates of the seed aerosol and the onset of the SOA formation in the experiment $\left(\sim 0.5 \mathrm{~h}\right.$ after $\mathrm{UV}$ lights were turned on). With a $k_{\mathrm{O}_{3}}$ of $10^{-16}$ molecules ${ }^{-1} \mathrm{~cm}^{3} \mathrm{~s}^{-1}$ and a $D_{0, \mathrm{O}_{3}}$ of $10^{-8} \mathrm{~cm}^{2} \mathrm{~s}^{-1}$ the model shows the best agreement with the observed particle volume concentration more than $1.5 \mathrm{~h}$ after the UV lights are turned on. However, for all simulations in Fig. 14, ADCHAM underestimates the observed rapid SOA formation between 0.5 and $1.25 \mathrm{~h}$ for the particles suspended in air. Additionally, ADCHAM overestimates the total particle volume loss rates of the suspended particle at the end of the experiments, especially without heterogeneous ozonolysis and relatively rapid uptake of organic compounds onto the Teflon walls (Fig. 15b). According to this simulation the particle losses are caused not only by deposition but also evaporation. Heterogeneous ozonolysis or other particle-phase reactions allows for more gas-phase monomers to partition into the particle phase and delay the time when the evaporation and deposition losses dominates over the SOA formation (see Supplement Fig. S21). Additionally, the SOA formed from these particle-phase reactions is less volatile (in the model non-volatile) and will therefore decrease the evaporation loss rates (see Sect. 3.2).

Opposite to the simulation results in Fig. 14b, the maximum particle volume is larger without heterogeneous ozonolysis in Fig. 14a. For these simulations the SOA formation onto the wall-deposited particles is more efficient $(\Delta x=$ $0.1 \mathrm{~cm}$ ) and the gas uptake onto the Teflon walls smaller. The wall-deposited particles may not always serve as a sink of SOA but can also become a source of condensable organic compounds from the walls to the air. This is especially the case if the formed SOA is relatively volatile. The more volatile the SOA is, the smaller the SOA fraction found on the wall-deposited particles will be. Hence, while the formed total SOA mass (air + walls) is larger with heterogeneous 

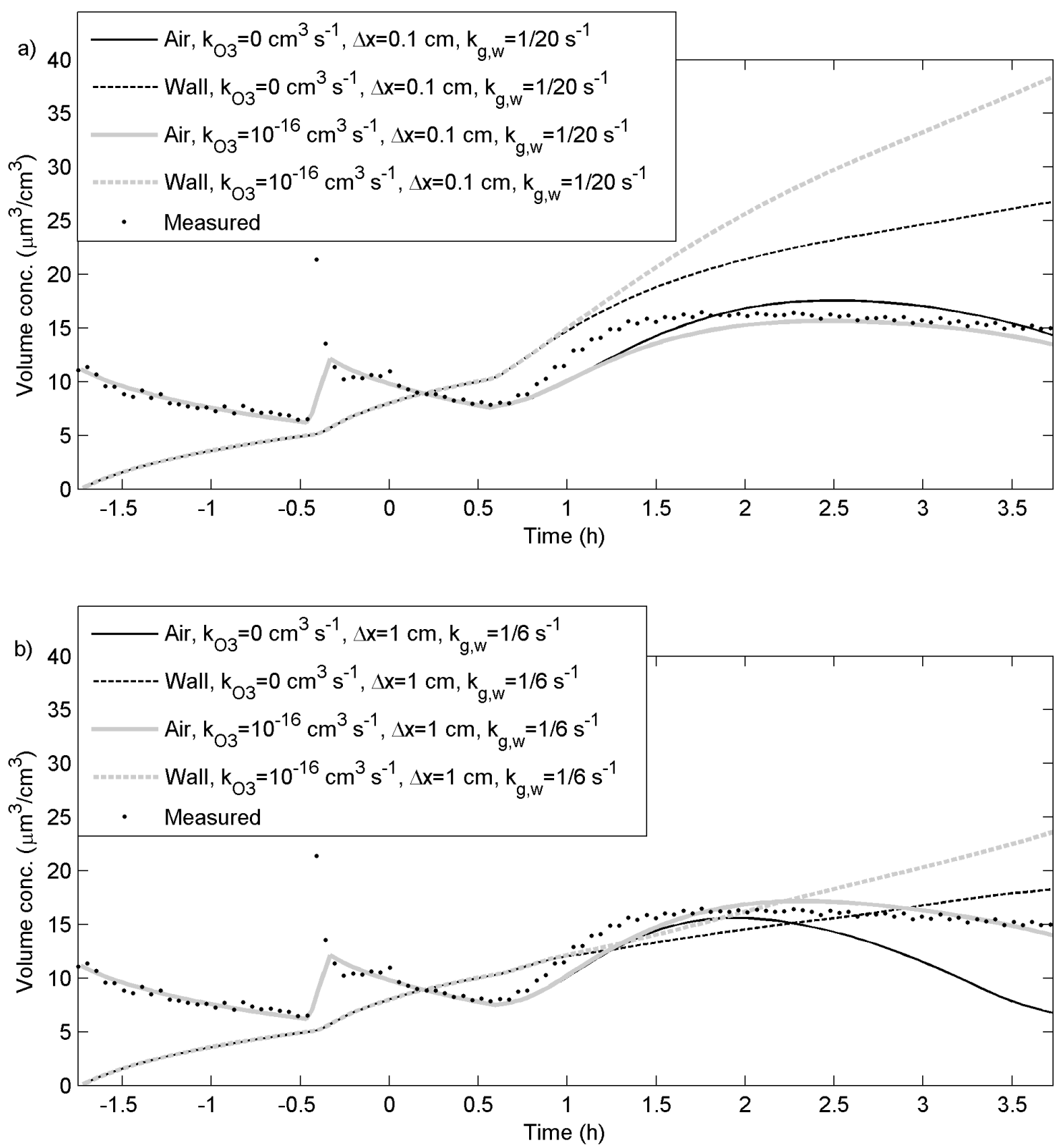

Figure 14. Modelled and measured volume concentrations of (seed aerosol + SOA coating) during the $m$-xylene oxidation experiment by Nordin et al. (2013). The model results are given both for the particles in the air and for those that have deposited on the chamber walls. The results in (a) are from simulations with a laminar layer width $(\Delta x)$ of $0.1 \mathrm{~cm}$ adjacent to the chamber walls and a first-order loss rate from the near-wall gas phase to the walls $\left(k_{\mathrm{g}, \mathrm{w}}\right)$ of $1 / 20 \mathrm{~s}^{-1}$. The results in (b) are from simulations with a $\Delta x$ of $1.0 \mathrm{~cm}$ and a $k_{\mathrm{g}, \mathrm{w}}$ of $1 / 6 \mathrm{~s}$. The figures show both the results from simulations without or with heterogeneous reactions between $\mathrm{O}_{3}$ and unsaturated organic compounds $\left(k_{\mathrm{O}_{3}}=10^{-16}\right.$ molecules ${ }^{-1} \mathrm{~cm}^{3} \mathrm{~s}^{-1}$ and $D_{0, \mathrm{O}_{3}}=10^{-8} \mathrm{~cm}^{2} \mathrm{~s}^{-1}$ ).

reactions in Fig. 14a, the SOA mass formed on the particles in the air is smaller (see also Fig. S22 in the Supplement).

Figure S23 in the Supplement compares the modelled particle volume from simulations with the SIMPOL and Nannoolal vapour pressure method or the semi-empirical two product model parameterization (see Sect. 3.4.2). The model simulations were performed with a $\Delta x$ of $0.1 \mathrm{~cm}$ and $k_{\mathrm{g}, \mathrm{w}}=1 / 20 \mathrm{~s}^{-1}$. For the simulations with the SIMPOL and the Nannoolal method, heterogeneous ozonolysis was also considered $\left(k_{\mathrm{O}_{3}}=10^{-16}\right.$ molecules ${ }^{-1} \mathrm{~cm}^{3} \mathrm{~s}^{-1}$ and $D_{0, \mathrm{O}_{3}}=$ $10^{-8} \mathrm{~cm}^{2} \mathrm{~s}^{-1}$ ). From this figure it is evident that both methods give almost identical SOA mass formation at the end of the experiment. However, with the Nannoolal method the onset of the SOA formation is approximately $15 \mathrm{~min}$ too late. The reason for this is that the modelled early-stage SOA formation is dominated by two MCM oxidation products 


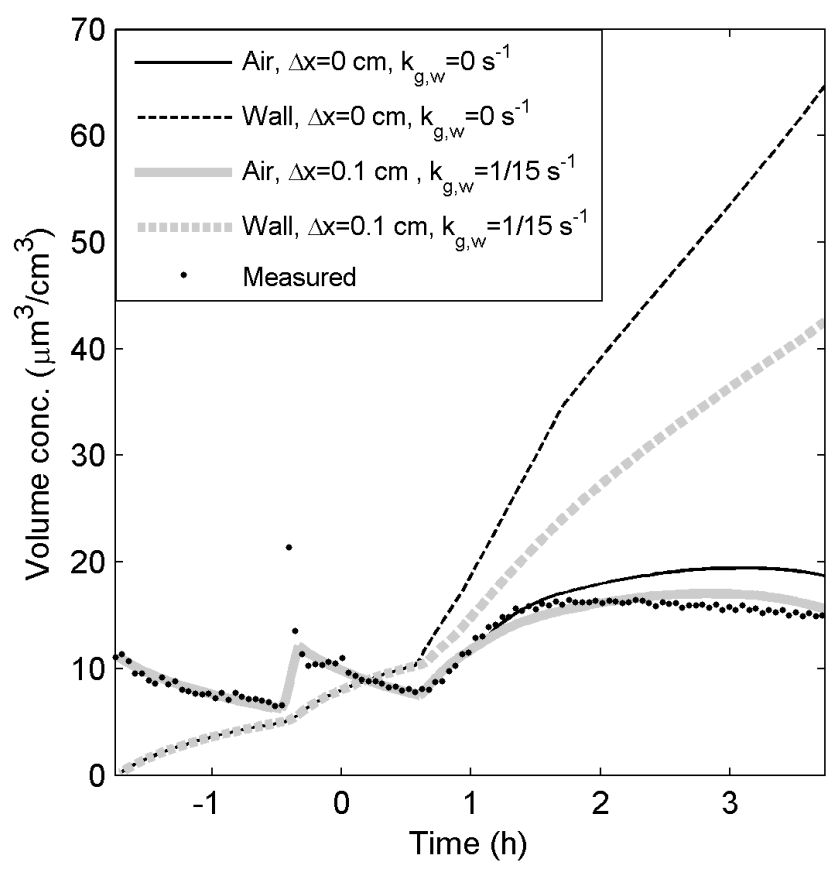

Figure 15. Modelled and measured volume concentrations (seed aerosol + SOA coating) during the $m$-xylene oxidation experiment from Nordin et al. (2013). The model results are from simulations with relatively rapid $\left(k_{\mathrm{f}}=10^{-22}\right.$ molecules $\left.{ }^{-1} \mathrm{~cm}^{3} \mathrm{~s}^{-1}\right)$ peroxyhemiacetal and hemiacetal formation, $\Delta x=0$ or $0.1 \mathrm{~cm}$ and $k_{\mathrm{g}, \mathrm{w}}=0$ or $1 / 15 \mathrm{~s}^{-1}$. The model results are given both for the particles in the air and the particles deposited on the chamber walls.

(MXNCATECH and MXYMUCNO3) (formed through the high NO oxidation pathway; see Sect. 3.4.3). Both of these compounds have higher vapour pressures with the Nannoolal method $\left(3.1 \times 10^{-3}\right.$ and $\left.1.31 \times 10^{-4} \mathrm{~Pa}\right)$ compared to the SIMPOL method $\left(1.9 \times 10^{-4}\right.$ and $\left.7.5 \times 10^{-5} \mathrm{~Pa}\right)$.

With the semi-empirical parameterization, derived from experiments in a similar but larger Teflon chamber $\left(28 \mathrm{~m}^{3}\right)$ (Ng et al., 2007), ADCHAM gives a too early onset of the SOA formation and overestimates the SOA formation when $k_{\mathrm{g}, \mathrm{w}}=1 / 20 \mathrm{~s}^{-1}$. The reason for this is that the three model compounds of this method all have relatively low vapour pressures (see Sect. 3.4.2). Hence, the gas phase is rapidly saturated with respect to all these three compounds, which are effectively taken up by the particles before they are lost to the Teflon wall surfaces. In order to not overestimate the final SOA mass, $k_{\mathrm{g}, \mathrm{w}}$ needs to $\sim 1 \mathrm{~s}^{-1}$. However, then the model substantially underestimates the early-stage SOA formation rate.

We also modelled the SOA formation without losses of condensable organic compounds onto the Teflon wall (see Fig. S24 in the Supplement). With a $\Delta x$ of $0.1 \mathrm{~cm}$, ADCHAM is now able to capture the rapid early-stage SOA formation in the chamber. However, the final particle volume concentration in the air is overestimated with $\sim 40 \%$. If we instead assume that the gas-particle partitioning onto the chamber-wall-deposited particles is identical to the uptake onto the particles suspended in the air $(\Delta x=0 \mathrm{~cm})$ (see Sect. 2.2.3 and references there in), then the model again substantially underestimates the early-stage SOA formation rate, while it gives reasonable particle volume concentrations at the end of the simulation.

Finally we also tested whether a relatively rapid oligomerization process in the particle phase could improve the agreement with the modelled and measured SOA formation. For these simulations we again use the SIMPOL vapour pressure method and assume that peroxyhemiacetal and hemiacetal dimers form in the particle phase. We find the best agreement between the modelled and measured SOA formation when we use a $k_{\mathrm{f}}$ of $10^{-22}$ molecules ${ }^{-1} \mathrm{~cm}^{3} \mathrm{~s}^{-1}$. This value of $k_{\mathrm{f}}$ corresponds well with previously reported values of $k_{\mathrm{f}}$ for hemiacetal and peroxyhemiacetal formation under weekly acidic conditions $(\mathrm{pH} \approx 4)$ (see Sect. 2.3.4). In order to shift the equilibrium toward the particle phase (which might explain the rapid early-stage SOA formation seen in the experiment) we assume that the oligomers and monomers form one mixed phase.

Figure 15 shows the modelled particle volume concentrations when considering peroxyhemiacetal and hemiacetal dimer formation and with $\Delta x=0$ or $0.1 \mathrm{~cm}$ and $k_{\mathrm{g}, \mathrm{w}}=0$ or $1 / 15 \mathrm{~s}^{-1}$. Without gas-phase losses onto the Teflon walls and ideal uptake onto wall-deposited particles $(\Delta x=0 \mathrm{~cm})$ the model is able to capture the rapid early-stage SOA formation seen in the experiment. After this the modelled particle volume concentration in the air continues to increase slowly for additionally $\sim 2 \mathrm{~h}$, while in the experiment the measured particle volume slowly decreases.

With mass-transfer-limited diffusion and losses of condensable organic compounds from the near-wall gas phase to the Teflon walls $\left(\Delta x=0.1 \mathrm{~cm}\right.$ and $\left.k_{\mathrm{g}, \mathrm{w}}=1 / 1 \mathrm{~s} \mathrm{~s}^{-1}\right)$, the model results are in better agreement with the measurements at the end of the experiment and can nearly reproduce the rapid SOA formation at the beginning of the experiment.

Hence, these simulations indicate that relatively rapid heterogeneous reactions (either oligomerization or oxidation) are required in order to explain the observed rapid SOA formation at the beginning of the $m$-xylene oxidation experiment. Still, the model cannot fully explain the sharp transition between the rapid SOA formation between 0.5 and $1.25 \mathrm{~h}$ after the UV light is turned on and the slow almost linear volume (mass) loss observed during the latter half of the experiment.

In Fig. 16 we compare the temporal evolution of the modelled SOA formation without wall losses to the chamber walls (ideal chamber), using the SIMPOL, Nannoolal or the semi-empirical parameterization method from $\mathrm{Ng}$ et al. (2007). The figure also illustrates the influence from heterogeneous ozonolysis $\left(\mathrm{O}_{3}\right.$ ox.) of unsaturated organic compounds $\left(k_{\mathrm{O}_{3}}=10^{-16}\right.$ molecules ${ }^{-1} \mathrm{~cm}^{3} \mathrm{~s}^{-1}$ and $\left.D_{0, \mathrm{O}_{3}}=10^{-8} \mathrm{~cm}^{2} \mathrm{~s}^{-1}\right)$ and peroxyhemiacetal and hemiacetal oligomer formation $\left(k_{\mathrm{f}}=10^{-22}\right.$ molecules $\left.{ }^{-1} \mathrm{~cm}^{3} \mathrm{~s}^{-1}\right)$. 
We have also included the measured wall-loss-corrected SOA mass (SOA mass scaled with the measured relative sulfate loss rate from the time when the UV lights are turned on) (see Sect. 2.2.3).

The simulation with SIMPOL and no heterogeneous reactions gives best agreement with the measured final SOA mass formation ( 70 and $65 \mu \mathrm{g} \mathrm{m}^{-3}$, respectively). However, this simulation substantially underestimates the SOA formation during the start of the experiment. The best agreement between the model and measurements at the beginning of the experiment is instead reached when we include relatively rapid oligomerization in the particle phase. The results from this simulation also show surprisingly good agreement with the model simulation using the semi-empirical parameterizations from $\mathrm{Ng}$ et al. (2007). This again indicates that heterogeneous reactions are likely to be important for the SOA formation. The larger SOA formation from these model simulations compared to the measurements can likely be attributed to substantial gas-phase losses directly onto the Teflon walls in the chamber. This effect will be especially pronounced at the end of the experiment, when the surface-area-to-volume ratio is large (see Sect. 3.4.1). Hence for this experiment, the model simulations indicate that the wall corrections (which assume continued uptake of condensable organic compounds onto the wall-deposited particles) do not give an upper estimate of the actual (atmospheric relevant) SOA formation (see Sect. 2.2.3).

\section{Summary and conclusions}

We have developed the novel Aerosol Dynamics, gas- and particle-phase chemistry model for laboratory CHAMber studies (ADCHAM). ADCHAM combines the detailed gasphase chemistry from MCMv3.2; a kinetic multilayer module for diffusion-limited transport of compounds between the gas phase, particle surface and particle bulk phase; and an aerosol dynamics and particle-phase chemistry module which is based on the ADCHEM model (Roldin et al., 2011a) but with important updates, among others process-based algorithms for non-ideal interactions (salt effects) between water, organic and inorganic compounds, acidity-catalysed oligomerization, and oxidation of organic compounds in the particle phase.

In this work we have illustrated the usefulness of ADCHAM in studying potentially influential but poorly known processes, i.e. different dimerization mechanisms; organic salt formation; salting-out effects; and heterogeneous oxidation reactions and mass transfer limitations between the gas-particle phase, between the particle surface and particle bulk phase, and within the particle bulk phase. All these processes influence the modelled SOA formation and chemical and physical properties (e.g. volatility, phase state, oxidation state and hygroscopicity).

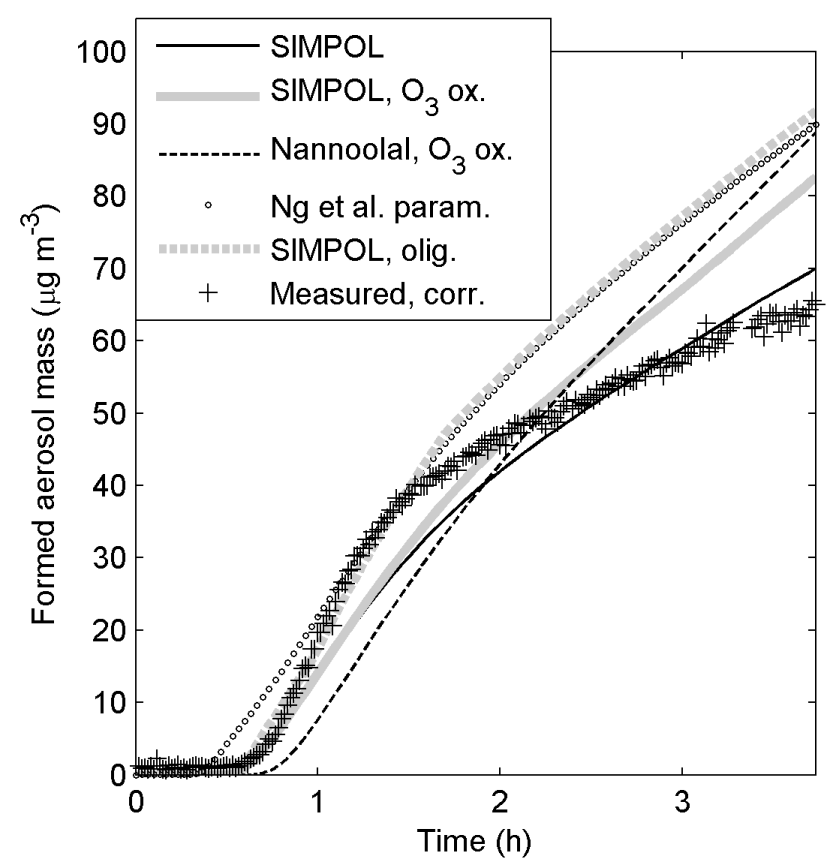

Figure 16. Modelled and measured (wall-loss-corrected) SOA mass during the $m$-xylene oxidation experiment by Nordin et al. (2013). The model results are from simulations without wall losses to the chamber walls. The simulations were performed with the SIMPOL vapour pressure method without or with heterogeneous reactions between $\mathrm{O}_{3}$ and the unsaturated organic compounds $\left(k_{\mathrm{O}_{3}}=10^{-16}\right.$ molecules ${ }^{-1} \mathrm{~cm}^{3} \mathrm{~s}^{-1}$ and $\left.D_{0, \mathrm{O}_{3}}=10^{-8} \mathrm{~cm}^{2} \mathrm{~s}^{-1}\right)$, the Nannoolal vapour pressure method and heterogeneous reactions between $\mathrm{O}_{3}$ and the unsaturated organic compounds, the semiempirical parameterizations from $\mathrm{Ng}$ et al. (2007), and the SIMPOL vapour pressure method and peroxyhemiacetal and hemiacetal dimer formation $\left(k_{\mathrm{f}}=10^{-22}\right.$ molecules $\left.{ }^{-1} \mathrm{~cm}^{3} \mathrm{~s}^{-1}\right)$.

Additionally, we have also shown how ADCHAM can be used to study the influence of the chamber wall effects on the SOA mass formation, evaporation properties, particle number size distribution and gas-phase chemistry. These effects are important to constrain because current knowledge concerning SOA formation in the atmosphere is to a large extent based on smog chamber experiments, and global climate models and chemistry transport models rely on simplified semi-empirical parameterizations of SOA formation derived from these experiments.

The most important findings from the model simulations performed in this article are as follows:

1. Our simulations of the $\alpha$-pinene SOA evaporation experiments from Vaden et al. (2011) support the recent experimental findings that these particles are very viscous (tar-like amorphous SOA) (Virtanen et al., 2010; Vaden et al., 2010, 2011; Kuwata and Martin, 2012; Zelenyuk et al., 2012; Abramson et al., 2013; Zhou et al., 2013). In these particles low-volatility dimers can accumulate in the particle surface-bulk layer upon 
evaporation. With this dimer coating, ADCHAM is able to reproduce the main features of the observed slow evaporation rates if it is controlled by the reversible degradation of dimers back to monomers. The model simulations illustrate that the mass fraction of long-lived dimers needs to increase with decreasing particle size to explain the nearly size-independent evaporation rates. Because of the Kelvin effect, this can be accomplished if a considerable fraction of the dimers are formed in the gas phase or if they are formed in the particle phase from the least volatile monomer compounds. The model simulations also reveal that the dimer particle content and thus the observed evaporation rates of $\alpha$-pinene SOA particles may not only depend on chemical aging but also on the wall losses in the chamber where the particles are formed.

2. The effect of $\mathrm{NH}_{3}(\mathrm{~g})$ on the $\alpha$-pinene $\mathrm{SOA}$ properties and formation depends on (1) the reactive uptake of carboxylic acids and $\mathrm{NH}_{3}(\mathrm{~g})$ from the gas phase, (2) the viscosity of the SOA particles (ammonium and organic compound diffusion rates) and (3) the salting-out effects of $\mathrm{NH}_{4}^{+}$. In order to distinguish between these effects we recommend future experiments with AMS, in which the SOA particles are exposed to $\mathrm{NH}_{3}$ in the absence of gasphase carboxylic acids. In the model simulations the organic salts between ammonium and carboxylic acids are involved in the initial growth of the particles. However, for atmospherically more relevant $\mathrm{NH}_{3}(\mathrm{~g})$ and $\alpha$-pinene concentrations, $\mathrm{NH}_{3}$ has only a minor influence on the uptake of carboxylic acids to the particle phase. Thus analogous to Yli-Juuti et al. (2013), our simulations indicate that it is unlikely that $\mathrm{NH}_{3}$ and carboxylic acids from $\alpha$-pinene oxidation are responsible for the initial growth of nanometre-sized particles over the boreal forest.

3. Mass transfer limitations between the smog chamber air volume and the chamber walls because of a thin laminar layer adjacent to the walls have a large influence on the uptake of gases onto the wall-deposited particles or directly onto the walls. If the formed SOA material is semi-volatile, the SOA particles on the chamber walls may even start to evaporate and hence become a source of SOA at the end of smog chamber experiments. Paradoxically, heterogeneous reactions which give less volatile SOA and generally more SOA mass can increase the fraction of SOA which is found on the chamber walls and can thus even decrease the detectable SOA mass suspended in the chamber air volume.
4. In order to capture the rapid SOA formation observed during the oxidation of $m$-xylene in the Lund University smog chamber, we need to consider relatively rapid dimerization and/or some other heterogeneous reactions (e.g. ozonolysis of unsaturated organic compounds). When considering peroxyhemiacetal and hemiacetal dimer formation in the particle phase, ADCHAM is able to capture the observed early-stage rapid SOA formation in our own $m$-xylene experiment and gives almost identical SOA mass formation to the semi-empirical parameterizations from $\mathrm{Ng}$ et al. (2007). This indicates that heterogeneous particle-phase reactions are not only important for the SOA properties (e.g. volatility) but also for the concentration and formation rates.

Another more general conclusion which can be drawn from the simulations performed in this work is that many of the parameters (processes) with large uncertainties (e.g. SOA viscosity, oligomerization rates and mechanisms, pure-liquid saturation vapour pressures, surface tension and chamber wall effects) have a large influence on the SOA formation and/or the chemical and physical properties of the SOA. To be able to constrain the uncertainties related to these parameters (processes), the experiments need to be designed in such a way that as many variables as possible are varied (e.g. time of aging, temperature, $\mathrm{RH}$, concentrations, dilution, oxidation agents and light intensities). In addition to from evaluating experimental results, ADCHAM can be used as a valuable model tool when planning, designing and selecting which experiments and instrumentation are needed in order to be able to answer specific research questions. The $m$-xylene experiment studied in Sect. 3.4 is part of a larger experiment campaign designed in order to study aging of anthropogenic SOA precursors and petrol car exhausts (Nordin et al., 2013). In that experiment campaign an early version of ADCHAM was used to study chamber wall effects, gasphase chemistry and SOA formation before the experiments were performed. Currently we are applying ADCHAM to study the aging of gasoline car exhausts and ELVOC formation from $\alpha$-pinene ozonolysis. We have also started to implement many of the detailed processes (e.g. the kinetic multilayer model, different dimerization processes and the detailed MCMv3.2 gas-phase chemistry) in the ADCHEM model (Roldin et al., 2011a), which we use for detailed atmospheric process studies. 


\section{Appendix A}

Table A1. Nomenclature.

\begin{tabular}{|c|c|}
\hline Symbol & Description \\
\hline$\alpha_{\mathrm{s}}$ & Surface-bulk accommodation coefficient \\
\hline$\alpha_{0, \mathrm{~s}}$ & $\begin{array}{l}\text { Surface accommodation coefficient of surface free from } \\
\text { adsorbing material }\end{array}$ \\
\hline$\gamma$ & Activity coefficient \\
\hline$\gamma_{\mathrm{w}, i}$ & Activity coefficient of compound $i$ in a Teflon wall film \\
\hline$\delta_{k}$ & Width of particle layer $k$ \\
\hline$\Delta x$ & $\begin{array}{l}\text { Laminar layer width adjacent to chamber walls or char- } \\
\text { coal denuder }\end{array}$ \\
\hline$\theta_{\mathrm{S}}$ & Relative surface coverage of the adsorbed species \\
\hline$\mu$ & Dynamic viscosity of air \\
\hline$\rho_{\text {air }}$ & Density of air \\
\hline$\rho_{\mathrm{p}}$ & Particle-phase density \\
\hline$\sigma$ & Surface tension of organic compounds \\
\hline$\tau_{\mathrm{d}, Z_{\mathrm{ox}}}$ & Desorption lifetime of $Z_{\mathrm{ox}}$ \\
\hline$\omega_{Z_{\mathrm{ox}}}$ & Mean thermal velocity of $Z_{\mathrm{Ox}}$ \\
\hline$v_{\mathrm{e}}$ & $\begin{array}{l}\text { Characteristic average deposition velocity due to elec- } \\
\text { trostatic forces }\end{array}$ \\
\hline$\Omega_{A B}^{(1,1)}$ & Collision integral between molecules $A$ and $B$ \\
\hline$A_{k}$ & Area of exchange between particle layer $k-1$ and $k$ \\
\hline$A_{\text {chamber }}$ & Chamber surface area \\
\hline$c_{\mathrm{d}}$ & Dimer particle-phase concentration \\
\hline$c_{\mathrm{H}^{+}}$ & Hydrogen ion concentration \\
\hline$c_{\mathrm{m}}$ & Monomer particle-phase concentration \\
\hline$C_{\mathrm{c}}$ & Cunningham slip correction factor \\
\hline$C_{\mathrm{k}}$ & Kelvin effect \\
\hline$C_{\infty}$ & Gas-phase concentration far from the particle surfaces \\
\hline$C_{\mathrm{s}}$ & $\begin{array}{l}\text { Saturation gas-phase concentration at the particle sur- } \\
\text { face }\end{array}$ \\
\hline$C_{\mathrm{W}}$ & Effective wall-equivalent mass concentration \\
\hline $\mathrm{d}_{Z_{\mathrm{ox}}}$ & Width of the $Z_{\mathrm{ox}}$ sorption layer \\
\hline$d_{i}$ & Collision diameter of compound $i$ \\
\hline$d_{\text {air }}$ & Collision diameter of compound air molecules \\
\hline$d_{i, \text { air }}$ & $\begin{array}{l}\text { Collision diameter for binary collisions between com- } \\
\text { pound } i \text { and air molecules }\end{array}$ \\
\hline$D_{\mathrm{p}}$ & Particle diameter \\
\hline$D_{\text {va }}$ & Vacuum aerodynamic diameter \\
\hline$D_{0, X_{i}}$ & $\begin{array}{l}\text { Diffusivity coefficient of compound } X_{i} \text { without ob- } \\
\text { structing material }\end{array}$ \\
\hline$D_{X_{i}}$ & Diffusion coefficient of compound $X_{i}$ \\
\hline$e^{\cdots}$ & Elementary charge of a single proton \\
\hline$E^{\prime \prime}$ & Mean electrical field strength \\
\hline$\overline{E_{0}}$ & Initial mean electrical field strength \\
\hline$F$ & Fuchs-Sutugin correction factor in the transition region \\
\hline$f_{\mathrm{p}}$ & $\begin{array}{l}\text { Particle volume fraction of solid or semi-solid obstruct- } \\
\text { ing material }\end{array}$ \\
\hline$F_{\mathrm{f}}(\mathrm{p})$ & Dimer formation rates in the particle phase \\
\hline$h$ & Distance between the roof and ceiling of the chamber \\
\hline$I$ & Molar condensation growth rate \\
\hline$J_{\mathrm{ads},} Z_{\mathrm{ox}}$ & Adsorption rate of $Z_{\mathrm{ox}}$ to the sorption layer \\
\hline$J_{\mathrm{des}, Z_{\mathrm{ox}}}$ & Desorption rate of $Z_{\mathrm{ox}}$ from the sorption layer \\
\hline$k_{\mathrm{b}}$ & The Boltzmann constant \\
\hline$k_{\text {charge }}$ & First-order deposition loss rate due to charge \\
\hline
\end{tabular}

Table A1. Continued.

\begin{tabular}{|c|c|}
\hline Symbol & Description \\
\hline$k_{\mathrm{d}}$ & $\begin{array}{l}\text { First-order dimer-specific degradation reaction rate } \\
\text { constant }\end{array}$ \\
\hline$k_{\mathrm{f}}$ & Second-order dimer formation rate constant \\
\hline$k_{\mathrm{f}, \mathrm{H}^{+}}$ & $\begin{array}{l}\text { Acid-catalysed third-order dimer formation rate con- } \\
\text { stant }\end{array}$ \\
\hline$k_{k, k+1, X_{i}}$ & $\begin{array}{l}\text { Transport velocity of compound } X_{i} \text { between the layers } \\
k \text { and layer } k+1 \text {. }\end{array}$ \\
\hline$k_{\mathrm{Ox}}$ & Oxidation reaction rate constant in the particle phase \\
\hline$k_{\mathrm{so}, \mathrm{su}, Z_{\mathrm{ox}}}$ & $\begin{array}{l}\text { Transport velocity of } Z_{\mathrm{ox}} \text { from the sorption layer to the } \\
\text { surface-bulk layer }\end{array}$ \\
\hline$k_{\mathrm{su}, \mathrm{so}, Z_{\mathrm{ox}}}$ & $\begin{array}{l}\text { Transport velocity of } Z_{\mathrm{ox}} \text { from the surface-bulk layer to } \\
\text { the sorption layer }\end{array}$ \\
\hline$k_{\mathrm{g}, \mathrm{w}}$ & $\begin{array}{l}\text { First-order loss rate from the near-wall gas phase to the } \\
\text { walls }\end{array}$ \\
\hline$k_{\mathrm{W}, \mathrm{g}}$ & Desorption rate from the chamber wall Teflon surfaces \\
\hline$k_{\mathrm{W}}$ & Effective particle wall deposition loss rate \\
\hline$K_{\mathrm{a}}$ & Acid dissociation constant \\
\hline$K_{\mathrm{H}}$ & Henry's law constant \\
\hline$K_{\mathrm{S}}$ & Solubility product of salt \\
\hline$K_{\mathrm{s}}^{*}$ & Effective solubility product of organic salts \\
\hline$K n$ & Non-dimensional Knudsen number \\
\hline$m_{i}$ & Molecular mass of compound $i$ \\
\hline$m_{\text {air }}$ & Average air molecular mass \\
\hline$M_{i}$ & Molar mass of compound $i$ \\
\hline$M_{\mathrm{W}}$ & Average molar mass of a Teflon wall film \\
\hline$N$ & Number of elemental charges of a particle \\
\hline$N_{\mathrm{a}}$ & Avogadros's number \\
\hline$p$ & Total pressure \\
\hline$p_{0}$ & Pure-liquid saturation vapour pressure \\
\hline$p_{\mathrm{s}}$ & Equilibrium vapour pressure \\
\hline $\mathrm{pH}$ & $\begin{array}{l}\text { Negative 10-logarithm of the hydrogen ion concentra- } \\
\text { tion }\end{array}$ \\
\hline $\mathrm{pK}_{\mathrm{a}}$ & Negative 10-logarithm of the acid dissociation constant \\
\hline$R$ & Universal gas constant $\left(8.3145 \mathrm{~J} \mathrm{~K}^{-1} \mathrm{~mol}^{-1}\right)$ \\
\hline RH & Relative humidity in percent \\
\hline$t$ & Time \\
\hline$T$ & Temperature in kelvin \\
\hline$u^{*}$ & Friction velocity \\
\hline$V_{k}$ & Volume of particle layer $k$ \\
\hline$V_{\text {chamber }}$ & Chamber volume \\
\hline$V_{\text {wall }}$ & Air volume of a thin layer adjacent to the chamber walls \\
\hline$\left[V_{X_{i}}\right]_{k}$ & $\begin{array}{l}\text { Absolute volume concentration of compound } X_{i} \text { in par- } \\
\text { ticle layer } k \text {. }\end{array}$ \\
\hline$x$ & Mole fractions \\
\hline$x_{k}$ & $\begin{array}{l}\text { Ratio between the smaller and larger of the two volume } \\
\text { fluxes across } A_{k}\end{array}$ \\
\hline$X$ & Condensable organic compound \\
\hline$\left[X_{i}\right]_{k}$ & $\begin{array}{l}\text { Relative volume concentration of compound } X_{i} \text { in par- } \\
\text { ticle layer } k \text {. }\end{array}$ \\
\hline$\left[X_{i, \mathrm{~g}, \mathrm{w}}\right]$ & $\begin{array}{l}\text { Concentrations of compound } X_{i} \text { in the thin layer adja- } \\
\text { cent to the chamber walls }\end{array}$ \\
\hline$\left[X_{i, \mathrm{w}}\right]$ & Concentration of compound $X_{i}$ on the chamber wall \\
\hline$Y$ & $\begin{array}{l}\text { Organic compound formed by particle-phase oxidation } \\
\text { reaction }\end{array}$ \\
\hline$Z_{\mathrm{ox}}$ & $\begin{array}{l}\text { Oxidation agent in the particle phase (e.g. } \mathrm{OH}, \mathrm{O}_{3}, \mathrm{NO}_{3} \\
\text { and } \mathrm{NO}_{2} \text { ) }\end{array}$ \\
\hline
\end{tabular}


Acknowledgements. This work was supported by the strategic research area MERGE at Lund University; the Swedish Research Council for Environment, Agricultural Sciences and Spatial Planning FORMAS through projects 2007-1205, 2008-1467, 2009-615 and 2010-1678; the Swedish Research Council through project 2006-5940; and by Metalund, the Centre for Medicine and Technology for Working Life and Society, a competence centre at Lund University, Sweden, supported by FAS, the Swedish Council for Working Life and Social Research. Support for A. Zelenyuk was provided by US Department of Energy (DOE), Office of Science, Office of Basic Energy Sciences (BES), Chemical Sciences, Geosciences, and Biosciences Division.

The authors would like to thank Prof. Gordon McFiggans' research group at the University of Manchester, and especially Dr. David Topping, for helpful discussions and for providing the Python script (now a publicly available function called CompSysProp: http://ratty.cas.manchester.ac.uk/informatics/) to calculate Nannoolal-based sub-cooled liquid saturation vapour pressures for all organic compounds included in this paper.

Edited by: D. Topping

\section{References}

Abramson, E., Imre, D., Beránek, J., Wilson, J., Zelenyuk, A.: Experimental determination of chemical diffusion within secondary organic aerosol particles, Phys. Chem. Chem. Phys., 15, 29832991,2013

Ammann, M. and Pöschl, U.: Kinetic model framework for aerosol and cloud surface chemistry and gas-particle interactions - Part 2: Exemplary practical applications and numerical simulations, Atmos. Chem. Phys., 7, 6025-6045, doi:10.5194/acp-7-60252007, 2007.

Barley, M. H. and McFiggans, G.: The critical assessment of vapour pressure estimation methods for use in modelling the formation of atmospheric organic aerosol, Atmos. Chem. Phys., 10, 749767, doi:10.5194/acp-10-749-2010, 2010.

Barsanti, K. C. and Pankow, J. F: Thermodynamics of the formation of atmospheric organic particulate matter by accretion reactions-Part 1: aldehydes and ketones, Atmos. Environ., 38, 4371-4382, 2004.

Barsanti, K. C. and Pankow, J. F: Thermodynamics of the formation of atmospheric organic particulate matter by accretion reactions - Part 3: Carboxylic and dicarboxylic acids, Atmos. Environ., 40, 6676-6686, 2006.

Barsanti, K. C., McMurry, P. H., and Smith, J. N.: The potential contribution of organic salts to new particle growth, Atmos. Chem. Phys., 9, 2949-2957, doi:10.5194/acp-9-2949-2009, 2009.

Bergström, R., Denier van der Gon, H. A. C., Prévôt, A. S. H., Yttri, K. E., and Simpson, D.: Modelling of organic aerosols over Europe (2002-2007) using a volatility basis set (VBS) framework: application of different assumptions regarding the formation of secondary organic aerosol, Atmos. Chem. Phys., 12, 8499-8527, doi:10.5194/acp-12-8499-2012, 2012.

Berkemeier, T., Huisman, A. J., Ammann, M., Shiraiwa, M., Koop, T., and Pöschl, U.: Kinetic regimes and limiting cases of gas uptake and heterogeneous reactions in atmospheric aerosols and clouds: a general classification scheme, Atmos. Chem. Phys., 13, 6663-6686, doi:10.5194/acp-13-6663-2013, 2013.
Bertram, A. K., Martin, S. T., Hanna, S. J., Smith, M. L., Bodsworth, A., Chen, Q., Kuwata, M., Liu, A., You, Y., and Zorn, S. R.: Predicting the relative humidities of liquid-liquid phase separation, efflorescence, and deliquescence of mixed particles of ammonium sulphate, organic material, and water using the organic-to-sulphate mass ratio of the particle and the oxygen-to-carbon elemental ratio of the organic component, Atmos. Chem. Phys., 11, 10995-11006, doi:10.5194/acp-1110995-2011, 2011.

Bloss, C., Wagner, V., Bonzanini, A., Jenkin, M. E., Wirtz, K., Martin-Reviejo, M., and Pilling, M. J.: Evaluation of detailed aromatic mechanisms (MCMv3 and MCMv3.1) against environmental chamber data, Atmos. Chem. Phys., 5, 623-639, 2005a, http://www.atmos-chem-phys.net/5/623/2005/.

Bloss, C., Wagner, V., Jenkin, M. E., Volkamer, R., Bloss, W. J., Lee, J. D., Heard, D. E., Wirtz, K., Martin-Reviejo, M., Rea, G., Wenger, J. C., and Pilling, M. J.: Development of a detailed chemical mechanism (MCMv3.1) for the atmospheric oxidation of aromatic hydrocarbons, Atmos. Chem. Phys., 5, 641-664, doi:10.5194/acp-5-641-2005, 2005b.

Boy, M., Hellmuth, O., Korhonen, H., Nilsson, E. D., ReVelle, D., Turnipseed, A., Arnold, F., and Kulmala, M.: MALTE - model to predict new aerosol formation in the lower troposphere, Atmos. Chem. Phys., 6, 4499-4517, doi:10.5194/acp-6-4499-2006, 2006.

Camredon, M., Hamilton, J. F., Alam, M. S., Wyche, K. P., Carr, T., White, I. R., Monks, P. S., Rickard, A. R., and Bloss, W. J.: Distribution of gaseous and particulate organic composition during dark $\alpha$-pinene ozonolysis, Atmos. Chem. Phys., 10, 2893-2917, doi:10.5194/acp-10-2893-2010, 2010.

Cappa, C. D. and Wilson, K. R.: Evolution of organic aerosol mass spectra upon heating: implications for OA phase and partitioning behavior, Atmos. Chem. Phys., 11, 1895-1911, doi:10.5194/acp11-1895-2011, 2011.

Casale, M. T, Richman, A. R., Elrod, M. J., Garland, R. M., Beaver M. R., and Tolbert, M. A.: Kinetics of acid-catalyzed aldol condensation reactions of aliphatic aldehydes Atmos. Environ., 41, 6212-6224, 2007.

Chapman, S. and Cowling, T. G.: The Mathematical Theory of Nonuniform Gases, Cambridge University Press, Cambridge, 1970.

Compernolle, S., Ceulemans, K., and Müller, J.-F.: Influence of non-ideality on condensation to aerosol, Atmos. Chem. Phys. 9, 1325-1337, doi:10.5194/acp-9-1325-2009, 2009.

DePalma, J. W., Horan, A. J., Hall, W. A., and Johnston, M. V.: Thermodynamics of oligomer formation: implications for secondary organic aerosol formation and reactivity, Phys. Chem. Chem. Phys., 15, 6935-6944, 2013.

Donahue, N. M., Epstein, S. A., Pandis, S. N., and Robinson, A. L.: A two-dimensional volatility basis set: 1 . organic-aerosol mixing thermodynamics, Atmos. Chem. Phys., 11, 3303-3318, doi:10.5194/acp-11-3303-2011, 2011.

Dzepina, K., Volkamer, R. M., Madronich, S., Tulet, P., U1brich, I. M., Zhang, Q., Cappa, C. D., Ziemann, P. J., and Jimenez, J. L.: Evaluation of recently-proposed secondary organic aerosol models for a case study in Mexico City, Atmos. Chem. Phys., 9, 5681-5709, doi:10.5194/acp-9-5681-2009, 2009. 
Ervens, B. and Volkamer, R.: Glyoxal processing by aerosol multiphase chemistry: towards a kinetic modelling framework of secondary organic aerosol formation in aqueous particles, Atmos. Chem. Phys., 10, 8219-8244, doi:10.5194/acp-10-82192010, 2010.

Fuchs, N. A. and Sutugin, A. G.: In Topics in Current Aerosol Research, Pergamon Press, 1971.

Gao, S., Keywood, M., Ng, N. L., Surratt, J., Varutbangkul, V., Bahreini, R., Flagan, R. C., and Seinfeld, J. H.: Low-MolecularWeight and Oligomeric Components in Secondary Organic Aerosol from the Ozonolysis of Cycloalkenes and $\alpha$-Pinene, J. Phys. Chem. A, 108, 10147-10164, 2004.

George, C., Strekowski, R. S., Kleffmann, J., Stemmler, K., and Ammann, M.: Photoenhanced uptake of gaseous $\mathrm{NO}_{2}$ on solid organic compounds: a photochemical source of HONO?, Faraday Discuss., 130, 195-210, 2005.

Greaves, T. L. and Drummond, C. J.: Protic ionic liquids: Properties and applications, Chem. Rev., 108, 206-237, 2008.

Grieshop, A. P., Donahue, N. M., and Robinson, A. L.: Is the gas-particle partitioning in alpha-pinene secondary organic aerosol reversible?, Geophys. Res. Lett., 34, L14810, doi:10.1029/2007GL029987, 2007.

Griffin, R. J., Cocker III, D. R., Flagan, R. C., and Seinfeld, J. H.: Organic aerosol formation from the oxidation of biogenic hydrocarbons, J. Geophys. Res., 104, 3555-3567, 1999.

Gutzwiller, L., Arens, F., Baltensperger, U., Gäggeler, H. W., and Ammann, M.: Significance of Semivolatile Diesel Exhaust Organics for Secondary HONO Formation, Environ. Sci. Technol., 36, 677-682, 2002.

Hallquist, M., Wenger, J. C., Baltensperger, U., Rudich, Y., Simpson, D., Claeys, M., Dommen, J., Donahue, N. M., George, C., Goldstein, A. H., Hamilton, J. F., Herrmann, H., Hoffmann, T., Iinuma, Y., Jang, M., Jenkin, M. E., Jimenez, J. L., Kiendler-Scharr, A., Maenhaut, W., McFiggans, G., Mentel, Th. F., Monod, A., Prévôt, A. S. H., Seinfeld, J. H., Surratt, J. D., Szmigielski, R., and Wildt, J.: The formation, properties and impact of secondary organic aerosol: current and emerging issues, Atmos. Chem. Phys., 9, 5155-5236, doi:10.5194/acp-9- 51552009, 2009.

Hansen, H. K., Rasmussen, P., Fredenslund, A., Schiller, M., and Gmehling, J.: Vapour-liquid equilibria by UNIFAC group contribution. 5. Revision and extension, Ind. Eng. Chem. Res., 30, 2352-2355, 1991.

Hildebrandt, L., Donahue, N. M., and Pandis, S. N.: High formation of secondary organic aerosol from the photo-oxidation of toluene. Atmos. Chem. Phys. 9, 2973-2986, 2009.

Hirschfelder, J. O., Curtiss, C. F., and Bird, R. B.: Molecular Theory of Gases and Liquids. John Wiley, New York, 1954.

Hoffmann, T., Odum, J. R., Bowman, F., Collins, D., Klockow, D., Flagan, R. C., and Seinfeld, J. H.: Formation of organic aerosols from the oxidation of biogenic hydrocarbons, J. Atmos. Chem., 26, 189-222, 1997.

Hu, D., Tolocka, M., Li, Q., and Kamens, R. M.: A kinetic mechanism for predicting secondary organic aerosol formation from toluene oxidation in the presence of $\mathrm{NOx}$ and natural sunlight, Atmos. Environ., 41, 6478-6496, 2007.

Huff Hartz, K. E. H., Weitkamp, E. A., Sage, A. M., Donahue, N. M., and Robinson, A. L.: Laboratory measurements of the oxidation kinetics of organic aerosol mixtures using a relative rate constants approach, J. Geophys. Res.-Atmos., 112, D04204, doi:10.1029/2006jd007526, 2007.

Hyder, M., Genberg, J., and Jönsson, J. Å.: Application of hollow fiber liquid phase microextraction for pinic acid and pinonic acid analysis from organic aerosols, Analyt. Chim. Ac., 713, 79-85, 2012.

Iinuma, Y., Böge, O., Gnauk, T., and Herrmann, H.: Aerosolchamber study of the $\alpha$-pinene $/ \mathrm{O}_{3}$ reaction: Influence of particle acidity on aerosol yields and products, Atmos. Environ., 38, 761773, 2004.

Jacobson, M. Z.: Fundamentals of Atmospheric Modelling (2nd edition), Cambridge University Press, Cambridge, United Kingdom and New York, NY, USA, ISBN: 052154865 9, 2005a.

Jacobson, M. Z.: A Solution to the Problem of Nonequilibrium Acid/Base Gas-Particle Transfer at Long Time Step, Aerosol Sci. Technol., 39, 92-103, 2005b.

Jenkin, M. E., Saunders, S. M., and Pilling, M. J.: The tropospheric degradation of volatile organic compounds: A protocol for mechanism development, Atmos. Environ., 31, 81-104, 1997.

Jenkin, M. E., Saunders, S. M., Wagner, V., and Pilling, M. J.: Protocol for the development of the Master Chemical Mechanism, MCM v3 (Part B): tropospheric degradation of aromatic volatile organic compounds, Atmos. Chem. Phys., 3, 181-193, doi:10.5194/acp-3-181-2003, 2003.

Jimenez, J. L., Canagaratna, M. R., Donahue, N. M., Prevot, A. S. H., Zhang, Q., Kroll, J. H., DeCarlo, P. F., Allan, J. D., Coe, H., Ng, N. L., Aiken, A. C., Docherty, K. S., Ulbrich, I. M., Grieshop, A. P., Robinson, A. L., Duplissy, J., Smith, J. D., Wilson, K. R., Lanz, V. A., Hueglin, C., Sun, Y. L., Tian, J., Laaksonen, A., Raatikainen, T., Rautiainen, J., Vaattovaara, P., Ehn, M., Kulmala, M., Tomlinson, J. M., Collins, D. R., Cubison, M. J., Dunlea, E. J., Huffman, J. A., Onasch, T. B., Alfarra, M. R., Williams, P. I., Bower, K., Kondo, Y., Schneider, J., Drewnick, F., Borrmann, S., Weimer, S., Demerjian, K., Salcedo, D., Cottrell, L., Griffin, R., Takami, A., Miyoshi, T., Hatakeyama, S., Shimono, A., Sun, J. Y, Zhang, Y. M., Dzepina, K., Kimmel, J. R., Sueper, D., Jayne, J. T., Herndon, S. C., Trimborn, A. M., Williams, L. R., Wood, E. C., Middlebrook, A. M., Kolb, C. E., Baltensperger, U., and Worsnop, D. R.: Evolution of Organic Aerosols in the Atmosphere, Science, 326, 1525-1529, 2009.

Johnson, D., Jenkin, M. E., Wirtz, K., and Martin-Reviejo, M.: Simulating the formation of secondary organic aerosol from the photooxidation of aromatic hydrocarbons, Environ. Chem., 2, 35-48, 2005.

Johnson, D., Utembe, S. R., and Jenkin, M. E.: Simulating the detailed chemical composition of secondary organic aerosol formed on a regional scale during the TORCH 2003 campaign in the southern UK, Atmos. Chem. Phys., 6, 419-431, 2006, http://www.atmos-chem-phys.net/6/419/2006/.

Jonsson, Å. M., Hallquist, M., and Ljungström, E.: The effect of temperature and water on secondary organic aerosol formation from ozonolysis of limonene, $\Delta^{3}$-carene and $\alpha$-pinene, Atmos. Chem. Phys., 8, 6541-6549, doi:10.5194/acp-8-6541-2008, 2008.

Kalberer, M., Paulsen, D., Sax, M., Steinbacher, M., Dommen, J., Prévôt, A. S. H., Fisseha, R., Weingartner, E., Frankevich, V., Zenobi, R., and Baltensperger, U.: Identification of polymers as major components of atmospheric organic aerosols, Science, 303, 1659-1662, 2004. 
Knopf, D. A., Anthony, L. M., and Bertram, A. K.: Reactive uptake of $\mathrm{O}_{3}$ by multicomponent and multiphase mixtures containing oleic acid, J. Phys. Chem. A, 109, 5579-5589, 2005.

Koop, T., Bookhold, J., Shiraiwa, M., and Pöschl, U.: Glass transition and phase state of organic compounds: dependency on molecular properties and implications for secondary organic aerosols in the atmosphere, Phys. Chem. Chem. Phys., 13, 19238-19255, 2011.

Korhonen, H., Lehtinen, K. E. J., and Kulmala, M.: Multicomponent aerosol dynamics model UHMA: model development and validation, Atmos. Chem. Phys., 4, 757-771, doi:10.5194/acp-4757-2004, 2004.

Kroll, J., and Seinfeld, J. H.: Chemistry of secondary organic aerosol: Formation and evolution of low-volatility organics in the atmosphere, Atmos. Env., 42, 3593-3624, 2008.

Kuwata, M. and Martin, S., T.: Phase of atmospheric secondary organic material affects its reactivity, P. Natl. Acad. Sci., 109, 17354-17359, doi:10.1073/pnas.1209071109, 2012.

Lai, A. and Nazaroff, W. W.: Modelling indoor particle deposition from turbulent flow onto smooth surfaces, J. Aerosol Sci., 31, 463-476, 2000.

Li, Q., Hu, D., Leungsakul, S., and Kamens, R. M.: Large outdoor chamber experiments and computer simulations: (I) Secondary organic aerosol formation from the oxidation of a mixture of dlimonene and $\alpha$-pinene, Atmos. Environ., 41, 9341-9352, 2007.

Lide, D. R. (Ed.): CRC Handbook of chemistry and physics, Taylor and Francis Group, Boca Raton, FL, USA, 88th Edition, 2008.

Liggio, J. and Li, S.-M.: Organosulfate formation during the uptake of pinonaldehyde in acidic sulphate aerosols, Geophys. Res. Lett., 33, L13808, doi:10.1029/2006GL026079, 2006.

Loza, C. L., Chhabra, P. S., Yee, L. D., Craven, J. S., Flagan, R. C., and Seinfeld, J. H.: Chemical aging of $m$-xylene secondary organic aerosol: laboratory chamber study, Atmos. Chem. Phys., 12, 151-167, doi:10.5194/acp-12-151-2012, 2012.

Maksymiuk, C. S., Gayahtri, C., Gil, R. R., and Donahue, N. M.: Secondary organic aerosol formation from multiphase oxidation of limonene by ozone: mechanistic constraints via twodimensional heteronuclear NMR spectroscopy, Phys. Chem. Chem. Phys., 2009, 11, 7810-7818, 2009.

Marcolli, C. and Peter, Th.: Water activity in polyol/water systems: new UNIFAC parameterization, Atmos. Chem. Phys., 5, 15451555, doi:10.5194/acp-5-1545-2005, 2005.

Matsunaga, A. and Ziemann, P. J.: Gas-Wall Partitioning of Organic Compounds in a Teflon Film Chamber and Potential Effects on Reaction Product and Aerosol Yield Measurements, Aerosol Sci. Technol., 44, 881-892, 2010.

McFiggans, G., Topping, D. O., and Barley, M. H.: The sensitivity of secondary organic aerosol component partitioning to the predictions of component properties - Part 1: A systematic evaluation of some available estimation techniques, Atmos. Chem. Phys., 10, 10255-10272, doi:10.5194/acp-10-10255-2010, 2010.

McMurry, P. H. and Rader, D. J.: Aerosol wall losses in electrically charged chambers. Aerosol Sci. Technol., 4, 249-268, 1985.

Metzger, A., Dommen, J., Gaeggeler, K., Duplissy, J., Prevot, A. S. H., Kleffmann, J., Elshorbany, Y., Wisthaler, A., and Baltensperger, U.: Evaluation of 1,3,5 trimethylbenzene degradation in the detailed tropospheric chemistry mechanism, MCMv3.1, using environmental chamber data, Atmos. Chem. Phys., 8, 6453-6468, doi:10.5194/acp-8-6453-2008, 2008.
Na, K., Song, C., Switzer, C., and Cocker, D.: Effect of Ammonia on Secondary Organic Aerosol Formation from $\alpha$-Pinene Ozonolysis in Dry and Humid Conditions. Environ. Sci. Technol., 41, 6096-6102, 2007.

Nannoolal, J., Rarey, J., and Ramjugernath, D.: Estimation of pure component properties Part 3. Estimation of the vapour pressure of non-electrolyte organic compounds via group contributions and group interactions Fuild Phase Equilibria, 269, 117-133, 2008.

Nash, D. G., Tolocka, M. P., and Baer, T.: The uptake of $\mathrm{O}_{3}$ by myristic acid-oleic acid mixed particles: evidence for solid surface layers, Phys. Chem. Chem. Phys., 8, 4468-4475, doi:10.1039/b609855j, 2006.

Ng, N. L., Kroll, J. H., Chan, A. W. H., Chhabra, P. S., Flagan, R. C., and Seinfeld, J. H.: Secondary organic aerosol formation from $m$-xylene, toluene, and benzene, Atmos. Chem. Phys., 7, 3909-3922, doi:10.5194/acp-7-3909-2007, 2007.

Ng, N. L., Kwan, A. J., Surratt, J. D., Chan, A. W. H., Chhabra, P. S., Sorooshian, A., Pye, H. O. T., Crounse, J. D., Wennberg, P. O., Flagan, R. C., and Seinfeld, J. H.: Secondary organic aerosol (SOA) formation from reaction of isoprene with nitrate radicals $\left(\mathrm{NO}_{3}\right)$, Atmos. Chem. Phys., 8, 4117-4140, doi:10.5194/acp-84117-2008, 2008.

Nordin, E. Z., Eriksson, A. C., Roldin, P., Nilsson, P. T., Carlsson, J. E., Kajos, M. K., Hellén, H., Wittbom, C., Rissler, J., Löndahl, J., Swietlicki, E., Svenningsson, B., Bohgard, M., Kulmala, M., Hallquist, M., and Pagels, J. H.: Secondary organic aerosol formation from idling gasoline passenger vehicle emissions investigated in a smog chamber, Atmos. Chem. Phys., 13, 6101-6116, doi:10.5194/acp-13-6101-2013, 2013.

Odum, J. R., Hoffmann, T., Bowman, F., Collins, D., Flagan, R. C., and Seinfeld, J. H.: Gas/particle partitioning and secondary organic aerosol yields, Environ. Sci. Technol., 30, 2580-2585, 1996.

Pankow, J. F.: An absorption-model of the gas aerosol partitioning involved in the formation of secondary organic aerosol, Atmos. Environ., 28, 189-193, 1994.

Pankow, J. F. and Asher, W. E.: SIMPOL.1: a simple group contribution method for predicting vapour pressures and enthalpies of vaporization of multifunctional organic compounds, Atmos. Chem. Phys., 8, 2773-2796, doi:10.5194/acp-8-27732008, 2008.

Pathak, R. K., Presto, A. A., Lane, T. E., Stanier, C. O., Donahue, N. M., and Pandis, S. N.: Ozonolysis of $\alpha$-pinene: parameterization of secondary organic aerosol mass fraction, Atmos. Chem. Phys., 7, 3811-3821, doi:10.5194/acp-7-3811-2007, 2007.

Paulsen, D., Dommen, J., Kalberer, M., Prevot, A. S. H., Richter, R., Sax, M., Steinbacher, M., Weingartner, E., and Baltensperger, U.: Secondary organic aerosol formation by irradiation of 1,3,5trimethylbenzene-NOx-H2O in a new reaction chamber for atmospheric chemistry and physics, Environ. Sci. Technol., 39, 2668-2678, 2005.

Pfrang, C., Shiraiwa, M., and Pöschl, U.: Chemical ageing and transformation of diffusivity in semi-solid multi-component organic aerosol particles, Atmos. Chem. Phys., 11, 7343-7354, doi:10.5194/acp-11-7343-2011, 2011.

Pierce, J. R., Engelhart, G. J., Hildebrandt, L., Weitkamp, E. A., Pathak, R. K., Donahue, N. M., Robinson, A. L., Adams, P. J., 
and Pandis, S. N.: Constraining Particle Evolution from Wall Losses, Coagulation, and Condensation-Evaporation in SmogChamber Experiments: Optimal Estimation Based on Size Distribution Measurements, Aerosol Sci. Technol., 42, 1001-1015, 2008.

Pun, B. K. and Seigneur, C.: Investigative modelling of new pathways for secondary organic aerosol formation, Atmos. Chem. Phys., 7, 2199-2216, doi:10.5194/acp-7-2199-2007, 2007.

Pöschl, U., Rudich, Y., and Ammann, M.: Kinetic model framework for aerosol and cloud surface chemistry and gas-particle interactions - Part 1: General equations, parameters, and terminology, Atmos. Chem. Phys., 7, 5989-6023, doi:10.5194/acp-75989-2007, 2007.

Pöschl, U.: Gas-particle interactions of tropospheric aerosols: Kinetic and thermodynamic perspectives of multiphase chemical reactions, amorphous organic substances, and the activation of cloud condensation nuclei, Atmos. Res., 101, 562-573, 2011.

Rader, D. J., McMurry, P. H., and Smith, S.: Evaporation Rates of Monodisperse Organic Aerosols in the 0.02- to 0.2- $\mu \mathrm{m}$-Diameter Range, Aerosol Sci. Technol., 6, 247-260, 1987.

Ray, A. K., Davis, E. J., and Ravindran, P.: Determination of ultralow vapour-pressures by sub-micron droplet evaporation, J. Chem. Phys., 71, 582-587, 1979.

Ray, A. K, Lee, J., and Tilley, H. L.: Direct Measurements of Evaporation Rates of Single Droplets at Large Knudsen Numbers, Langmuir, 4, 631-637, 1988.

Rickard, A. R., Wyche, K. P., Metzger, A., Monks, P. S., Ellis, A. M., Dommenc, J., Baltensperger, U., Jenkin, M. E., and Pilling, M. J.: Gas phase precursors to anthropogenic secondary organic aerosol: Using the Master Chemical Mechanism to probe detailed observations of 1,3,5-trimethylbenzene photo-oxidation, Atmos. Env., 44, 5423-5433, 2010.

Riipinen, I., Pierce, J. R., Donahue, N. M., and Pandis, S. N.: Equilibration time scales of organic aerosol inside thermodenuders: Evaporation kinetics versus thermodynamics, Atmos. Environ., 44, 597-607, 2010.

Rohrer, F., Bohn, B., Brauers, T., Brüning, D., Johnen, F.-J., Wahner, A., and Kleffmann, J.: Characterisation of the photolytic HONO-source in the atmosphere simulation chamber SAPHIR, Atmos. Chem. Phys., 5, 2189-2201, doi:10.5194/acp-5-21892005, 2005.

Roldin, P., Swietlicki, E., Schurgers, G., Arneth, A., Lehtinen, K. E. J., Boy, M., and Kulmala, M.: Development and evaluation of the aerosol dynamics and gas phase chemistry model ADCHEM, Atmos. Chem. Phys., 11, 5867-5896, doi:10.5194/acp-11-58672011, 2011a.

Roldin, P., Swietlicki, E., Massling, A., Kristensson, A., Löndahl, J., Eriksson, A., Pagels, J., and Gustafsson, S.: Aerosol ageing in an urban plume - implication for climate, Atmos. Chem. Phys., 11, 5897-5915, doi:10.5194/acp-11-5897-2011, 2011 b.

Rudich, Y., Donahue, N. M., and Mentel, T. F.: Aging of organic aerosol: Bridging the gap between laboratory and field studies, Annu. Rev. Phys. Chem., 58, 321-352, 2007.

Saukko, E., Lambe, A. T., Massoli, P., Koop, T., Wright, J. P., Croasdale, D. R., Pedernera, D. A., Onasch, T. B., Laaksonen, A., Davidovits, P., Worsnop, D. R., and Virtanen, A.: Humiditydependent phase state of SOA particles from biogenic and anthropogenic precursors, Atmos. Chem. Phys., 12, 7517-7529, doi:10.5194/acp-12-7517-2012, 2012.
Saunders, S. M., Jenkin, M. E., Derwent, R. G., and Pilling, M. J.: Protocol for the development of the Master Chemical Mechanism, MCM v3 (Part A): tropospheric degradation of nonaromatic volatile organic compounds, Atmos. Chem. Phys., 3, 161-180, doi:10.5194/acp-3-161-2003, 2003.

Seinfeld, J. H. and Pandis, S. N.: Atmospheric Chemistry and Physics: From Air Pollution to Climate Change, (2nd edition), Wiley, New Jersey, ISBN: 0-471-72018-6, 2006.

Shiraiwa, M., Pfrang, C., and Pöschl, U.: Kinetic multi-layer model of aerosol surface and bulk chemistry (KM-SUB): the influence of interfacial transport and bulk diffusion on the oxidation of oleic acid by ozone, Atmos. Chem. Phys., 10, 3673-3691, doi:10.5194/acp-10-3673-2010, 2010.

Shiraiwa, M., Ammann, M., Koop, T., Pöschl, U.: Gas uptake and chemical aging of semisolid organic aerosol particles, P. Natl Acad. Sci., 108, 11003-11008, doi:10.1073/pnas.1103045108, 2011.

Shiraiwa, M. and Seinfeld, J. H.: Equilibration timescale of atmospheric secondary organic aerosol partitioning, Geophys. Res. Lett., 39, L24801, 2012.

Shiraiwa, M., Pfrang, C., Koop, T., and Pöschl, U.: Kinetic multilayer model of gas-particle interactions in aerosols and clouds (KM-GAP): linking condensation, evaporation and chemical reactions of organics, oxidants and water, Atmos. Chem. Phys., 12, 2777-2794, 2012,

http://www.atmos-chem-phys.net/12/2777/2012/.

Shiraiwa, M., Yee, L. D., Schilling, K. A., Loza, C. L., Craven, J. S., Zuend, A., Ziemann, P. J., and Seinfeld, J. H.: Size distribution dynamics reveal particle-phase chemistry in organic aerosol formation, P. Natl. Acad. Sci., 110, 11746-11750, $2013 \mathrm{a}$.

Shiraiwa, M., Zuend, A., Bertram, A. K., and Seinfeld, J. H.: Gasparticle partitioning of atmospheric aerosols: interplay of physical state, non-ideal mixing and morphology, Phys. Chem. Chem. Phys., 15, 11441-11453, 2013b.

Smith, J. N., Dunn, M. J., VanReken, T. M., Iida, K., Stolzenburg, M. R., McMurry, P. H., and Huey, L. G.: Chemical composition of atmospheric nanoparticles formed from nucleation in Tecamac, Mexico: Evidence for an important role for organic species in nanoparticle growth, Geophys. Res. Lett., 35, L04808, doi:10.1029/2007g1032523, 2008.

Smith, J. N., Barsanti, K. C, Friedli, H. R., Ehn, M., Kulmala, M., Collins, D. R., Scheckman, J. H., Williams, B. J., and McMurry, P. H.: Observations of aminium salts in atmospheric nanoparticles and possible climatic implications, P. Natl Acad. Sci. 107, 6634-6639, 2010.

Smith, M. L., Kuwata, M., and Martin, S. T.: Secondary Organic Material Produced by the Dark Ozonolysis of $\alpha$-Pinene Minimally Affects the Deliquescence and Efflorescence of Ammonium Sulphate, Aerosol Sci. Technol., 45, 244-261, doi:10.1080/02786826.2010.532178, 2011.

Stroeve, P.: On the Diffusion of Gases in Protein Solutions, Ind. Eng. Chem. Fund., 14, 140-141, 1975.

Surratt, J. D, Murphy, S. M, Kroll, J. H, Ng, N. L., Hildebrandt, L., Sorooshian, A., Szmigielski, R., Vermeylen, R., Maenhaut, W., Claeys, M., Flagan, F. C., and Seinfeld, J. H.: Chemical composition of secondary organic aerosol formed from the photooxidation of isoprene, J. Phys. Chem. A, 110, 9665-9690, 2006

Surratt, J. D., Kroll, J. H., Kleindienst, T. E., Edney, E. O., Claeys, M., Sorooshian, A., Ng, N. L., Offenberg, J. H., Lewandowski, 
M., Jaoui, M., Flagan, R. C., and Seinfeld, J. H.: Evidence for organosulfates in secondary organic aerosol, Environ. Sci. Technol., 41, 517-527, 2007.

Svenningsson, B., Rissler, J., Swietlicki, E., Mircea, M., Bilde, M., Facchini, M. C., Decesari, S., Fuzzi, S., Zhou, J., Mønster, J., and Rosenørn, T.: Hygroscopic growth and critical supersaturations for mixed aerosol particles of inorganic and organic compounds of atmospheric relevance, Atmos. Chem. Phys., 6, 1937-1952, doi:10.5194/acp-6-1937-2006, 2006.

Tobias, H. J. and Ziemann, P. J.: Thermal desorption mass spectrometric analysis of organic aerosol formed from reactions of 1-tetradecene and O-3 in the presence of alcohols and carboxylic acids, Environ. Sci. Technol., 34, 2105-2115, 2000.

Tolocka, M. P., Jang, M., Ginter, J. M., Cox, F. J., Kamens R. M., and Johnston, M. V.: Formation of Oligomers in Secondary Organic Aerosol, Environ. Sci. Technol., 38, 1428-1434, 2004.

Topping, D., Barley, M., and McFiggans, G.: Including phase separation in a unified model to calculate partitioning of vapours to mixed inorganic-organic aerosol particles, Faraday Discuss., $165,273-288,2013$.

Vaden, T. D., Song, C., Zaveri, R. A., Imre, D., and Zelenyuk, A.: Morphology of mixed primary and secondary organic particles and the adsorption of spectator organic gases during aerosol formation, P. Natl. Acad. Sci., 107, 6658-6663, 2010.

Vaden, T. D., Imreb, D., Beráneka, J., Shrivastavaa, M., and Zelenyuka, A.: Evaporation kinetics and phase of laboratory and ambient secondary organic aerosol, P. Natl. Acad. Sci., 108, 2190-2195, 2011.

Valorso, R., Aumont, B., Camredon, M., Raventos-Duran, T., Mouchel-Vallon, C., Ng, N. L., Seinfeld, J. H., Lee-Taylor, J., and Madronich, S.: Explicit modelling of SOA formation from $\alpha$-pinene photooxidation: sensitivity to vapour pressure estimation, Atmos. Chem. Phys., 11, 6895-6910, doi:10.5194/acp-116895-2011, 2011.

Vesterinen, M., Lehtinen, K. E. J., Kulmala, M., and Laaksonen, A.: Effect of particle phase oligomer formation on aerosol growth, Atmos. Environ., 41, 1768-1776, 2007.

Virtanen, A., Joutsensaari, J., Koop, T., Yli-Pirilä, P., Leskinen, J., Mäkelä, J. M., Holopainen, J. K., Pöschl, U., Kulmala, M., Worsnop, D. R. and Laaksonen, A.: An amorphous solid state of biogenic secondary organic aerosol particles, Nature, 467, 824827,2010

Widmann, J., Heusmann, C. M., and Davis, E. J.: The effect of a polymeric additive on the evaporation of organic aerocolloidal droplets, Colloid and Polymer Science, 276, 197-205, 1998.

Wiedensohler, A., Birmili, W., Nowak, A., Sonntag, A., Weinhold, K., Merkel, M., Wehner, B., Tuch, T., Pfeifer, S., Fiebig, M., Fjäraa, A. M., Asmi, E., Sellegri, K., Depuy, R., Venzac, H., Villani, P., Laj, P., Aalto, P., Ogren, J. A., Swietlicki, E., Williams, P., Roldin, P., Quincey, P., Hüglin, C., FierzSchmidhauser, R., Gysel, M., Weingartner, E., Riccobono, F., Santos, S., Grüning, C., Faloon, K., Beddows, D., Harrison, R., Monahan, C., Jennings, S. G., O’Dowd, C. D., Marinoni, A., Horn, H.-G., Keck, L., Jiang, J., Scheckman, J., McMurry, P. H., Deng, Z., Zhao, C. S., Moerman, M., Henzing, B., de Leeuw, G., Löschau, G., and Bastian, S.: Mobility particle size spectrometers: harmonization of technical standards and data structure to facilitate high quality long-term observations of atmospheric par- ticle number size distributions, Atmos. Meas. Tech., 5, 657-685, doi:10.5194/amt-5-657-2012, 2012.

Yli-Juuti, T., Barsanti, K., Hildebrandt Ruiz, L., Kieloaho, A.J., Makkonen, U., Petäjä, T., Ruuskanen, T., Kulmala, M., and Riipinen, I.: Model for acid-base chemistry in nanoparticle growth (MABNAG), Atmos. Chem. Phys., 13, 12507-12524, doi:10.5194/acp-13-12507-2013, 2013.

Zelenyuk, A., Yang, J., Song, C., Zaveri, R. A., and Imre, D.: A New Real-Time Method for Determining Particles' Sphericity and Density: Application to Secondary Organic Aerosol Formed by Ozonolysis of $\alpha$-Pinene, Environ. Sci. Technol., 42, 80338038, 2008.

Zelenyuk, A., Imre, D., Beránek, J., Abramson, E., Wilson, J., and Shrivastava, M.: Synergy between Secondary Organic Aerosols and Long-Range Transport of Polycyclic Aromatic Hydrocarbons, Environ. Sci. Technol., 46, 12459-12466, 2012.

Zhang, S-H., Seifeld, J. H., and Flagan, R. C.: Determination of Particle Vapour Pressures Using the Tandem Differential Mobility Analyzer, Aerosol Sci. Technol., 19, 3-14, 1993.

Zhou, S., Shiraiwa, M., McWhinney, R., Pöschl, U., and Abbatt, J. P. D.: Kinetic limitations in gas-particle reactions arising from slow diffusion in secondary organic aerosol, Faraday Discuss., 165, 391-406, 2013.

Zobrist, B., Soonsin, V., Luo, B. P., Krieger, U. K., Marcolli, C., Peter, T., and Koop, T.: Ultra-slow water diffusion in aqueous sucrose glasses, Phys. Chem. Chem. Phys., 13, 3514-3526, doi:10.1039/c0cp01273d, 2011.

Zuend, A., Marcolli, C., Luo, B. P., and Peter, T.: A thermodynamic model of mixed organic-inorganic aerosols to predict activity coefficients, Atmos. Chem. Phys., 8, 4559-4593, doi:10.5194/acp8-4559-2008, 2008.

Zuend, A., Marcolli, C., Peter, T., and Seinfeld, J. H.: Computation of liquid-liquid equilibria and phase stabilities: implications for RH-dependent gas/particle partitioning of organic-inorganic aerosols, Atmos. Chem. Phys., 10, 7795-7820, doi:10.5194/acp10-7795-2010, 2010.

Zuend, A., Marcolli C., Booth , A. M., Lienhard, D. M., Soonsin, V., Krieger, U. K., Topping, D. O., McFiggans G., Peter, T., and Seinfeld, J. H.: New and extended parameterization of the thermodynamic model AIOMFAC: calculation of activity coefficients for organic-inorganic mixtures containing carboxyl, hydroxyl, carbonyl, ether, ester, alkenyl, alkyl, and aromatic functional groups, Atmos. Chem. Phys., 11, 9155-9206, doi:10.5194/acp11-9155-2011, 2011.

Zuend, A. and Seinfeld, J. H.: Modelling the gas-particle partitioning of secondary organic aerosol: the importance of liquidliquid phase separation, Atmos. Chem. Phys., 12, 3857-3882, doi:10.5194/acp-12-3857-2012, 2012. 